Portland State University

PDXScholar

Winter 4-2-2019

\title{
Perceived Partner Responsiveness, Sleep and Pain: a Dyadic Study of Military-Connected Couples
}

AnnaMarie Sophia O'Neill

Portland State University

Follow this and additional works at: https://pdxscholar.library.pdx.edu/open_access_etds

Part of the Psychology Commons

Let us know how access to this document benefits you.

\section{Recommended Citation}

O'Neill, AnnaMarie Sophia, "Perceived Partner Responsiveness, Sleep and Pain: a Dyadic Study of MilitaryConnected Couples" (2019). Dissertations and Theses. Paper 4941.

https://doi.org/10.15760/etd.6817

This Thesis is brought to you for free and open access. It has been accepted for inclusion in Dissertations and Theses by an authorized administrator of PDXScholar. Please contact us if we can make this document more accessible: pdxscholar@pdx.edu. 
Perceived Partner Responsiveness, Sleep and Pain:

A Dyadic Study of Military-Connected Couples

by

AnnaMarie Sophia O’Neill

A thesis submitted in partial fulfillment of the requirements for the degree of

Master of Science

in

Psychology

Thesis Committee:

Cynthia Mohr, Chair

Leslie Hammer

Todd Bodner

Portland State University

2019 
(C) 2019 AnnaMarie Sophia O’Neill 


\begin{abstract}
The health-promoting influence of high-quality, supportive close relationships has been extensively documented, yet the mechanisms of this effect are less well-understood. Leading researchers have galvanized the field to test particular relationship processes and the mediating psychological processes they facilitate to pinpoint how close relationships exert their salutary effects. The purpose of this study was to investigate the influence of the intimacy process on health outcomes of sleep and pain and if this effect depends on the facilitation of psychological processes in a sample of veterans and spouses (collectively called military-connected couples; $\mathrm{N}=147$ ). Sleep problems are highly prevalent among military-connected couples and pain is highly prevalent among veterans. Results of actor-partner interdependence models revealed that perceived partner responsiveness (PPR), a core component of the intimacy process, was found to predict sleep for military-connected couples and to predict pain for veterans. Indirect effects of PPR on sleep via the psychological process of downregulation of vigilance for militaryconnected couples emerged. The indirect effect of PPR on pain via the psychological process of emotion-regulation was found for veterans only. Partner effects were observed for veteran PPR on spouse positive affect. Overall, greater PPR was associated with positive health outcomes for military-connected couples. The implications of this study include further establishing the intimacy process as a particular mechanism by which close relationships promote health as well as providing insights for holistic interventions for sleep problems and pain in military-connected couples.
\end{abstract}


RESPONSIVENESS, SLEEP AND PAIN IN VETERANS AND SPOUSES

\section{Acknowledgements}

The completion of this thesis would not have been possible without the support of many wonderful people I have met throughout my graduate school training. I would like to extend my deepest appreciation to my committee chair and advisor, Dr. Cynthia Mohr. I appreciate the support you have provided in this project such taking the time to provide thoughtful feedback and to foster critical thinking about this work. I would like to express my gratitude to each member of my committee for their support of this thesis. Dr. Leslie Hammer, thank you for your involvement, insights, as well as the opportunities you have granted me. Dr. Todd Bodner, thank you for your statistical expertise as well as your enthusiasm when working with me to consider analytical issues. Finally, I would like to

express my gratitude to my partner, Brian, for always believing in me. Thanks for serving as a reminder of the health-promoting power of responsiveness throughout our life together and the challenging but rewarding journey of graduate school. 


\section{Table of Contents}

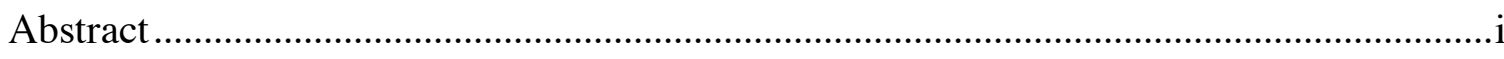

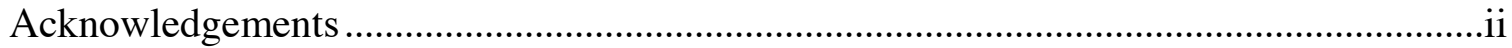

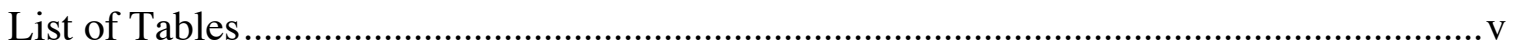

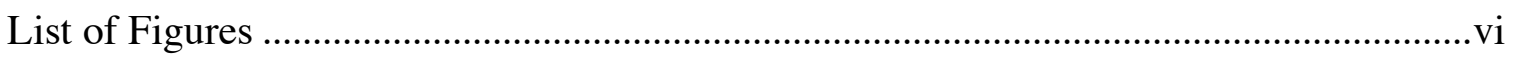

Chapter One - Introduction and Literature Review ........................................................ 1

Problem Statement ................................................................................................. 1

Overview of Health Problems of Service Members and Veterans .............................. 1

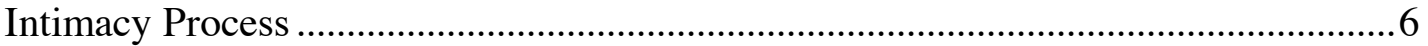

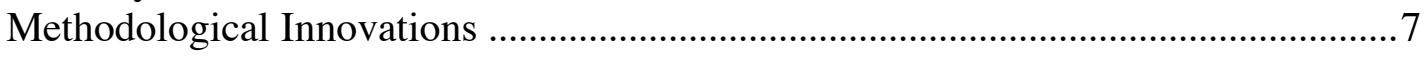

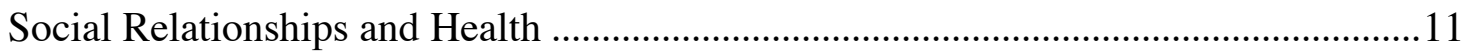

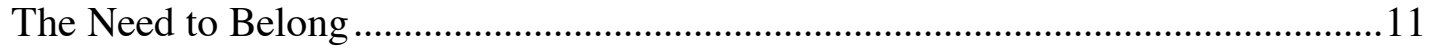

Mechanisms Linking Social Relationships and Health .........................................14

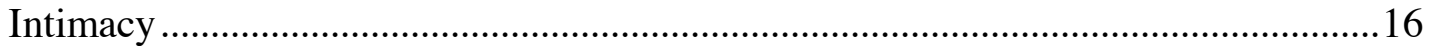

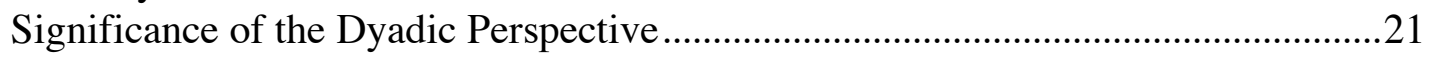

Military-Connected Couples .................................................................................24

Approach to the Study of Health in the Military-Connected Couple .........................24

Intimacy Process in Military-Connected Couples .......................................................31

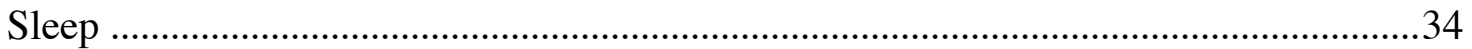

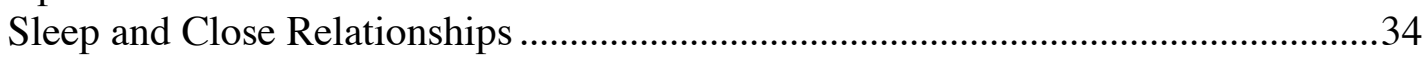

Military-Connected Couples and Sleep Problems ....................................................40

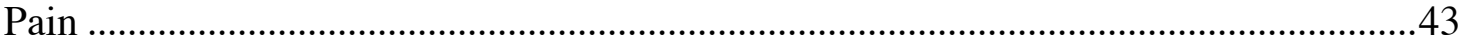

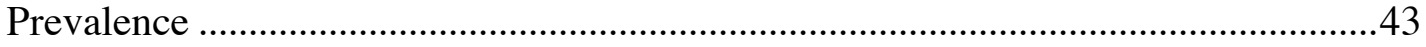

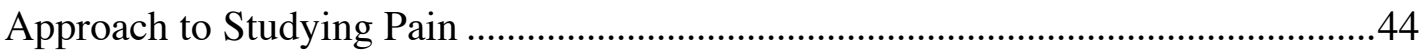

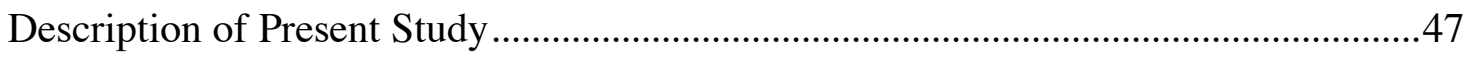

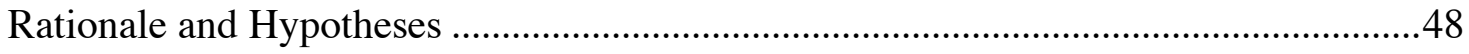

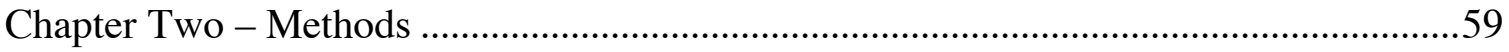

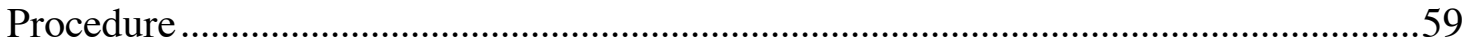

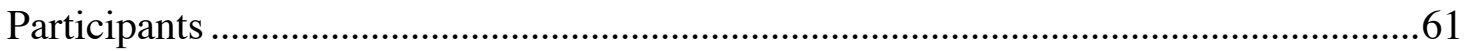

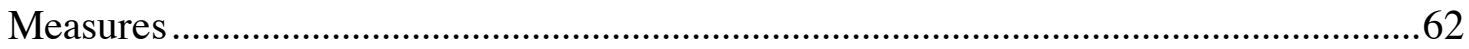

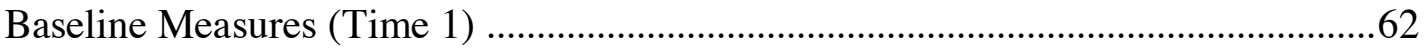

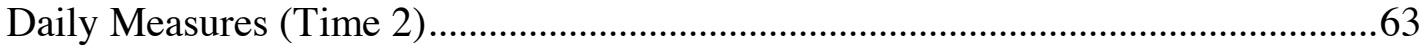

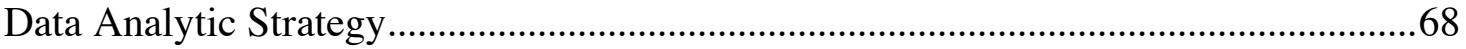

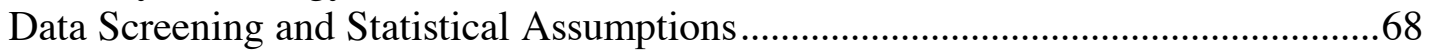

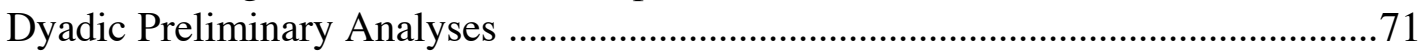

Hypothesis Testing using APIMs and APIMeMs ..................................................76 


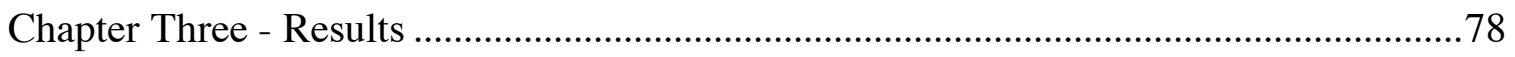

Descriptive Information and Correlational Statistics ......................................................78

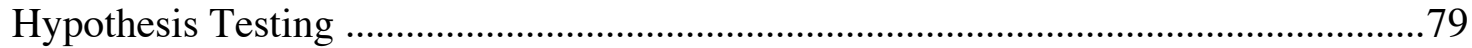

Results of Perceived Partner Responsiveness-Sleep Quality APIM ...........................79

Results of Perceived Partner Responsiveness-Positive Affect-Sleep Quality

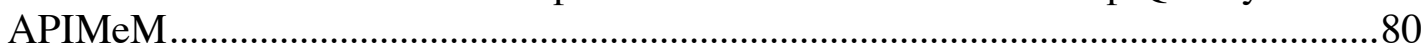

Results of Perceived Partner Responsiveness-Negative Affect-Sleep Quality

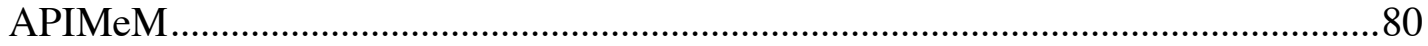

Results of Perceived Partner Responsiveness-Pain APIM..........................................81

Results of Perceived Partner Responsiveness-Positive Affect-Pain APIMeM ..........81

Results of Perceived Partner Responsiveness-Negative Affect-Pain APIMeM .........82

Chapter Four - Discussion ..........................................................................................8

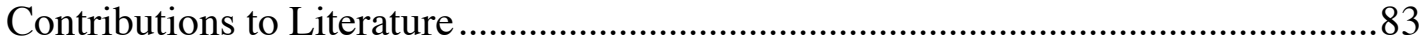

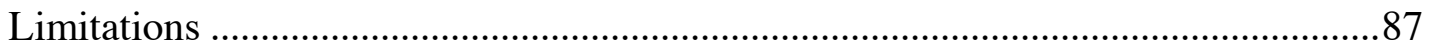

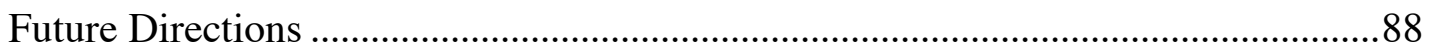

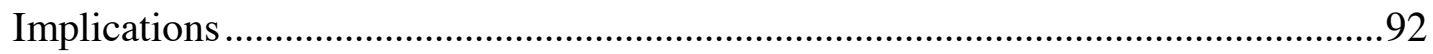

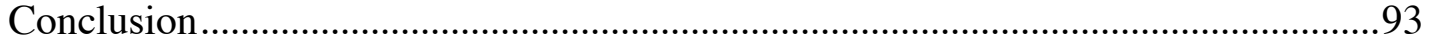

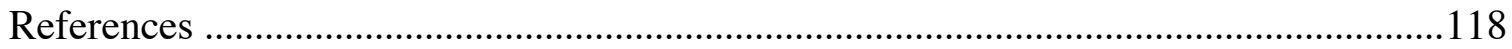




\section{List of Tables}

Table 1. Descriptive statistics for the demographics and control variables

Table 2. Descriptive statistics and paired sample t-test statistics for the primary study variables

Table 3. Within-veteran, within-spouse, inter-partner correlations and among study variables

Table 4. Indirect effects for the APIMeM of perceived partner responsiveness predicting sleep quality via positive affect

Table 5. Indirect effects for the APIMeM of perceived partner responsiveness predicting sleep quality via negative affect

Table 6. Indirect effects for the APIMeM of perceived partner responsiveness predicting pain via positive affect.

Table 7. Indirect effects for the APIMeM of perceived partner responsiveness pain via negative affect 


\section{List of Figures}

Figure 1. Theoretical framework from Pietromonaco \& Collins (2017) ..........................101

Figure 2. Conceptual model depicting how PPR promotes sleep ......................................102

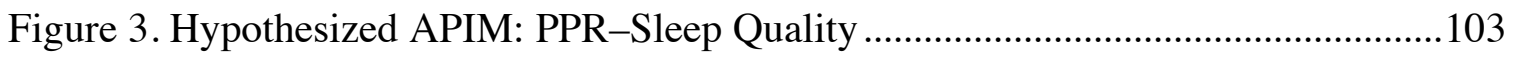

Figure 4. Hypothesized APIMeM: PPR-Downregulation of vigilance-Sleep Quality ..104

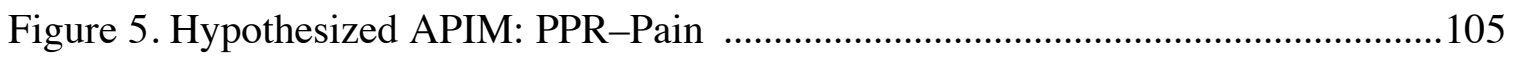

Figure 6. Hypothesized APIMeM: PPR-Emotion regulation-Pain .................................106

Figure 7. Pain Scale - Visual analog scale ....................................................................107

Figure 8. Histograms of the outcome of Sleep Quality ......................................................108

Figure 9. Histograms of the outcome of Pain.....................................................................109

Figure 10. Histograms of the mediator of Positive Affect …………………………......110

Figure 11. Histograms of the mediator of Negative Affect................................................111

Figure 12. Results of APIM: PPR-Sleep Quality ..........................................................112

Figure 13. Results of APIMeM: PPR-Positive Affect - Sleep Quality .............................113

Figure 14. Results of APIMeM: PPR-Negative Affect-Sleep Quality..............................114

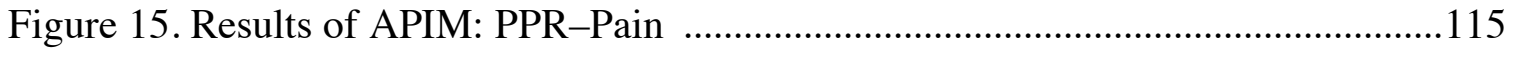

Figure 16. Results of APIMeM: PPR-Positive Affect-Pain ...............................................116

Figure 17. Results of APIMeM: PPR-Negative Affect-Pain ..........................................117 


\section{Chapter One - Introduction and Literature Review \\ Problem Statement}

\section{Overview of Health Problems of Service Members and Veterans}

Over 2.6 million United States service members have deployed to Afghanistan and Iraq to participate in Operation Enduring Freedom (OEF), Operation Iraqi Freedom (OIF), and Operation New Dawn (OND; National Research Council, 2012). As of 2013, it was estimated that about 1.6 million of these service members have separated from the military (Adams, 2013). These military veterans contend with unique health challenges stemming from military experiences such as exposure to improvised explosive devices (National Research Council, 2013), resulting in higher rates of medical needs, mental health needs, and disability in post-9/11 veterans, compared to earlier generations of U.S. veterans (Autor et al., 2016; Nock et al., 2013). Examples of these physical and mental health needs include treatment for post-traumatic stress disorder (PTSD), traumatic brain injury (TBI), depression, and substance abuse (Adams et al., 2012; Barlas et al., 2013; Bray et al., 2009; Hoge, Auchterlonie, \& Milliken, 2006; Hyman, Ireland, Frost, \& Cottrell, 2012; Larson et al., 2013; Lazar, 2014; Pickett et al., 2015; Reger et al., 2015; Schoenbaum et al., 2014). Whereas these health issues contribute to difficulty at work, at home and for overall health and well-being, sleep disturbances and pain are especially prevalent and problematic for this population. As detailed below, they can exacerbate other health problems, complicate reintegration into civilian life, and worsen quality of life for veterans. 
The importance of sleep in health maintenance cannot be overstated as it is essential for healthy brain function, emotional well-being, repairing tissue damage from normal wear and tear, improving immune function, maintaining the balance of hormones, decreasing the risk of health problems such as obesity and stroke (National Heart, Lung and Blood Institute, 2018). The short-term consequences of insufficient sleep, such as grogginess, irritability, and overeating throughout the day, can be problematic. Insufficient sleep over time is predictive of a variety of diseases (e.g. diabetes, heart disease) as well as all-cause mortality (e.g. Cappuccio, D’Elia, Strazzullo, \& Miller, 2010; Chandola, Ferrie, Perski, Akbaraly, \& Marmot, 2010). Clearly, sleep is an important health behavior that ameliorates other physical and mental health issues. Given that veterans contend with elevated rates of certain physical and mental health issues (as detailed below), it is critical to optimize sleep in veterans in order to promote their overall health. Taken together, promoting sleep would not only ameliorate symptoms from other comorbid health problems, it would also enable the veteran to fully engage in work, manage responsibilities at home, and to enjoy a rich social life.

Likewise, pain is an important health outcome to investigate due to the overwhelmingly negative impact that both acute and chronic pain have on most parts of daily life, including the ability to adequately perform in roles at work and at home. As such, pain is widely recognized as a quality of life indicator (Niv \& Kreitler, 2001). In the long-term, individuals with chronic pain are more likely to have difficulty working and to have depression or anxiety than people without chronic pain (Gureje,Von Korff, Simon, 
\& Gater, 1998). In the following section, I review the current understanding of these problems and their impact on the lives of veterans and their spouses in further detail.

Sleep Disturbances. Sleep disturbances encompass a variety of symptoms such as sleeping less than the recommended minimum of 7 hours per night and requiring an excessive amount of time to fall asleep. High prevalence of sleep disturbances has been documented among service members and veterans (Plumb, Peachey, \& Zelman, 2014; Troxel et al., 2015). In a sample of 375 currently non-deployed OEF and OIF service members and veterans, Plumb and colleagues (2014) found that $89 \%$ were poor sleepers as assessed by the global Pittsburgh Sleep Quality Index (PSQI). In particular, 21\% slept less than 4.5 hours per night, $45 \%$ took longer than 30 minutes to fall asleep, and $56 \%$ of them rated themselves to be bad sleepers. There are a variety of risk factors associated with military life that may contribute to sleep problems at various points of the military career. From the extreme demands and irregular schedules of basic training to the stressful sleep environments and overnight watch duties of deployment, service members endure occupational environments that contribute to sleep disturbances during these career stages and beyond (Hughes, Ulmer, Gierisch, Hastings, \& Howard, 2018; Peterson, Goodie, Satterfield \& Brim, 2008; Troxel et al., 2015). As mentioned above, sleep disturbances have profound consequences in the short term (e.g. cognitive impairment, increased emotional irritability, increased incidence of interpersonal conflicts) as well as devastating impacts in the long term [e.g. increased mortality and morbidity risk, exacerbated mental health issues, and increased risk of suicidal ideation and suicide attempts (for reviews, see Barnes \& Drake, 2015; Buysse, 2014; Pigeon, 
Pinquart \& Conner, 2012; Troxel, 2010)]. Further, sleep disturbances and mental health issues share a bidirectional relationship (Hoge et al., 2004; Martindale, Morissette, Rowland, \& Dolan, 2017). For example, PTSD symptoms such as hypervigilance delay sleep onset and cause sleep disruptions, which is problematic because poor sleep quality exacerbates PTSD symptomology (Hoge et al., 2004; Martindale et al., 2017).

To address widespread sleep disturbances, the Department of Defense and the branches of the military have recently taken crucial steps, such as establishing policies and programs that aim to promote sleep health (see Troxel et al., 2015 for review). While much is known about the individual-level factors that influence sleep (such as caffeine use, exposure to blue light from technology before bed, worrying before bed), relatively little is known about the specific relationship processes (or series of interactions that occur between two individuals) that facilitate or hinder restorative sleep. Yet, sleep processes are embedded in the marital context because most adults share the bed with their romantic partner (about 70\%; National Sleep Foundation, 2012) and because relationship processes are both influenced by sleep and influence sleep (Troxel, 2010). For example, daytime interpersonal conflict with one's partner has deleterious effects on sleep that night (Hicks \& Diamond, 2011). Further, a previous night's poor sleep increases the likelihood of marital conflict the next day (Gordon \& Chen, 2014). In hopes of developing a more comprehensive understanding of sleep, research has increasingly included both members of a romantic couple to examine the relationship processes unfolding between them, and how they might influence sleep (Troxel, Robles, Hall, \& Buysse, 2007; Troxel, 2010). Researchers have found important preliminary evidence for 
the influence of relationship processes on sleep. One recent empirical study found that feeling supported by one's partner facilitates the downregulation of vigilance, which is required for high quality sleep, and is associated with improved sleep quality (Selcuk, Stanton, Slatcher \& Ong, 2017). Taken together, it is clear that service members and veterans struggle with sleep disturbances, and commonly used individual-level approaches to research and intervene upon sleep problems do not address the social influences of romantic partners. As the paragraph above details, relationships with close others have the ability to influence sleep. Similarly, the next section reviews the current understanding of how relationships affect pain.

Pain. Pain is especially relevant for military veterans, as military experiences (such as explosions experienced in combat) contribute to pain. Pain experiences lasting longer than three to six months are diagnosed as chronic pain. It is estimated that $50 \%$ of veterans meet diagnostic criteria for chronic pain (Kerns et al., 2003). The influence of pain on physical and psychological health problems can be far-reaching. For example, one study of $\mathrm{OEF} / \mathrm{OIF} / \mathrm{OND}$ veterans found that pain predicted poor sleep quality and reexperiencing symptoms of PTSD (e.g. Powell et al., 2015). Further, the pain of service members and veterans is relevant to their romantic partners, as pain is influenced by social factors, in addition to biological and psychological factors (Gatchel et al. 2007). In a systematic review, Krahé, Springer, Weinman and Fotopoulou (2013) documented an example of the social modulation of pain wherein positive interactions with romantic partners provided stronger analgesic effects than acquaintances or strangers in the context of experimentally-induced pain. The mechanisms for such analgesic effects of close 
relationships is not well-understood, but it is theorized that relationship processes impact one's ability to manage one's emotions (Coan, 2011). In turn, this fostering of emotionregulation might extend into other experiences that have a strong affective component, such as pain (Melzack \& Casey, 1968).

\section{Intimacy Process}

To explain the analgesic and sleep-promoting effects that close relationships can facilitate as described above, current empirical work has pointed to a particular relationship process as a possible contributor of these salutary effects-- the intimacy process. The intimacy process consists of reciprocal and iterative interactions, including self-disclosures (the sharing of personal emotional information), response to selfdisclosure, and perceived partner responsiveness (the degree to which one feels validated, understood, and cared for by one's partner; Laurenceau, Rivera, Schaffer, \& Pietromonaco, 2004; Reis \& Shaver, 1988). The intimacy process emerges as a likely explanatory mechanism of the health-promoting effects that close relationships foster. This is due, in part, to the notion that feeling supported by another person, especially a close loved one, is a major predictor of the analgesic and sleep-promoting effects of close relationships, as evidenced by the aforementioned research (e.g. Master et al., 2009; Oishi, Schiller, \& Gross, 2013; Selcuk et al., 2017). Feelings of being supported are fostered by the intimacy process. The intimacy process has been significantly associated with positive health outcomes. For example, Slatcher, Secluk and Ong (2015) found that perceived partner responsiveness predicted healthier cortisol slopes after 10 years. One reason for this significant health impact is that perceived partner responsiveness has been 
found to downregulate anxiety and arousal, and to instill a sense of security and calmness (Selcuk, Zayas, \& Hazan, 2010). In essence, the intimacy process is likely healthpromoting for pain, sleep, and general physical health outcomes because it sets into motion downstream positive psychological processes that promote health.

\section{Methodological Innovations}

Research about health has overwhelmingly been approached on the individual level, ignoring the mutual influence of significant others. This is because theories about the mechanisms by which relationships impact health have evolved in only the last few decades and the advanced statistical methods required to test these theories have only been innovated as recently as the early 2000s (Reed, Butler \& Kenny, 2013). This exclusion of influential and enduring close relationships, such as those with spouses, from research misses a substantial piece of the health puzzle, as it is widely documented that close relationships play a fundamental role in promoting health and well-being (see Pietromonaco \& Collins, 2017 for review). For example, a husband can enthusiastically respond to his wife's news of the getting a long-awaited promotion at work and his response of the good news (i.e. capitalization) can foster positive affect beyond the influence of the positive event itself (Gable \& Reis, 2010). This fostering of positive affect, in turn, predicts better physical health outcomes, such as improved cardiovascular health (Boehm \& Kubzansky, 2012). Given that significant others are often the primary relationship and source of support for adults (e.g. Birditt \& Antonucci, 2007; Barger \& Cribbet, 2016), it is unsurprising that high-quality partnerships or marriages are highly predictive of better health (e.g. Kiecolt-Glaser \& Newton, 2001; Robles, Slatcher, 
Trombello, \& McGinn, 2014). To investigate the way that members of militaryconnected couples influence one another's health, this thesis incorporates the perspectives of both the veterans and their spouses to examine interdependencies. Note that military-connected couples refer to couples in which at least one member is a current or former service member.

The prevailing standard of modeling dyadic data (i.e. data that incorporates two members of a pair such as in a romantic couple) is the Actor-Partner Interdependence Model (APIM; Cook \& Kenny, 2005; Reed et al., 2013 for review). The APIM models how members of a dyad influence each other and themselves. For an example relevant to this paper, an APIM can simultaneously model the impact of a veteran's feelings of being supported (i.e. PPR) on his own sleep quality and on his spouse's sleep quality as well as his spouse's PPR on both her own and her husband's sleep quality through the mediator of downregulation of vigilance. In layman's terms, an individual who generally feels supported by his or her spouse might be able to relax more and thus sleep better. Similarly, an individual who feels supported might be able to regulate his or her emotions better and thus feel less pain due to the highly affective nature of pain.

Everyday mundane interactions, as well as fleeting emotional states, such as relaxation, can have lasting implications for health but these interactions need to be captured close in time to their occurrence as they can be forgotten or interpreted inaccurately later. To address this methodological concern, this study utilizes daily diary methodology to reduce biases attributable to misremembering events (i.e. retrospective bias; Reis \& Gosling, 2010). For the present thesis, I aggregated daily diary data about 
emotions, sleep and pain. This approach is intended to answer the questions regarding if members of military-connected couples who feel more supported in general sleep better and feel less pain. Future analyses will assess how relationship processes that influence sleep and pain over time to examine how these processes unfold. Together, the innovations of dyadic data analysis and daily diary designs are powerful tools to investigate the relationship processes underlying the well-documented links between close relationships and health (Reed et al., 2013).

The Present Research. The current study uses the innovations of dyadic data analysis and daily diary designs to investigate whether greater perceived partner responsiveness predicts higher sleep quality and less pain. Investigating the influence of romantic partner is crucial for understanding the veterans' and spouses' sleep quality and pain for several reasons. First, most OEF/OIF/OND veterans are married (Department of Defense, 2016). Secondly, both members of the military-connected couple cope with health problems experienced by the veteran and these health problems share a bidirectional relationship with relationship functioning (Lewis, Lamson \& Leseuer, 2012; Trump, Lamson, Lewis, \& Muse, 2015). Last, the health outcomes of pain and sleep are increasingly being researched with respect to the social contexts in which they occur, rather than employing the traditional individualistic model, thus restricting the scope to individual-level factors. The overarching theoretical framework being tested in this thesis is based on Pietromonaco and Collins (2017), which asserts that relationship processes impact health outcomes by facilitating psychological processes. More about this framework, as well as sleep-specific and pain-specific theories that are consistent with 
the overarching Pietromonaco and Collins' framework (2017), will be probed in subsequent sections. Therefore, this study contributes to the close relationship-health literature by utilizing the dyadic APIM approach and daily diary design to examine the effects that the intimacy process has on the health outcomes of pain and sleep via psychological processes. This approach may serve to inform potential new venues of intervention for military-connected couples struggling with sleep disturbances and/or pain. The following sections will review the literature relevant to the hypotheses that the intimacy process promotes sleep and decreases pain through intermediary psychological processes. 


\section{Social Relationships and Health}

\section{The Need to Belong}

The need to belong is the fundamental "drive to form and maintain at least a minimum quantity of lasting, positive, and significant interpersonal relationships" (Baumeister \& Leary, 1995, p. 497). This deep-rooted evolutionary drive stems from the significant survival and reproductive benefits associated with close social bonds. Evolutionary mechanisms appear to have developed to reinforce social contact and relatedness with positive emotion and to punish real, imagined or potential threats to social bonds with emotional distress (Baumeister \& Leary, 1995). Researchers have found that social relationships characterized by positive interactions that are both regular and ongoing while mostly being free from conflict satisfy the need to belong (Baumeister \& Leary, 1995). Accordingly, belonging has important implications for physical health and well-being. In their seminal work, Baumeister and Leary (1995) reviewed the literature to show that belonging is associated with a multitude of psychological benefits, (e.g. increased happiness, contentment, and calmness) and physical health benefits (e.g. lowered mortality rates). As it is a fundamental human need, the chronic failure to satisfy the need to belong can result in pathological consequences beyond the temporary emotional distress of detecting rejection, as described above (Baumeister \& Leary, 1995). Individuals lacking close social ties, and therefore belongingness, suffer more from psychological and physical health problems than those with close social ties (Baumeister \& Leary, 1995). For example, people who lack close relationships more often contract cancer and heart disease, have damaged immune systems, and have increased mortality 
risk (Berscheid \& Reis, 1998). Importantly, the causality is unclear. It may be true that relationships enhance health, good health fosters supportive relationships, bidirectional in that both effects feed into each other, or that this effect could be confounded by some other variable all together (Fiske, 2004). However, there is a sizable body of literature showing that social relationships, and especially high-quality relationships characterized by supportiveness that would satiate the need to belong, are predictive of improved health outcomes.

An impressive wealth of evidence, rooted in disciplines including health psychology, social psychology, sociology and medicine, have consistently revealed profound effects of social relationships on psychological and physical health. This body of research stems from the seminal work of sociologist Émile Durkheim who found that lacking social ties and the social resources that follow from them contribute to suicide risk (Durkheim, 1951). Considerable empirical evidence has demonstrated that social integration with a network of diverse social ties and social support are positively associated with and causally linked to psychological health and physical health (e.g. Berkman, 1995; Cohen \& Wills, 1985; Ertel, Glymour, \& Berkman, 2009; House, Landis, \& Umberson, 1988; Reynolds \& Kaplan, 1990; Seeman, 1996; Uchino, 2004; Umberson \& Montez, 2010). A meta-analysis of 148 longitudinal studies consisting of data from 308,849 individuals over an average of 7.5 years found a $50 \%$ increased survival rate for participants with stronger social relationships leading them to conclude that the influence of social relationships on risk of mortality is comparable to wellestablished risk factors for mortality such as obesity and physical inactivity (Holt- 
Lunstad, Smith, \& Layton, 2010). Similarly, significant health issues have been linked with low social integration, including greater mortality, poor immune system functioning, and an increased risk of mortality from circulatory disease, heart disease, and cancer (Berkman et al., 2000; Cohen, 2004; Cohen \& Lemay, 2007; House, Landis, \& Umberson, 1988; Kuntsche, Knibbe, Gmel, 2009; Pressman, Cohen, Miller, \& Rabin, 2005; Reynolds \& Kaplan, 1990).

As romantic partners are the primary relationship and source of support in adulthood, they are often the most impactful social relationship on health outcomes (Robles et al., 2014). Relationship quality is the global evaluation of the relationship across domains such as positive aspects (e.g. satisfaction) and negative aspects (e.g. conflict; Bradbury et al., 2000; Fincham \& Bradbury, 1987). Importantly, relationship quality determines if the marriage or partnership has a beneficial or deleterious effect on health. For example, a review of 64 studies of married individuals found that marital functioning impacts health. Negative dimensions (such as interpersonal conflict) impacted health indirectly through depression and poor health habits, as well as directly by altering biological pathways such as cardiovascular, endocrine, immune, and neurosensory systems (Kiecolt-Glaser \& Newton, 2001). In the same vein, a metaanalysis of over 72,000 partnered individuals found that greater marital quality was associated with higher self-rated health, lower mortality, healthier cardiovascular functioning, and structural markers indicating less cardiovascular disease (Robles et al., 2014). Taken together, it is widely-documented that close relationships, especially those with romantic partners, are important for health. Whereas the satisfaction of the need to 
belong is the most fundamental reason why high-quality social bonds are salubrious, the particular mechanisms by which close relationships exert their health-promoting effects are not well-understood (Feeney \& Collins, 2015).

\section{Mechanisms Linking Social Relationships and Health}

For the past several decades, researchers have been calling attention to the paucity of research aimed at understanding the underlying mechanisms which would explain the links between social relationships and health as well as provide interventionists with evidence about the key components to try to promote in order to foster health (e.g. Berkman et al., 2000; Cohen, 2004; Kawachi \& Berkman, 2001; Thoits, 1995; Uchino, Cacioppo \& Kiecolt-Glaser, 1996). Feeney and Collins (2015) offered a few reasons for this gap in the literature, including that much of the extant empirical work has examined characteristics of one's social environment (e.g. social integration, marital status, marital quality), rather than the specific relationship processes that underlie the links between social relationships and health (Feeney \& Collins, 2015; Uchino, Bowen, Carlisle, \& Birmingham, 2012) Additionally, the overwhelming focus on the relationship process of social support in the context of stress or adversity, while mostly neglecting other critical relationship pathways, has also contributed to the gap in the literature (Berkman et al., 2000; Feeney \& Collins, 2015). Berkman and colleagues (2000) argued that although social support is among the pathways by which social networks influence health, it is not the only pathway. As such, researchers should broaden their focus to include other pathways for a richer understanding of the complex ways that social relationships impact health. 
RESPONSIVENESS, SLEEP AND PAIN IN VETERANS AND SPOUSES

Overarching Theoretical Framework. Recently, Pietromonaco and Collins

(2017) organized the body of research into a helpful guiding framework that identifies the key relationship processes (also called interpersonal processes) that affect health-relevant intrapersonal pathways to ultimately impact longer-term psychological well-being and physical health (see Figure 1). Relationship processes facilitate a number of intrapersonal processes which, in turn, affect health outcomes. Potential intrapersonal mechanisms include psychological (e.g. emotion, cognition), biological (e.g. cardiovascular, cortisol, immune responses), and lifestyle (e.g. diet and exercise) pathways. In the framework from Pietromonaco and Collins (2017), any of the relationship processes can affect health through any of the intrapersonal mechanisms. For example, capitalization and the subsequent supportive response to the sharing of one's happy news, has been found to boost positive affect (which is a psychosocial intrapersonal pathway) and ultimately foster well-being (which is a mental health outcome; Gable \& Reis, 2010; Langston, 1994). This framework is rooted in attachment theory, which states that patterns of experiences in early childhood with one's caregiver shape relatively stable mental representations or working models of close relationships with others that carry forward into adulthood (Ainsworth, 1979; Bowlby, 1969). For example, secure base support refers to seeing one's primary attachment figure, which could be a parent or a spouse, as a reliable and safe anchor that encourages a person to strive to search the surroundings, in the case of infants, or to seek new opportunities for growth, in the case of adults. See Figure 1 for a graphic depiction of the organizational framework. 
The current study investigates the salubrious effects of the intimacy process, a relationship process that is categorized under social connection type of relationship processes in Figure 1, through the intermediary psychological pathway of emotion to impact the health outcomes of sleep and pain. Before reviewing the intimacy process and the health-promoting intrapersonal effects it sets into motion, I will review theory and research regarding intimacy as a central process driving close relationships' analgesic and sleep-promoting effects.

\section{Intimacy}

Intimacy is considered to be both a feeling and a process that fosters closeness (Laurenceau et al., 1998; Reis \& Shaver, 1988). Early intimacy research described it in terms of its link to the self. For example, Erickson $(1950,1968)$ described intimacy as a merging of two initially independent identities through interactions in which participants the reveal deeply personal parts of the self and the validation of those revelations, which also validates self-worth (Partridge, 1966; Sullivan, 1953). Intimacy has also been conceptualized as feelings closeness between two people (Hendrick \& Hendrick, 1983; Sternberg, 1986). Another important characterization of intimacy is that of interdependence, in which one person's actions influence the other's outcomes (Kelley \& Thibaut, 1978).

Later work sought to investigate how intimacy develops. The major contribution in this body of work was from Reis and Shaver (1988), who developed the intimacy process. The intimacy process entails patterns of interactions in which Person A makes self-disclosures, Person B responds, and Person A evaluates that response to the degree 
that it engendered feelings of being supported (i.e. perceived partner responsiveness; Reis \& Patrick, 1996; Reis \& Shaver, 1988). Self-disclosure has been defined as verbally communicating information, thoughts, or feelings relevant to oneself to another person (Derlega, Metts, Petronio, \& Margulis, 1993). Making self-disclosures increases the listener's liking of the person who disclosed and, likewise, liking a person increases the probability of disclosing in return. Thereby a relationship is formed and reinforced by mutual liking, disclosing, and validating disclosures (Reis \& Shaver, 1988). According to the social penetration theory (SPT), relationships develop through initial self-disclosures of a relatively superficial, low-risk nature (e.g. sharing favorite movies and food preferences), later evolving to deeper and more vulnerable in nature (e.g. life goals and religious beliefs), ultimately revealing the true self (Altman \& Taylor, 1973). The analogy of peeling layers of an onion is helpful in understanding SPT. Like an onion, the self is multi-layered and intimacy is achieved by "peeling" through the layers of the onion to reach the core of the self. Reciprocity in sharing increasingly more intimate information, followed by other person's supportive response increases the likelihood of forming a close relationship and the fostering of intimacy (Altman \& Taylor, 1973). Interactions of self-disclosures and responsiveness, over time and proceeding in a reciprocal way, characterize the intimacy process (Clark \& Reis, 1988).

Responsiveness, known as the "active ingredient" of the intimacy process, is considered to be a central aspect of satisfying relationships (Lemay, Clark, \& Feeney, 2007). Responsiveness is also an organizing principle that underlies various theories (e.g. Attachment Theory) and relationship processes in social relationship research (Reis, 
Clark \& Holmes, 2004). Responsiveness consists of three key components as briefly mentioned above. The first is understanding, which is characterized by comprehending the partner's values and self. The second is validation, which is characterized by valuing the partner's perspectives of the self. The third and final component is caring, which is characterized by warmth and concern for the partner (Reis \& Shaver, 1988). The global view of one's partner as responsive is formed through accumulated specific interactions, where self-disclosures are met with a positive reaction from one's partner (Laurenceau et al., 1998). This global view of one's partner can also change based on responses to specific disclosures that were inconsistent with the former global view of one's partner (Maisel \& Gable, 2009). Self-disclosures allow the responding partner to affirm their supportiveness for the disclosing partner. Further, responsiveness grants the discloser with insight into the state of their relationship with the responder, as well as validation and reaffirmation. Each interaction can validate the person's goals, values, and at the most fundamental level, the self (Reis \& Shaver, 1988). Finally, the intimacy process is driven by the fundamental need to belong (Reis \& Shaver, 1988).

Intimacy and Health. Pietromonaco and Collins (2017) identified the intimacy process as one of the relationship processes that facilitates intrapersonal processes to ultimately impact health. Although the intimacy process has been relatively understudied as a predictor of physical health, longitudinal studies have discovered promising results. In a large sample of married or cohabiting individuals $(\mathrm{N}=1,078)$, greater perceived partner responsiveness predicted higher cortisol values at awakening and steeper (i.e. healthier) diurnal cortisol slopes 10 years later (Slatcher et al., 2015). Interestingly, 
researchers have discovered that perceived partner responsiveness accounts for the apparent paradox that receiving social support from close others can actually result in worse physical health (Maisel \& Gable, 2009). Specifically, a national longitudinal study of 1,803 married or cohabiting individuals recruited from MIDUS found that receiving social support predicts higher all-cause mortality over 10 years, but only for individuals who did not perceive their partners to be responsive (Selcuk \& Ong, 2013). It should be noted that the findings remained in both studies even while controlling for a wide range of covariates including demographic factors, personality traits, and physical health status (Selcuk \& Ong, 2013; Slatcher et al., 2015). In a daily diary study of married couples, daily self-disclosure predicted sleep quality and sleep efficiency for wives, as well as reductions in waking during the night for husbands (Kane, Slatcher, Reynolds, Repetti \& Robles, 2014). Another study found that responsive interactions with partners promoted the release of endogenous opioids, which in turn reduce pain (Machin \& Dunbar, 2011). Together these studies provide evidence to support the hypotheses that the intimacy process influences both sleep and pain. I will discuss the effect of intimacy on these health outcomes in detail in the following sections.

There are many intrapersonal pathways that can mediate the relationship between intimacy and health. For example, intimacy plays a large role in galvanizing individual growth (such as the pursuit of personal goals), which also promotes health (Reis \& Shaver, 1988). In this pathway, intimacy is theorized to work by fostering nondefensiveness and openness to feedback about personal shortcomings, which can motivate goal-oriented behavior (Caprariello \& Reis, 2011; Kumashiro \& Sedikides, 
2005). The intrapersonal processes regarding emotion are especially relevant as a pathway by which intimacy affects health for the present work. As Reis (2014) stated, close relationships are characterized by affective interdependence, which is the extent to which emotions and emotion-regulation are influenced by partners (Kelley \& Thibaut, 1978; Rusbult \& Van Lange, 2008). Emotion-regulation is the hypothesized intrapersonal pathway that acts as the mediating mechanism between the intimacy process and lessened pain and improved sleep quality. This is supported in the literature, as intimate partners influence each other's emotions (e.g., Reis \& Shaver, 1988).

Distinction from a Related Construct. Importantly, the intimacy process is related to but distinct from social support. Cohen and Wills (1985) proposed two theoretical models to explain how relationships influence health: the stress-buffering model and the main effects model. The stress-buffering model asserts that social relationships provide informational, emotional, and tangible resources that foster adaptive responses to acute or chronic stressors (Cohen \& Wills, 1985). The main effects model proposed that social relationships impact health directly rather than through the buffering of stress (Cohen \& Wills 1985). This model has received considerably less attention in empirical studies than the stress-buffering model. While the stress-buffering model considers the benefits of social support in the context of stress or adversity, the main effects model is not limited to such contexts. Instead, the main effects model asserts that social relationships have been linked to well-being outside of stressful contexts (Lakey \& Orehek, 2011). 
The intimacy process functions through the main effects model because it is not bound to contexts of real or imagined adversity. Rather, it occurs whenever two people share emotional and meaningful information and validate each other. For example, in their laboratory-based observational study of 79 dating couples, Maisel and colleagues (2008) found that responsive behaviors can be observed when the partners discussed a positive event as well as a negative event. Further, some of the many purposes of the intimacy process are to become closer, to understand, and to be understood. The main purpose of social support is to assist another person in coping with real or imagined threats. Although intimacy can grow during a social support process (especially if it involves disclosures and responsiveness), it is distinct from social support. Both involve sharing something emotionally significant, either a negative event in the context of social support or an emotional disclosure about something personally relevant in the context of the intimacy process (Gable \& Reis, 2010). Social support and the intimacy process also differ because the former, ideally, results in ameliorated negative outcomes and the latter fosters positive psychological and interpersonal outcomes (Gable \& Reis, 2010).

\section{Significance of the Dyadic Perspective}

As summarized above, leading researchers investigating close relationships and health have galvanized the field to focus on relationship processes by which health benefits are fostered (Pietromonaco \& Collins, 2017). Relatively recently, methodological advances have allowed for the modeling of the mutual influence between two members of a dyad. Specifically, the Actor-Partner Interdependence Model (APIM) which was developed by Cook and Kenny (2005) is a standard for modeling these 
interactions and has been widely-utilized in the field. The APIM statistically accounts Person A's influence on Person A's own outcome (an actor effect) as well as Person B's influence on Person A's outcome (a partner effect). In distinguishable dyads such as a husband and wife (versus a set of twins or a pair of friends), there are two sets of actor effects and two sets of partner effects. For example, the wife's actor effect is the influence that the wife's independent variable (IV) has on the wife's dependent variable (DV) and the wife's partner effect is the influence of the husband's IV on the wife's DV. The partner effects capture the interdependence of the model. Additionally, the correlations between the wife's and husband's IVs as well as the error terms of the wife's and husband's DVs are calculated in this model.

The current research also utilizes the Actor-Partner Interdependence Mediated Model (APIMeM; Ledermann \& Bodenmann, 2006) to model the indirect effect of the intimacy process through the psychological processes on the resulting health outcomes of sleep and pain. The APIMeM is an extension of the standard APIM. The APIMeM adds an additional variable pair to serve as a mediator between the predictors and the outcomes (Ledermann \& Bodenmann, 2006). The APIMeM has three pairs of variables - X, Y, and M - for the two members of the dyad (Ledermann, Macho \& Kenny, 2011; see Figure 4 for the conceptual model depicting the APIMeM hypotheses test about sleep). Each member of the military-connected couple have their own predictor, perceived partner responsiveness (PPR). Each member of the couple also has their own mediator, the downregulation of vigilance, which is the psychological pathway through which it is hypothesized that intimacy impacts sleep. Finally, both members have their own sleep 
outcome. The upper three variables in Figure 4 are the veterans' predictor, mediator and outcome. The lower three variables in Figure 4 are the spouses' corresponding variables. Additionally, the thick horizontal lines represent the actor effect, or how each individual's PPR predicts their own sleep outcome. The dashed diagonal lines depict the partner effects, or how the veteran's PPR predicts the spouse's sleep (and vice versa). The shorter lines represent both actor and partner effects involving the mediator. For example, the dotted line leading from the veteran's downregulation of vigilance to the spouse's sleep represents how the veteran's mediator impacts the spouse's sleep (a partner effect). The other dotted line represents how the veteran's downregulation of vigilance influences his own sleep (an actor effect).

In conclusion, this section summarized the literature establishing connections between close relationships and health, as well as called attention to the gap in the literature regarding the mechanisms by which close relationships impact health. Supporting theoretical and empirical evidence for the hypotheses regarding the intimacy process as health-promoting were explored. The significance of the dyadic approach in researching how relationship processes influence health was emphasized. The next section will transition away from the general close relationship and health literature to thoroughly review current knowledge about military-connected couples and risk factors for sleep and pain as well as their relationship functioning. 


\section{Military-Connected Couples}

\section{Approach to the Study of Health in the Military-Connected Couple}

Existing research on veteran health outcomes, such as sleep and pain, has typically focused exclusively on current or former service members (e.g. active duty service members, reservists and/or separated service). However, recent work has increasingly begun to explore the experiences of civilian spouses and of the militaryconnected couple as a unit. This expansion of research focus from the unit of individual to the unit of the romantic couple in the military health literature mirrors the individualistic-to-dyadic shift in the health literature of the general population that was described in detail in the last section. Further, the dyadic approach to studying health is extremely relevant in the current wave of service members for at least two reasons. First, over half the total military force is married (DOD, 2016). Second, the health problems of service members and veterans profoundly impact the health of the spouse in several ways, according to a review from Lewis and colleagues (2012) and a more recent article from Trump and colleagues (2015).

Specifically, both members of the military-connected couple experience the health problems of one member in several ways. Health problems may worsen relationship functioning and put an added strain on the marriage (Lewis et al., 2012). Further, veteran health problems contribute to worsened health outcomes for the spouse (Lewis et al., 2012). Researchers have found that spouses' health issues often reflect the experiences, symptoms, or diagnoses of their partner (Menchaca \& Dehle, 2005). For example, in a sample of 75 matched military-connected couples recruited through a military medical 
center (with the current or former service members consisting of mostly active duty or retired Air force), Trump and colleagues (2015) found that the military-spouses' pain predicted both military-spouses' and civilian-spouse' positive marital quality. Further, they found that both sets of spouses' depressive symptoms predicted only civilianspouses' negative marital quality. Taken together, these studies suggest that the influences of current or former service member health are best captured by studying matched military-connected couples. For these reasons, leading researchers have encouraged interventionists and military healthcare providers to recognize the interdependence between members of military-connected couples in regard to physical health, psychological health and relationship functioning by adopting integrated care, couple-centered interventions, or family-centered care approaches (e.g. Lewis et al., 2012; Lewis et al., 2013; MacDermid Wadsworth et al., 2013).

Note that military-connected couples are defined as consisting of at least one partner who is currently serving or has previously served in the U.S. military. The other partner in a military-connected couple can either be civilian (i.e. military-civilian couples) or may have also served or currently serve in the military (i.e. dual-military couples). In this thesis, the spouses of current or previous service members will be termed "spouses" despite their own military history, for clarity.

Health Issues After OEF/OIF/OND Deployments. Over 2.6 million United States service members have deployed to Afghanistan and Iraq to participate in OEF, OIF, and OND (National Research Council, 2012). According to a 2017 Congressional Research Service Report, since the beginning of the post-9/11 U.S. military conflicts 
from October 2001 to April 2017, there have been a combined 5,362 hostile deaths (including those who were killed in action, died of wounds, or died of terrorist activities) of service members from all four branches of the military in OEF/OIF/OND (DeBruyne, 2017). Further, this same group has reported a combined 1,468 non-hostile deaths (including deaths due to accident, illness, injury, homicide, self-inflicted, unknown causes; DeBruyne, 2017). In the same timeframe, there have been 52,341 service members who have been wounded in action in these military engagements (DeBruyne, 2017). Veterans returning from deployment in Afghanistan and Iraq have an elevated risk for physical health problems (e.g. amputations, combat injuries, pain, traumatic brain injury, musculoskeletal issues, sleep disorders), mental health disorders (e.g. anxiety disorders, depression, post-traumatic stress disorder), and suicide (Fischer, 2015; Haskell et al., 2006; Hoge, Auchterlonie, \& Milliken, 2006; Hyman et al., 2012; Lazar, 2014; Pickett et al., 2015; Reger et al., 2015; Schoenbaum et al., 2014; Tan et al., 2009). Enhanced survival rates, because of quickly-delivered and sophisticated medical care, means that even the most grievously-injured service members often return to their families. Additionally, the enduring physical and psychological health problems with which veterans return home are often managed by and indirectly experienced by the loved ones of the service members (Baptist et al. 2011; Clark, Bair, Buckenmaier, Gironda \& Walker, 2007; Hosek, Kavanagh, \& Miller, 2006).

Risk Factors of Military Life. The demands placed on the service members have been more pronounced in the recent military engagements of OEF and OIF than at any time since the Vietnam War (Hosek et al., 2006). Specifically, deployments have been 
longer, more frequent, with shorter intervals of time between deployments (Defense Manpower Data Center, 2004; Nock et al., 2013). This is especially true for the Army and the Marines (Defense Manpower Data Center, 2004; Nock et al., 2013). Further, the warfare itself can be characterized as extremely unpredictable and treacherous. With terrorist and guerrilla warfare tactics such as the use of suicide bombers and IEDs becoming increasingly common, combat experiences and injuries sustained during these experiences can contribute to pain (Baptist et al., 2011). Of particular interest to this study, sleep problems in the military are not isolated to those with deployment history. This suggests that other aspects of military life may be contribute to these issues (Hughes et al., 2018; Troxel et al., 2015). For example, during basic training, service members are subjected to extreme ongoing psychological and physical demands, as well as irregular schedules (Peterson et al., 2008). During deployment, service members endure crossing multiple time zones, overnight watch demands, stressful sleep environments (overcrowded, noisy, dangerous) that demand vigilance, and missions that continue overnight. These factors force service members to either not sleep or to sleep in shifts in the field (Peterson et al., 2008; Troxel et al., 2015). Other aspects of military life that are not confined to deployment or basic training that could contribute to sleep problems include too many days spent in physical training, feeling overwhelmed by work, unpredictability of duty hours, and experiencing work-family conflict (Holliday, Haas, Shih \& Troxel, 2016; Troxel et al., 2015). Shifting to the major stressor of deployment, this thesis will review deployment's impact on military-connected couples by summarizing findings from systematic reviews exploring the perspective of spouses, as 
well as one large longitudinal study incorporating data from matched service members and spouses.

Impact of Deployment on Couples. Deployment contributes many challenges that military-connected couples contend with as a unit, such as the stress of separation. It also challenges each member of the couple with unique sets of stressors, such as uncertainty over the service member's safety for the spouse and dangerous working environments for the service member (e.g. APA Presidential Task Force on Military Deployment Services for Youth, Families, and Service Members, 2007; Burrell, Adams, Durand, \& Castro, 2006; Faber et al. 2008; Lincoln, Swift, \& Shorteno-Fraser, 2008; Segal, 1989). De Burgh, White, Fear, and Iversen (2011) conducted a systematic review to assess the literature about the health and well-being of female spouses of male military personnel (mostly from the Army or Marines) who have deployed to post-9/11 conflicts in Iraq. They concluded that the challenges associated with deployment that militaryconnected spouses face pose an increased risk of mental health problems. Of the many of the challenges associated with deployments for spouses, the unpredictability of deployments, such as involuntary extensions, stand out as especially problematic, in terms of contributing to psychological problems for spouses (De Burgh et al., 2011).

There are not many longitudinal studies following both members of militaryconnected couples through the deployment cycle (pre-deployment, during deployment, and post-deployment). Such studies provide a rare glimpse into the lives of militaryconnected couples to see the effects of deployment, how their relationship functioning fluctuates and how their physical and psychological health changes over time. One such 
study is the RAND Deployment Life Study (DLS). This was a longitudinal study of 2,700 married military families from all branches and components (active, reserve, and guard) of the military, aimed at understanding what happens to families when a family member deployed (Meadows, Tanielian \& Karney, 2016). The study was conducted between 2011 and 2015 and up to three family members (the service member, spouse and up to one child aged 11-18) were surveyed every four months for three years. Overall, they found that military families are resilient. Despite all the challenges that deployment entails for all members of the family, they generally return to pre-deployment levels of psychological and relationship functioning, as assessed by a wide range of measurements over the course of the study. In fact, their results suggested that by the end of each family's participation in the study (about 3 years) there was little difference between families who experienced a deployment and those who did not. The main differences regarded the military-connected children, such that teens reported less family cohesion and lower relationship quality with their deployed parent. This research team also assessed behaviors during deployment that predicted better outcomes for the family. They found that when spouses reported frequent and satisfying communication during deployment, their marital satisfaction when the service member returned was higher (Meadows et al. 2016). This further demonstrates the importance of intimacy for relationship functioning as well as for downstream benefits of health.

The impact of deployment on military relationships is nuanced (Karney \& Crown, 2011; Karney \& Trail, 2017). Deployment is associated with lowered marital satisfaction compared with no deployment, but this association is not strengthened by multiple 
deployments or longer duration of deployments (Karney \& Trail, 2017; Meadows et al., 2016). Also, as noted above, military-connected couples and families exhibit resilience, in that they can return to pre-deployment levels of functioning after a few years postdeployment (Meadows et al., 2016). While deployment introduces a variety of stressors to the military-connected couples, there is no evidence to suggest that deployments cause divorce. Some researchers have suggested that any previously-documented relationship between deployments and subsequent divorce may instead be due to self-selection or predeployment factors (Bell \& Schumm, 2000). Further, Karney and Trail (2017) assert that any previous associations that have been found between deployment and divorce have largely been explained by PTSD. Specifically, the challenge of PTSD symptoms stemming from the combat experiences, which makes communication difficult and strains relationships, rather than by the deployment itself have been documented to explain findings seemingly linking deployment to divorce (Hoge et al., 2006; Karney \& Trail, 2017). In their review of military records and post-deployment self-reports from active duty Army service members between 2003 and 2010, Negrusa, Negrusa and Hosek (2014) found that those who had deployed were more likely to divorce than were those who had never deployed if self-reported PTSD symptoms were present.

The link between PTSD and worsened relationship functioning has been welldocumented for civilian and military samples alike (Erbes, 2011; Galovski \& Lyons, 2004; Lambert, Engh, Hasbun, \& Holzer, 2012). For example, in a study of married or partnered National Guard soldiers recently returned from combat duty in Iraq, the symptoms of PTSD (i.e. re-experiencing, avoidance, dysphoria, and hyperarousal) 
strongly predicted poorer relationship adjustment (Erbes et al., 2011). A reason for this is that symptoms of PTSD, such as avoidance and withdrawal, contribute to difficulties trusting and sharing, which are crucial to communication and the intimacy process (Baptist et al., 2011; Buchanan et al., 2011; Gerlock, Grimesey \& Sayre, 2014; Solomon et al., 2008). Importantly, interventions for PTSD have shown the promising benefit of improving reciprocal disclosures and general responsiveness processes in militaryconnected couples for PTSD recovery and other positive mental health outcomes (e.g. Bowen, Shelley, Helmes, \& Landman, 2010).

In addition to PTSD symptomatology, military-connected couples have other barriers to the intimacy process and relationship functioning stemming from deployment. A sizable body of literature has demonstrated the negative impact on relational wellbeing of traumatic brain injury (TBI), a pervasive public health problem faced by many military service members (Terrio et al., 2009). Individuals who have experienced TBI and their spouses report lower levels of relationship quality and stability (Claude Blais \& Boisvert, 2005; Wood \& Yurdakul, 1997). Even mild cases of TBI may increase the likelihood of relationship dissolution (Vanderploeg et al., 2003). Furthermore, spouses of individuals with TBI may face additional challenges in the form of mental and physical health issues, social isolation, and financial strain (Moriarty et al., 2016).

\section{Intimacy Process in Military-Connected Couples}

Military-connected couples contend with unique challenges that most civilian couples are unlikely to experience as outlined above (Erbes, 2011; Karney \& Trail, 
2017). These unique challenges that current and former service members have experienced take an enormous toll on relationship functioning and marital satisfaction (Bowen \& Orthner, 1989; Goff et al. 2007; Hourani et al., 2006; Lewis et al., 2012; Mansfield et al., 2010; Orthner \& Rose 2009; Taft et al. 2011). Particularly, deployment and reintegration pose challenges to maintaining marital intimacy in part because they contribute to difficulties with communication (Baptist et al.2011). Healthy intimate relationships facilitate service members' recovery from physical and psychological trauma as well as reintegration after deployment. Conversely, a lack of a healthy intimate relationships hinders recovery and may contribute to ongoing mental health problems (Satcher, Tepper, Thrasher, \& Rachel, 2012).

The intimacy process has been suggested as a relevant predictor of health in military-connected couples. A study of military-connected couples found that not sharing war-related experiences hindered a civilian wife's ability to provide social support to her husband and was detrimental to intimacy (Baptist et al., 2011). Relatedly, BalderramaDurbin and colleagues (2013) found that sharing of distressing deployment experiences was beneficial in intimate relationships when validating and supportive responses were provided. Fortunately, there is evidence that the intimacy process can be optimized to enhance its health-promoting effects. For example, one study of an intervention aimed at improving reintegration of service members from National Guard and Reserves who deployed to OEF/OIF arenas and their spouses found that enhancing the likelihood of the disclosure of positive emotions predicted decreased symptomology of PTSD, even when controlling for prior PTSD symptoms (Hoyt \& Renshaw, 2014). Taken together, these 
studies show support for the theory that the intimacy process is essential to improving health outcomes. The following section evaluates the state of sleep research in general and information about military-connected couples and sleep specifically to ground the present hypotheses and research questions about the intimacy process and sleep. 


\section{Sleep}

Sleep is both a core biological need and a behavioral process that has profound impacts on physiological and psychological health. Sleep serves a variety of restorative functions, such as tissue repair and emotion regulation (Dement \& Vaughan, 1999). Sleep has been found to ameliorate the impact of stress on the body (Akerstedt, Kecklund, \& Axelsson, 2007). Given how important sleep is for health, it is troubling that around a third of American adults obtain less sleep than the recommended minimum of seven hours per night (National Sleep Foundation, 2012). The impact of sleep on physical and psychological health can hardly be overstated as it has been repeatedly linked to morbidity and mortality (Luyster, Strollo, Zee, \& Walsh, 2012; for recent reviews, see Barnes \& Drake, 2015; Buysse, 2014; Troxel, 2010). The connection between reduced sleep quality and poor psychological health is widely documented. For example, sleep disturbances have been found to be highly predictive of suicidal ideation and suicide attempts in a meta-analysis of the general population (Pigeon et al., 2012). Sleep disturbances can include problems like short duration, difficulty falling asleep, difficulty staying asleep, fragmentation (interrupted sleep), and poor sleep quality (Gordon, Mendes \& Prather, 2017).

\section{Sleep and Close Relationships}

Sleep research has largely isolated sleep from the social context in which it unfolds. Relatedly, social psychological research has not given much attention to sleep (Gordon et al., 2017). In recent years, researchers have been making great strides to address this by developing new integrative theoretical approaches (e.g. Troxel et al., 
2007; Troxel, 2010) and finding impressive empirical results. Sleep is one important pathway through which relationships exert their impact on physiological health (McHale, King, \& Buxton, 2017). Although different kinds of social relationships and interactions can impact sleep, of particular relevance to this study is how romantic partners impact sleep.

Troxel (2010) introduced a conceptual framework about the bidirectional links between close relationships and sleep, which impact psychological and physical health. Positive dimensions of relationship functioning, such as support and intimacy, improve sleep. Meanwhile, negative dimensions, such as conflict and avoidance/withdrawal patterns of behavior, worsen sleep, which in turn impacts health. In this model, poor sleep also interferes with relationship functioning and contributes to interpersonal conflict, whereas high-quality sleep positively impacts relationship functioning. Attachment theory, the framework in which Troxel's model is rooted, states that patterns of interactions with caregivers early in life result in expectations about how supportive or responsive one's primary attachment figure (i.e. one's partner or spouse in adulthood) will be (Bowlby, 1973). These expectations are especially important for regulating emotional arousal and relieving distress (Hazan \& Shaver, 1994). Given that attachment styles are relatively stable, they are more likely to influence sleep processes than to be altered by sleep processes. In contrast, relationship functioning can change over time and can both be influenced by and influence sleep. For example, interpersonal conflict with one's partner has been shown to worsen sleep quality (Hicks \& Diamond, 2011). In 
addition, the previous night's poor sleep quality increases the occurrence of interpersonal conflict (Gordon \& Chen, 2014).

Gordon and Chen (2014) explained one potential mechanism underlying the connection between worsened sleep and poorer relationship functioning. Specifically, poor sleep is predictive of less empathic accuracy (i.e. correctly evaluating others' emotions), decreased positive affect, increased negative affect, and poorer conflict resolution during a task. These outcomes would all contribute to worsened interactions with one's partner. Interpersonal distress is predictive of increased cognitive arousal (e.g. rumination) at bedtime which worsens sleep (Gunn et al., 2014). In a large study ( $\mathrm{N}=$ 4,981 ) of older adults over a period of 8 years found that marital quality and sleep quality covaried, such that as marital quality increased, sleep quality also increased (Lee, Chopik, \& Schiamberg, 2017). Taken together, these results exemplify the interdependence of sleep and relationship functioning which was summarized in Troxel's framework (2010). According to Troxel (2010), people tend to derive physical and emotional safety from close others (especially close others one is sleeping near or speaking to near bedtime, such as a spouse). That safety fosters a relative lowering of awareness and vigilance, which is necessary for the behavioral process of sleep (Dahl, 1996). Vigilance and alertness are inherently incompatible with sleep. Meanwhile feelings of safety and security, which are fostered by attachment figures, are needed for high-quality sleep (Dahl \& El-Sheikh, 2007). Relatedly, in a study of healthy civilian participants without sleep complaints, it was revealed that stress does not impair sleep unless there is some degree of mental absorption with the stress around bedtime. This mental absorption might 
include rumination, worrying, or other forms of negative cognitive arousal (Akerstedt et al., 2007). Specifically, bedtime rumination was correlated with lower sleep quality, lower sleep efficiency, and higher sleep fragmentation (Akerstedt et al., 2007). Studies in civilian samples have shown that temporary physical separations can contribute to sleep problems for spouses. Individuals with a proclivity to ruminate and worry, as well as anxiously-attached individuals experienced negative sleep outcomes when separated from partner (Diamond, Hicks, \& Otter-Henderson, 2008; Harvey, 2000). Taken together, these findings demonstrate that a supportive attachment figure, such as a spouse, can serve as a signal of safety and security to allow the person to "let go" of their worries and get a full-night's rest. As Troxel (2010) asserted, "the ritual of going to bed with a trusted other may also serve as a powerful cue, allowing one to recover from the stresses of the day and reduce psychological and physiological arousal before falling asleep" (p. 581). Troxel's theoretical framework is consistent with the overarching theoretical framework from Pietromonaco and Collins (2017) that relationship processes impact health outcomes such as sleep through intrapersonal pathways such as the reduction of psychological arousal.

On the biological level, the influence of relationship processes on sleep through the downregulation of vigilance unfolds as follows. Social experiences activate the autonomic nervous system, which consists of the sympathetic (SNS) and parasympathetic nervous systems (PNS). It is the activation of the PNS or, alternatively, the SNS that impacts the ability to fall and stay asleep (Mendes, 2016). PNS activation is critical for facilitating sleep onset and allowing for sleep without interruptions, such as micro- 
awakenings. Social interactions that promote activation of the PNS would hasten sleep onset. For example, supportive 'pillow talk' with one's wife would boost one's mood, and thus allow the husband to fall asleep faster. Conversely, SNS activation, which is also associated with the "flight or fight response" would occur during social interactions such as interpersonal conflict. The resulting SNS activation would result in slower sleep onset, as well as worse sleep quality. SNS activation is damaging to sleep, especially around bedtime. As such, bedtime disagreements with a spouse would result in worsened sleep quality and longer sleep onset latency (Gordon et al., 2017). This is helpful to understand when considering the downstream effects of relationship processes, which should set off a chain of events: activation of the PNS, which decreases vigilance and hyperarousal, to ultimately foster restorative sleep.

Researchers have only recently begun to investigate specific behaviors and processes that explain the impact of close relationships on sleep (e.g. Arpin, Starkey, Mohr, Greenhalgh, \& Hammer, 2018; Gordon \& Chen, 2014; Hicks \& Diamond, 2011; Kane et al., 2014; Selcuk, et al., 2017). Of particular relevance to this study is Kane and colleagues' (2014) study. This research tested the impact of self-disclosures made to spouses on sleep in a 56-day daily diary study of 46 wives and 38 husbands. They found that more self-disclosures predicted less waking during the sleep period for husbands. Further they found that higher than average levels of self-disclosures predicted better sleep quality, sleep efficiency, less interrupted sleep periods, and longer sleep duration for wives. Self-disclosures are thought to promote better sleep through decreased rumination (Greene, Derlega, \& Mathews, 2006; Pennebaker \& Chung, 2011). 
A closely related and critical behavior that likely plays a role in the benefits of self-disclosures are the perception of responses to those self-disclosures (i.e. perceived partner responsiveness or PPR; Laurenceau et al., 2005; Greene et al., 2006). A recent study of 698 married/cohabiting adults (mean age 57 years, range 35-86 years) found that PPR predicted lower self-reported sleep problems through lower anxiety and depression and actigraph-assessed sleep efficiency through lower anxiety (Selcuk et al., 2017; see Figure 2 depicting the indirect effect of PPR on sleep). This effect is supported by other work demonstrating that feeling supported by one's partner (i.e. PPR) has been found to down-regulate anxiety and arousal and to instill a sense of security and quiescence (Selcuk al., 2010). This downregulation of arousal or vigilance is required for restorative sleep. Likewise, scanning the environment for threat or ruminating on worries hinders sleep (Selcuk et al., 2017).

A recent study from the author's research team, conducted using the sample of veterans and their spouses from the present investigation found that a particular kind of responsiveness, termed capitalization support, was predictive of better sleep (i.e. sleep difficulty, duration and quality) and that this relationship was mediated through psychological mechanisms (Arpin et al., 2018). Capitalization support is related to but distinct from perceived partner responsiveness (PPR). Capitalization support is perceived in the particular context of sharing good news (i.e. capitalization attempt) whereas the present work is investigating global perceptions of partner responsiveness. This study is the first of its kind to examine aggregate and daily associations among the relationship process of capitalization support, psychological mechanisms and sleep outcomes. 
Together, the studies about self-disclosure (Kane et al., 2014) and perceived partner responsiveness (Arpin et al., 2018; Selcuk et al., 2017) demonstrate the sleeppromoting benefits of the overarching intimacy process that they make up (Laurenceau et al., 1998; Reis \& Shaver, 1988). Specifically, the intimacy process represents a critical pathway by which romantic partners exert their calming effect to ultimately promote sleep. This lends support to the proposed intrapersonal mechanism of downregulation of vigilance and arousal as the way that the intimacy process impacts sleep quality in military-connected couples. As military-connected couples are identified as a high-risk group for sleep problems, the next section will focus on research unique to this group.

\section{Military-Connected Couples and Sleep Problems}

Estimates indicate that about one-half to two-thirds of the service members returning from post-9/11 engagements have reported insomnia symptoms (Amin, Parisi, Gold, \& Gold, 2010; Seelig et al., 2010). In a large sample $(\mathrm{N}=1$,957) of service members across all four branches of the military, Troxel and colleagues (2015) found that $63 \%$ of surveyed service members slept less than the lower limit of recommended sleep (seven hours per night) and further, $32 \%$ slept for five hours or less. Additionally, the same study found a high prevalence of poor sleep quality, nightmares, daytime sleepiness, and fatigue. To manage these problems, about $18 \%$ of the sample were using sleep medications. Each of these sleep-related outcomes have profound consequences including exacerbated mental health issues, poor daytime functioning, lessened operational readiness, and relationship conflict with one's romantic partner (Gordon \& Chen, 2014; Troxel et al., 2015). 
Unfortunately, the incidence of sleep problems in the military has been rising. One study documented significant increases of medical visits for insomnia and obstructive sleep apnea by 372\% and 517\%, respectively, between 2005 and 2014 (Caldwell, Knapik, \& Lieberman 2017). Caldwell and colleagues (2017) offered the following reasons for the increases in incidence rates over the last decade: increased incidence of medical conditions such as TBI, PTSD, pain and depression that are comorbid with sleep problems; the increasing normalization of sleep as crucial to health in the larger society that may encourage service members to seek care and thus be included in statistics about prevalence; and the military medical community's increased screening and treatment efforts. Regardless of the contributing factors, it is clear that sleep difficulties and disorders are at increasingly high rates for service members and veterans with and without deployment history.

In light of the dyadic nature of sleep as a process and the high prevalence of sleep difficulties in service members and veterans as described above, researchers have begun to explore the prevalence of sleep problems in military-connected spouses. Spouses of service members are at greater risk of developing sleep problems such as short duration sleep than their civilian counterparts (Holliday et al., 2016). This is theorized to be connected to the stressors of military culture and deployment, as well as to the impact of the sleep problems of service members and veterans (Holliday et al., 2016). Studies that include both members of military-connected couples in investigations of relationship functioning and sleep are scarce. One such study, which included 35 military veterans and their spouses, evaluated marital functioning on sleep (Fillo et al., 2017). Authors 
coded for hostility and relationship-enhancing attributions from a videotaped conflict interaction, revealing that both partners' positive interactions and conflict interactions were predictive of sleep quality such that hostility worsened sleep and alternatively, relationship-enhancing attributions improved sleep (Fillo et al., 2017).

Military life presents various times at which the service member and spouse may be separated (e.g. basic training, leadership training for officers, drill and deployment) and that separation may contribute to sleep problems. Together with the high prevalence of sleep disturbances in the military population, and the fact that romantic partner's sleep difficulties can increase one's own sleep difficulty, these findings highlight the importance of examining and addressing sleep issues in military-connected couples rather than focusing solely on service members and veterans. The next section will transition to exploring pain prevalence in the military, as well as the current state of the research of pain. 


\section{Pain}

\section{Prevalence}

The increasing incidence of pain for OEF/OIF veterans is believed to associated with the increased pace and length of deployment, which puts service members at increased risk of exposure to explosions and other threats (Hosek et al., 2006). Such challenges are coupled with enhanced survival rates due to improved medical care, even to the most seriously injured. These factors have increased the risk of injuries and survival of those injuries to ultimately increase occurrence of acute pain and chronic pain (Baptist et al. 2011; Clark et al., 2007; Hosek et al., 2006). Pain can have devastating impacts, including lost wages and productivity, disability, reduced quality of life, increased marital strain, and increased occurrence and severity of other illnesses and disorders (sleep problems, PTSD, etc.). Further, numerous studies have documented links between chronic pain and poorer psychological health and have found that it is most often associated with depressive disorders, anxiety disorders, and substance use disorders (for reviews see Bair, Robinson, Katon \& Kroenke, 2003; Gibson, 2012). On the extreme end, severe chronic pain has been associated with increased likelihood of suicidal ideation and attempts (Ilgen et al., 2010). This increasing prevalence of pain in the military and the challenges associated with pain have galvanized the VA to make pain management a top priority in order to improve veterans' quality of life (Kerns, Philip, Lee, \& Rosenberger, 2011). 


\section{Approach to Studying Pain}

Pain is a complex experience that incorporates sensory and emotional information to create an unpleasant experience. It occurs in response to actual or potential tissue damage (International Association for the Study of Pain, 1994). The emotional experience in response to real or potential tissue damage (i.e. pain) is influenced by a number of cognitive, emotional, and sensory inputs (Gifford, 1998; Carlino et al., 2014). Importantly, pain also occurs in response to the anticipation of tissue damage, not just in response to actual tissue damage (Butler \& Moseley, 2003). The biological purpose of pain is to alert the organism so that further damage is avoided and so that the organism can begin self-healing while the acute problem such as a cut or an infection runs its course. Pain is primarily a psychological experience, in which the brain projects the experience onto the body through altering the nervous system (both CNS \& PNS; Craig \& Hadjistavropoulos, 2004). Pain is a top-down process, in which the brain concludes that the body's tissues are in danger and produces the experience of pain to encourage the individual to attend to the current or potential tissue damage. In more precise terms, pain is a psychological output of the brain rather than an input to the brain from sensory input (Melzack, 2001; Gatchel et al. 2007).

Much of the contemporary work about pain, including the present research, investigates pain through the lens of the biopsychosocial model of pain [which is consistent with the overarching theoretical framework that this study utilizes from Pietromonaco and Collins (2017)]. The biopsychosocial model offers insight into the factors that influence pain and is considered to be the most comprehensive theory of pain 
to date (Turk \& Monarch, 2002). This model asserts that pain is a complex interaction of biological, psychological, and social factors (Carlino et al., 2014; Gatchel, 2005; Turk \& Monarch, 2002). This framework rejects the dualistic viewpoint that holds that the mind and body function separately. Instead, the biopsychosocial model highlights the ways that the mind (i.e. psychological factors) and the body (i.e. biological factors) interact to create and ameliorate the experience of pain. The biological factors mainly consist of physiology such as nerves sensing real or potential damage. The psychological factors include attitudes, emotion, cognition, and motivation. Pain signaling cues, termed nociception, are immediately reacted to by emotions. Cognitions attach meaning to emotional experience and can amplify emotional responses, and thus increase pain (Gatchel et al., 2007). The social factors include the cultural, environmental, and interpersonal contexts in which pain is experienced (Dogar, 2007). This study focuses on the interplay of interpersonal relationships, emotion and pain.

Analgesic effects of close relationships. The essence of the analgesic effects of social relationships is that they can promote emotion-regulation which in turn, strongly impacts pain (Cervero, 2012). Part of this effect is due to the fact that the mere social presence of trusted close others promotes the conservation of resources through the social regulation of emotion (including worries; Beckes \& Coan, 2011). This is consistent with Pietromonaco and Collins's (2017) argument that relationship processes facilitate the mediating psychosocial pathway of emotion regulation to impact health outcomes. Empirical studies have found support for the idea that social modulation of pain promotes emotion regulation and reduces pain. For example, the mere presence of another person 
in the face of threatening stimuli downregulates negative affect (i.e. modulate emotional responses) and reduces pain (Coan, Schaefer, \& Davidson, 2006; Eisenberger, 2013; Eisenberger et al., 2011; Younger, Aron, Parke, Chatterjee, \& Mackey, 2010). Further, a systematic review of twenty-six studies of healthy participants with experimentallyinduced pain found that positive verbal and non-verbal interactions reduce pain (Krahé et al., 2013). Taken together, these studies demonstrate that pain is modulated by social relationships through the facilitation of emotion-regulation. 


\section{Description of Present Study}

The purpose of this study is to investigate the relationship between the intimacy process and health outcomes via psychological mechanisms in members of militaryconnected couples. Particularly, this study explores associations among perceived partner responsiveness, positive affect, negative affect and sleep and pain outcomes, via the standard and mediated forms of the Actor-Partner Interdependence Model (APIM and APIMeM, respectively; Kenny, 1996; Kenny \& Cook, 1999; Ledermann et al., 2011). A preliminary step was to examine direct effects of perceived partner responsiveness as evaluated at baseline of the Study for Employment Retention for Veterans (SERVe) and the subsequent sleep quality and experiences of pain in military-connected couples aggregated over a 32-day daily diary study (administered after the SERVe baseline survey but prior to the supervisor intervention). Once direct effects were revealed, subsequent steps were taken to assess indirect effects of PPR predicting sleep quality and pain through the mediators of positive affect and negative affect which were aggregated over the 32-day daily diary study. SERVe, which is discussed in greater detail in the methods section, was cluster randomized control trial in which supervisory interventions were administered to participating organizations to improve employment retention of veterans who worked at these organizations. The overarching research question guiding this study was: do military-connected couples who report feeling more supported by their romantic partner (i.e. higher perceived partner responsiveness) demonstrate more positive downstream psychological and health outcomes? Specifically, this research explored the following hypotheses and research questions: Do individuals who perceive their partners 
as more responsive at baseline report higher sleep quality on average over 32 days, relative to those with less responsive partners (actor effect; direct effect)? To what extent does the downregulation of vigilance mediate the relationship between perceived partner responsiveness and sleep (actor effect; indirect effect)? Do individuals who perceive their partners as more responsive at baseline report less pain on average over 32 days, relative to those with less responsive partners (actor effect; direct effect)? To what extent does emotion-regulation mediate the relationship between perceived partner responsiveness and pain (actor effect; indirect effect)? Furthermore, does one's partner's level of PPR predict one's own positive affect, negative affect, sleep or pain (partner effects; direct and indirect effects)? Relatedly, does one's partner's positive affect and negative affect ratings influence one's own sleep or pain (partner effects; indirect effects)?

\section{Rationale and Hypotheses}

\section{Global Rationale and Assumptions of the Model}

With an interest in examining how the intimacy process influences health cumulatively over time, I examined aggregated health outcomes and psychological mediators aggregated across the 32-day daily diary study. This approach of aggregation of daily health outcomes and affective mechanisms is supported by work suggesting that connections between fleeting daily experiences accumulate over time to change longterm health trajectories by setting into motion a domino effect of physiological changes (Abelson, 1985; Chida \& Steptoe, 2008; Magnusson \& Cairns, 1996; Ong, 2010;

Pressman \& Cohen, 2005; Windsor, Gerstorf, Pearson, Ryan, \& Anstey, 2014). For 
example, feelings of relaxation and contentment that occur on a daily basis lower cardiovascular reactivity, which over time reduces risk of heart disease and heart attack. In their systematic review, Pressman and Cohen (2005) found that state positive affect (i.e. daily positive moods) can improve a variety of health outcomes, such as improved perceived health, pulmonary function, and less pain in clinical samples (e.g. patients with cancer, fibromyalgia, and rheumatoid arthritis). Therefore, in this thesis, it is assumed that supportive interactions with one's partner that facilitate positive affect accumulate to impact health changes over approximately a month's time, as opposed to the idea that downstream health outcomes of these processes are limited to the days on which these interpersonal processes and psychological processes occurred. Further, this idea is supported by previous research exploring general responsiveness, relationship satisfaction, and sleep (e.g., Selcuk et al., 2017) and the consequence of chronic experiences of loneliness, which has an inverse relationship with intimacy and perceived partner responsiveness for sleep (e.g., Segrin \& Burke, 2015; Cacioppo et al., 2002). Previous longitudinal research has demonstrated the cumulative effects of positive emotions to pain. By implementing a 10-week longitudinal study, Zautra, Johnson, and Davis (2005) revealed that higher average positive affect was associated with less pain week-to-week, across a large sample of women with chronic pain, and that that relative decreases in positive affect one week were not followed reliably by increases in pain the next week. This suggests that the overall accumulation of positive affect serves as a source of resilience against pain, even on weeks with relative decreases in positive affect (Zautra, Johnson \& Davis, 2005). Therefore, the following hypotheses state that 
individuals who report feeling more supported by their spouse (i.e. perceiving greater partner responsiveness) at baseline would report higher quality sleep and less pain over the subsequent daily diary survey. Further, the following hypotheses assert that perceived partner responsiveness would impact sleep quality and pain via increased positive affect and decreased negative affect. For sleep, increased positive affect and decreased negative affect represents downregulation of vigilance which is hypothesized to facilitate sleep processes and improve sleep quality. For pain, increased positive affect and decreased negative affect represents enhanced emotional regulation which is hypothesized to reduce pain. The following subsection presents my hypotheses and research questions with accompanying rationale.

\section{Hypotheses and Research Questions}

Hypothesis 1. Perceived partner responsiveness positively predicts sleep quality (actor effect; APIM).

As previously noted, sleep has been traditionally studied at the individual-level, but researchers have been moving towards the study of sleep as a dyadic process which is embedded in the marital context (Troxel et al., 2007; Troxel, 2010). One recent study found that self-disclosure (i.e. the sharing of emotional, meaningful personal information) improved sleep quality (Kane et al., 2014). However, that study did not measure responsiveness (i.e. the supportiveness of the partner's reactions) to those disclosures (Kane et al., 2014). It is reasonable to expect that the authors might have found even stronger associations if perceived partner responsiveness was measured, given that perceived partner responsiveness is essential for self-disclosure to be beneficial 
(Laurenceau et al., 2005; Greene et al., 2006). Arpin and colleagues (2018) found that responsiveness to capitalization attempts (i.e. the sharing of positive news in order to celebrate) showed positive effects on sleep through the mediators of loneliness and intimacy in the aggregated dyadic models for veterans and spouses. Although responsiveness to capitalization attempts is distinct from global perceptions of responsiveness due to its context-dependent nature, that study found actor effects drawing from the sample (from SERVe and the DFS) as the present investigation using dyadic analyses. Whereas this hypothesis presents a relatively novel link between specific relationship processes and sleep, the recent above-detailed study lends support for the hypothesis that perceived partner responsiveness fosters high quality sleep.

Hypothesis 2a. Perceived partner responsiveness will positively predict sleep quality through increased positive affect (actor effect; APIMeM).

Hypothesis 2b. Perceived partner responsiveness will positively predict sleep quality through decreased negative affect (actor effect; APIMeM).

Recent evidence supports the hypotheses that perceived partner responsiveness will impact sleep quality through the mechanism of downregulation of vigilance. Restorative sleep, which is high-quality sleep that is not interrupted by awakenings during the sleep period, requires a perceived absence of threat in the environment and downregulation of arousal and vigilance (Selcuk et al., 2017). Dahl (1996) found that the processes that promote downregulation of vigilance are optimized when a sense of physical and emotional safety and security is experienced, which are generally sought from relationships with close others through relationship processes (Troxel, 2010). 
Indeed, perceived partner responsiveness has been found to downregulate anxiety and arousal and to instill a sense of security and quiescence (Selcuk al., 2010). Taken together, the feelings of safety and security that close relationships offer foster the downregulation of vigilance that are required for high sleep quality.

A recent empirical study that tested the mediation of downregulation of vigilance on the impact of feeling supported by one's partner on sleep outcomes informed the following hypothesis. Selcuk and colleagues (2017) used data from a sample of 698 married or cohabiting adults who were first recruited from the National Survey of Midlife Development in the United States II (MIDUS II; a study on health and aging conducted in 2004-2006) and were later given sleep assessments upon recruitment into the Biomarkers Study. Selcuk and colleagues (2017) found that perceived partner responsiveness had a robust and significant direct effect on reducing survey-assessed sleep problems. When they included both mediators (symptoms of anxiety and depression) in the model, perceived partner responsiveness no longer had a direct effect on global sleep problems. Moving to the actigraphy-collected sleep assessments, perceived partner responsiveness was not directly associated with actigraphy-assessed sleep efficiency or sleep duration. However, perceived partner responsiveness indirectly predicted greater objective sleep efficiency via lower anxiety symptoms but not depression symptoms.

This large and well-designed study was the first to test the interpersonal process of intimacy (as represented by perceived partner responsiveness) on sleep. Selcuk and authors (2017) provided crucial empirical support for the link between perceived partner 
responsiveness and sleep quality. This effect was also fully mediated by downregulation of vigilance but was tested in only one member of romantic couples. The present study seeks to extend their findings by incorporating both members of the couple to model the actor and partner effects between the two partners. The above-listed hypotheses feature positive affect and negative affect as mediators which were selected to represent the downregulation of vigilance. The negative affect composite includes items such as sadness parallels the mediators used by Selcuck and colleagues' (2017) study such as depression. The positive affect measure which includes items such as relaxation reflect the construct of downregulation of vigilance in that it is intended to be a feeling of calmness, which is fostered by a supportive significant other (Selcuk al., 2010). This study uses the same subjective measurement their study used for sleep, the PSQI, to find significant results for the mediation model. It was hypothesized that the present mediation model will produce the similar results as Selcuk and authors (2017).

Research Question 1. Will perceived partner responsiveness impact partner's sleep quality (partner effect; APIM)?

Research Question 2a. Will perceived partner responsiveness impact partner's sleep quality through positive affect (partner effect; APIMeM)?

Research Question 2b. Will perceived partner responsiveness impact partner's sleep quality through negative affect (partner effect; APIMeM)?

As noted above, investigators approached the study of sleep as a dyadic process embedded in the marital context (Troxel et al., 2007; Troxel, 2010) so it is reasonable to predict that there is some degree of interdependence of interpersonal processes and health 
outcomes. There are few studies utilizing APIM or APIMem to examine this interaction. Hasler and Troxel (2010) found cross-partner effects of daily relationship functioning on that night's sleep efficiency. For example, they found that female partners' positive and negative interaction ratings predicted male partners' sleep efficiency more than the male partners' positive and negative interaction ratings predicted the female partners' sleep efficiency. Revenson and colleagues (2016) found significant partner effects for partnered women and men such that greater anxiety predicted shorter sleep duration in one's significant other. Segrin and Burke (2015) found that higher levels of men's loneliness significantly predicted lower women's self-reported sleep quality. However, the corresponding partner effect from women's' loneliness to men's sleep quality was not significant. In contrast to these findings about positive relationship processes predicting better sleep outcomes, one study found a partner effect in the opposite direction, whereby higher wives' average self-disclosure ratings were associated with significantly lower husbands' sleep efficiency and no significant partner effects were found for wives' sleep outcomes (Kane et al., 2014). Importantly, Arpin and colleagues (2018), who utilized the participants from the same sample as the present work, found that some partner effects were present for the spouses' sleep outcomes so there is some evidence to support the prediction of partner effects. Overall, these studies have found that negative relationship functioning, and higher anxiety contributed to worsened sleep outcomes for spouses. However, the study that tested part of the intimacy process (i.e. the making of selfdisclosures) found partner effects in the opposite direction for husbands' sleep outcomes (Kane et al., 2014). Therefore, the research questions about indirect and direct partner 
effects do not predict directionality. See Figure 3 for the standard APIM depicting Hypothesis 1 and Research Question 1 and Figure 4 for APIMeM depicting Hypotheses $2 \mathrm{ab}$ and research questions $2 \mathrm{ab}$.

Hypothesis 3. Perceived partner responsiveness will negatively predict pain (actor effect; APIM).

As described above, relationship processes can impact pain through being primed with a trusted other's real, imagined, or symbolic presence (see Xie et al., 2016, for review). As a result, the person feels calmer and safer, which reduces emotional and cognitive reactions to threatening stimuli and thus reduces pain (Beckes \& Coan, 2011; Coan, 2011; Coan \& Sbarra, 2015; Eisenberger et al., 2011; Xie et al., 2016, for review; Younger et al., 2010). Laboratory experiments have shown that when participants felt understood by another, they had higher pain tolerance, perceived a hill as less steep, and estimated shorter distances to target locations (Oishi, Schiller, \& Gross, 2013). It is conceivable that feeling understood and validated by one's romantic partner over time could predict lower reports of pain (potentially either through the mechanism of altering perception or increasing pain tolerance).

Another way that this influence might work is that individuals who perceive their interactions with their partners as unresponsive might feel rejected and thus feel pain resulting from that experience. Researchers have found that when a person feels severe interpersonal stress, such as perceiving social exclusion, they experience social pain. Social pain is a psychological phenomenon with a perceived loss of social connection (Macdonald \& Leary, 2005). Importantly, the social pain of feeling a loss of social 
connection stimulates the areas of the brain that are associated with physical pain (Eisenberger et al., 2003). Partners who are viewed as unresponsive (i.e. invalidating, uncaring, and negligent) could conceivably cause social pain in the disclosing partner, due to a perceived relative loss of social connectedness with one's significant other. This might stimulate the area in the brain associated with pain stemming from physical tissue damage. Researchers have been able to elicit social pain in the lab using a computer game called Cyberball in which the other players seem to refuse to pass the ball to the participant thus causing the participant to perceive ostracism (Williams \& Jarvis, 2006; Zadro, Williams \& Richardson, 2004). Admittedly, invalidating responses are unlikely to create as severe as a social pain as ostracism because it does not signal such an extreme level of social disconnection. However, there is greater expectation of romantic partners to be responsive, so a violation of that expectation would signal loss of social resources, which could conceivably generate some social pain and physical pain. Thus, this would support the hypothesis that individuals who perceive their partners as less responsive will have more pain.

Hypothesis 4a. Perceived partner responsiveness will negatively predict pain through increased positive affect (actor effect; APIMeM).

Hypothesis 4b. Perceived partner responsiveness will negatively predict pain through decreased negative affect (actor effect; APIMeM).

The second set of hypotheses which seek to explore the mechanism by which pain is impacted by perceived partner responsiveness are rooted in emotion-regulation. According to emotion-regulation theory, relationship processes can impact one's ability 
to manage one's own emotions (Coan, 2011). This fostering of emotion-regulation might extend into pain because it has a strong emotional component (Melzack \& Casey, 1968). Social emotion regulation is an active process by which one person intentionally regulates another person's emotions (Reeck, Ames, \& Ochsner 2015; Xie et al., 2016; Zaki \& Williams, 2013). A systematic review has found that social regulation of emotion (e.g. encouraging the other person, demonstrating empathy, holding hands during a fearevoking event) reduces pain (Krahé et al., 2013).

Echoing evidence from experimentally-induced pain studies, research about patients with chronic pain has also begun to utilize intimacy models to conceptualize verbal expressions of pain-related distress as emotional disclosure. The partner may then validate these disclosures with their responsiveness or invalidate them with indifference or criticism (Wilson, Martire, \& Sliwinski, 2017). Wilson and colleagues' (2017) dyadic daily diary study using patients with chronic pain and their significant others found that pain-specific responsiveness to verbal expressions of pain improved physical functioning, suggesting reduced pain. This study suggested that the intimacy process can even ameliorate pain in chronic pain populations. Because the present study is not a chronic pain sample, the current hypothesis would not limit intimacy process to pain-specific disclosures. Instead, it would broaden it to viewing one's partner as supportive in general. Limiting the intimacy model to pain-related conversations may miss the bigger picture of seeing a partner as responsive to one's needs in general, which would improve a person's well-being (Collins \& Ford, 2010). Taken together, these studies from healthy 
populations and chronic pain populations lend support to the hypotheses that perceived partner responsiveness fosters emotional regulation processes which in turn, reduce pain.

Research Question 3. Will perceived partner responsiveness impact partner's pain (partner effect; APIM)?

Research Question 4a. Will perceived partner responsiveness impact partner's pain through positive affect (partner effect; APIMeM)?

Research Question 4b. Will perceived partner responsiveness impact partner's pain through negative affect (partner effect; APIMeM)?

There is a paucity of dyadic studies about the association between relationshiprelated constructs (e.g. relationship functioning, loneliness, intimacy) and pain on which to base any predictions regarding partner effects. A study of experimentally-induced pain found that higher levels of men's empathy was related to lower pain ratings for women but no corresponding partner effect for men's pain outcomes (Goldstein, Shamay-Tsoory, Yellinek, \& Weissman-Fogel, 2016). Due to the lack of existing research to guide predictions, the research questions about indirect and direct partner effects do not predict directionality. See Figure 5 for APIM labeled with Hypothesis 3 and Research Question 3. See Figure 6 for APIMeM labeled with hypotheses and research questions 3-4. 


\section{Chapter Two - Methods}

\section{Procedure}

Study for Employment Retention of Veterans (SERVe). Data for this study were collected as part of the Study for Employment Retention of Veterans (SERVe), a randomized controlled trial (RCT) of a supervisor training designed to increase employment retention, work-family, and personal well-being outcomes for current or former service members. To be eligible to participate, participants must have been post9/11 separated active duty and current reservists in or around Oregon who were employed at least 20 hours per week in organizations that had agreed to participate in the SERVe study. For more information about SERVe and this sample's military background and experience see Hammer, Wan, Brockwood, Mohr, and Carlson (2017). This sample consisted of mostly separated service members (i.e. those who have left the U.S. military), with fewer active reservists (18\%), and most participants have deployed $(88.3 \%)$, so this study refers to the separated service members and active reservists collectively as veterans hereafter for simplicity. Data was collected before the supervisory intervention, called the Veteran-Supportive Supervisor Training (VSST), was administered (baseline) and twice post-intervention (three months and nine months following baseline). Participants received $\$ 25$ on a reloadable gift card for each time they completed one of the three surveys for the larger study. The current investigation used baseline data from the larger SERVe study and the baseline DFS, both of which occurred before the supervisory intervention. 
The Daily Family Study (DFS). Veterans who agreed to participate in the larger SERVe project were also invited to participate in the Daily Family Study (DFS) with spouses or cohabiting partners. The DFS was a 32-day web-based diary survey that was conducted before the SERVe supervisory intervention was administered. From the larger sample of 509 veterans participating in SERVe, 395 met eligibility criteria for the DFS (i.e., married or cohabiting with a romantic partner for at least six months). To be eligible to participate, both members of the dyad had to complete the baseline surveys. This resulted in a total of 260 matched couples who were eligible for the DFS. Of those, 191 veterans and 188 spouses consented and enrolled in the DFS, resulting in 173 matched dyads.

For the DFS, daily surveys were sent to participants via a secure email link, once daily for 32 days. The survey took 5-10 minutes to complete. The survey had to be completed between 5:00 PM and 11:00 PM (after work but before bedtime). For the veterans who did not work regular hours (i.e. shift workers; $18 \%$ ), both veterans and their spouses completed a complementary set of survey items each morning from 5:00 AM to 11:00 AM. Veteran and spouse dyads were asked to complete their surveys separately and to refrain from discussing survey responses. On average, participants of the DFS completed approximately 24 survey days (of a possible 32 ) for a total of 7,916 surveyday observations, resulting in an average compliance of $78 \%$. This compliance rate is comparable to other studies utilizing daily diary methodology (e.g. Harris, Daniels \& Briner, 2003; Mohr et al., 2005). Veterans and their spouses could each earn up to $\$ 90$ for their continued participation in the DFS. All research activities in the current study were 
RESPONSIVENESS, SLEEP AND PAIN IN VETERANS AND SPOUSES

approved by an Institutional Review Board and the U.S. Army Medical Research and Material Command, Human Research Protection Office. Veterans and spouses could receive up to $\$ 90$ each for their participation depending on the amount of surveys completed in the DFS.

\section{Participants}

Of the 173 matched dyads who participated in the DFS, nine couples completed a pilot version of the daily survey that did not include the primary study variables and two couples responded in a non-matching reporting window. The sample size was further reduced after an outlier and his spouse $(n=2)$ were excluded and after two participants who did not contribute data for the predictor variable and their partners were excluded $(n=4)$. After the application of the three-day minimum inclusion criterion, which resulted in the exclusion of an additional twelve dyads, the final sample for the present thesis was comprised of 147 dyads. I describe the procedures used to reach this final sample in the data analysis section. On average, the veterans and spouses were in their late thirties [38.2 (9.2) for veterans; 36.3 (9.1) for spouses]. The majority of participants were Caucasian ( $83.7 \%$ of veterans; $81.0 \%$ of spouses). The majority of veterans were male $(89.9 \%)$ and the majority of spouses were female (90.5\%). In the veteran group, $46.3 \%$ completed college or technical, 26.5\% attended some college or technical school but did not finish, $21.8 \%$ started or completed graduate school, and 5.4\% completed high school or a GED. In the spouse group, 53.7\% completed college or technical school, $23.1 \%$ attended some college or technical school but did not finish, $16.3 \%$ started or completed graduate school, $6.1 \%$ completed high school or a GED, and $0.7 \%$ completed less than 
high school. All of the dyads were heterosexual couples except for one same-sex couple. On average, couples reported a relationship length of 12 years $(S D=8.6)$. Less than half of the participants were parents (43.5\% for veterans and $40.1 \%$ for spouses). On average, the age of the youngest child living with the participants was about 6 years old. See Table 1 for complete descriptive statistics.

\section{Measures}

\section{Baseline Measures (Time 1)}

The baseline measures were collected in the baseline survey of larger study, SERVe. This survey was administered before the DFS 32-day study.

Demographic information and covariates. Demographic information including age, age of youngest child, education, emotional distress, gender, relationship length, parental status, PTSS, and number of children was collected at baseline.

Perceived Partner Responsiveness. Perceptions of spousal supportiveness were measured at baseline with an adapted form of the 3-item measure from Laurenceau and authors (1998), which are based on the intimacy process as originally described by Reis and Shaver (1988). The items were, “To what degree do you feel accepted by your spouse/partner?," "To what degree do you feel understood by your spouse/partner?," and

“To what degree do you feel cared for by your spouse/partner?” Response options ranged from (1) not at all to (7) very much. Items were coded such that a higher score represents more perceived partner responsiveness and then I averaged to create a composite score. This scale demonstrated acceptable reliability (Cronbach's $\alpha=.87$ ). 
Post-Traumatic Stress Symptoms (PTSS). Symptoms of PTSD assessed in the veteran using the four-item Post-Traumatic Stress Checklist (Bliese et al., 2008). Participants were prompted with the instructions, "Below is a list of reactions that veterans sometimes have in response to stressful military experiences. Please read each one carefully and select how much you have been bothered by that problem in the PAST 30 DAYS." The items were included "Repeated disturbing memories, thoughts, or images of the stressful experience," "Having physical reactions... when something reminded you of the stressful," "Avoiding activities or situations because they reminded you of the stressful experience," and "Having difficulty concentrating". Response options ranged from (1) not at all to (5) extremely. Items were coded such that a higher score represents more PTSS and then I summed the items to create a composite score. This scale demonstrated acceptable reliability (Cronbach's $\alpha=.91$ ).

Psychological Distress. Both veteran and spouse baseline surveys also included a 6-item measure from Kessler and colleagues (2002). The instructions were, "Thinking about the PAST MONTH, about how often did you..." Example items included "How often do you feel worthless?" and "How often did you feel nervous?" The response options ranged from (1) none of the time to (4) most of the time. I created composite scores by summing the items and higher composite scores indicated greater emotional distress. This scale demonstrated acceptable reliability (Cronbach's $\alpha=.87$ ).

\section{Daily Measures (Time 2)}

The daily measures were collected over 32 days in the Daily Family Study (DFS) which occurred after the larger SERVe baseline but before the supervisory intervention 
was administered. Each of these measures was aggregated over the daily diary study period.

Pain. Daily pain was assessed with a single item, "average level of pain experienced" in the last 24 hours (Mattacola, Perrin, Gansneder, Allen \& Mickey, 1997). The participants were asked to rate their pain on a visual analog scale (VAS) that ranged from no pain to unbearable pain (see Figure 7). The distance of their position from the lowest extreme was measured to determine the participant's value on the interval scale which was (0) for no pain to (100) for unbearable pain. The VAS is a type of instrument that has been used to assess a wide variety of constructs (such as perceptions of physical health and quality of life) and has been found to have good validity, excellent reliability, and good anchor-based responsiveness (De Boer et al., 2004). Single-item ratings of pain are the most widely used in part because they can be administered relatively quickly, making them convenient for both clinical and research use (Chapman et al., 2011; Turk \& Melzack, 2011). There are a multitude of benefits of using VAS scales as the way to present single-item measurement of pain. These include ease of administration and having "infinite" response options within the response range. Pain-specific VAS scales also demonstrated high construct validity when compared to other measures of pain intensity and observable pain behaviors (see Turk \& Melzack, 2011 for review about psychometric properties of pain scales). There are disadvantages of using such singleitem scales regarding pain, such as not being able to assess different dimensions of pain (such as location of pain, affect about pain, impact on physical functioning; Turk \& 
Melzack, 2011). However, the hypotheses regarding pain are exclusively focused on the dimension of pain intensity so the single-item measure is appropriate for this research.

Positive and Negative Affect. Moods assessed using selected items from the Positive and Negative Affect Schedule - Expanded form (PANAS-X; Watson \& Clark 1999), Larsen and Diener's (1992) mood circumplex model and Emmons and McCullough (2003). These items were selected from the scale to represent the latent variables of downregulation of vigilance and emotion-regulation. The purpose of downregulation of vigilance, the proposed mediating pathway linking perceived partner responsiveness and improved sleep quality, is achieving pleasant and less mentally active emotional state (such as relaxation) while decreasing mental absorption with negative things before bedtime (such as guiltiness, sadness, etc.). Similarly, the purpose of emotion-regulation, the proposed meditation pathway to reduce pain, is to reduce negative emotional states and increase positive emotional states (Gross, 1998). In the context of validating conversations with one spouse that foster perceived partner responsiveness, pain is likely influenced by the fostering of positive affect and relative reduction of negative affect (i.e. social regulation of emotion; Gross, 1998). Similarly, sleep has been shown to be improved by perceived partner responsiveness through the mediator of downregulation of vigilance as represented by nervousness and depression (Selcuk et al., 2017). Therefore, I categorized the items with positive valence into positive affect (happy, relaxed, and grateful) and the items with negative valence into negative affect (sad, angry, lonely, ashamed and guilty). 
The instructions for this measure were "This scale consists of a number of words and phrases that describe different feelings and emotions. Read each item and then mark the appropriate answer in the space next to that word. Indicate to what extent you feel this way RIGHT NOW." As mentioned above, the items included: happy, relaxed, grateful, sad, angry, lonely, ashamed, and guilty. Response options ranged from (1) not at all to (5) extremely. Other items that were assessed but were not selected for inclusion, such as bored, were excluded because they would not reflect the psychological processes of downregulation of vigilance and emotion-regulation. Each of the categories were divided by the number of items in each to create an average (i.e., 3 for positive affect and 5 for negative affect). A higher score in the positive affect for represent more positive affect. Similarly, a higher score in the negative affect category represents more negative affect. For aggregated APIMeM analyses, positive affect and negative affect were each averaged within individuals to create a composite score. These scales demonstrated adequate reliability (Cronbach's $\alpha=.82$ for positive affect; Cronbach's $\alpha=.89$ for negative affect).

Sleep. Sleep quality was assessed using one item from the full 19-item Pittsburgh Sleep Quality Index (PSQI; Buysse et al., 1989). PSQI is a validated and widely used self-rating scale that produces a quantitative index of sleep quality (Buysse et al., 1993; Carpenter \& Andrykowski, 1998). The full PSQI was not used, which produces a composite score of global sleep quality, because only selected items from the PSQI were included in the DFS to minimize participant burden. The item this study utilizes was an overall assessment of sleep quality. This item was chosen over any of the other items that 
were administered in the DFS because social relationships have been linked with sleep quality more consistently than other dimensions of sleep such as total duration of sleep (Bordeleau, Bernier, \& Carrier, 2012; Cacioppo et al., 2002). Although the sleep quality item is a subjective measure, sleep quality is highly predictive of physical and psychological outcomes and so it is a widely-used metric (Buysse, 2014). Previous studies lend support for the measurement of daily sleep outcomes with single items (e.g., Lee, Crain, McHale, Almeida, \& Buxton, 2017; Sin et al., 2017).

The adapted instructions in the survey for the current research read "The next several questions relate to your sleep. When considering these questions, please think of your experience of sleep over the past 24 hours." The adapted item for subjective sleep quality was "How would you rate last night's sleep quality overall?" The response options ranged from (1) very bad to (4) very good. This single-item measure was scored such that higher scores indicated improved sleep quality. 


\section{Data Analytic Strategy}

\section{Data Screening and Statistical Assumptions}

Prior to conducting hypothesis testing, it was necessary to investigate assumptions that my analyses are based on as well as to prepare the data for statistical analyses. This section reviews this process in detail such as providing descriptive information and correlational statistics between key study variables, checking of distributional assumptions, variable creation and centering, assessing the presence of and determining how to manage missing data and outliers.

\section{Variable Creation and Centering}

I created perceived partner responsiveness (PPR) by averaging the three items. I aggregated the daily variables (the affective items, sleep quality and pain) over the daily diary study. The health outcomes of sleep quality and pain are one item each so the final variables are simply average sleep and average pain over the daily diary study. The mediators consist of select items from the PANAS that were categorized into positive affect or negative affect. After aggregation of each affective item, I created a composite score for positive affect and for negative affect. The positive affect category was an average of three items: happy, relaxed, grateful. The negative affect category was an average of five items: angry, ashamed, guilty, lonely, and sad. In order to conduct the APIMs and APIMeMs, I grand mean centered my predictor variable (perceived partner responsiveness) and covariate (relationship length), as per the suggestion of Kenny and authors (2006). 
Minimum day requirement and compliance. Histograms revealed that there was no clear cutoff point regarding the minimum number of days completed to not consider data missing. Therefore, I assessed the number of days previous daily diary studies required to be completed in order to retain data from participants. As Gunthert and Wenze (2012) stated, a daily diary studies generally range from seven to thirty days and recommendations for optimal duration of daily diary studies have not been made. There was no clear precedent in either daily diary study duration or in requirements of compliance in regard to number of days contributed in the literature. For example, Mohr and colleagues (2005) retained data from participants who provided at least seven days of surveys (out of 21) whereas other researchers retained data from participants who provided at least four days of surveys (out of 8; Kelly \& Stephen, 2016). I elected to include participants who at least completed at least three days' worth of data out of 32 days in order to have enough data points to create a pattern as well as to retain as much data as possible. Thus, I excluded 12 dyads (or 24 participants) for not meeting this threeday compliance criterion. In the final sample of 147 dyads, the compliance rates were as follows. On average participants contributed 25.48 out of 32 days (79.61\% compliance). The majority of participants $(56.1 \%)$ contributed 29 days or more. Only $4.8 \%$ of participants contributed between 3 and 7 days.

Missingness. The hypothesis-testing analyses utilized aggregated variables and thus the daily items (positive affect, negative affect, pain and sleep) were only missing if participants provided no data for any of the 32 days. There was no missing data for the outcomes of pain and sleep before the three-day minimum requirement was applied. 
Once the three-day minimum requirement was applied, there was no longer missing data in the predictor or in the mediators. Before the application of the three-day minimum requirement, two participants did not provide data for the predictor of perceived partner responsiveness and one participant did not provide data for the mediators (positive affect and negative affect). After the application of the three-day minimum requirement, the final sample contained no missing data for any of the primary study variables.

Outliers. I computed Cook's distance values to screen for outliers, as they can bias the results. The sole outlier that I found evidence of was an individual with extremely high negative affect. The participant and his partner were ultimately eliminated by the application of the three-day minimum. The final sample resulting from the application of the three-day minimum contained no outliers.

Assessment of Assumptions. To assess the normality of the distribution Mardia's coefficients of skewness and kurtosis were calculated (Raykov \& Marcoulides, 2012; p. 81). The mediator of negative affect and the outcome of pain both had positive skew (skewness $b=4.043, S E=.136$, and skewness $=1.51, S E=.135$, respectively) and kurtosis (kurtosis=21.56, $S E=.271$, and kurtosis $=1.823, S E=.270$, respectively). In light of the significant problems with skew and kurtosis, transformation was attempted first by using the most common transformations for positively skewed variables, a log transformation, and later by a square root transformation. The distribution for pain became less skewed after a square root transformation but the distribution of negative affect did not become more normal after either transformation procedure. Because the transformation for negative affect did not reduce skew, bootstrapping was conducted to manage skew. 
Bootstrapping makes no assumption about the normality of a distribution thus enabling the use of the untransformed skewed variables. Because the results were largely consistent between analyses using non-bootstrapped transformed variables and analyses using bootstrapped untransformed variables, bootstrapping was chosen as the final approach to conduct the hypothesis-testing analyses below. However, the downside of bootstrapping is that the confidence intervals are inflated and there is a possibility that the p-value is significant whereas the confidence interval regarding the same estimate is nonsignificant (Kline, 2010). Therefore, estimates were flagged if that issue arose.

\section{Dyadic Preliminary Analyses}

Data Processing and Analyses for APIM and APIMeM. Because the intention of this work was to investigate how veterans and spouses impact their own as well as one another's health outcomes, it was determined that the most appropriate statistical model would be the Actor-Partner Interdependence Model (APIM). Additionally, this model has the added benefit of controlling for nonindependence among dyad members' scores on key study outcomes (Cook \& Kenny, 2005; Kenny et al., 2006). Further, it was deemed that Actor-Partner Interdependence Mediated Model (APIMeM) would be the most appropriate model for my hypotheses regarding indirect effects (Ledermann \& Bodenmann, 2006). The APIMeM differs structurally from the APIM in that is has three pairs of variables for two dyad members- the predictor, outcome and mediator whereas the APIM only has two pairs of variables: the predictor and the outcome. Power analyses were conducted before executing the APIMs and APIMeMs. Additionally, 
nonindependence and distinguishability of dyads were assessed before conducting the APIMs and APIMeMs (Kenny et al., 2006; Ledermann et al., 2011).

Sensitivity Power Analysis for Dyadic Data Analysis. I conducted a sensitivity power analysis to estimate effect size given the alpha, sample size and power using a free web-based program. I utilized this program to determine the effect size of the standard APIM (Ackerman, Ledermann, \& Kenny, 2015). The following power analyses were conducted with a sample size of 147 dyads, $\alpha=0.05$, two tailed tests, and power $=0.80$ in APIM Power calculator (Kenny \& Ackerman, 2015). The minimal detectable effect size is 0.16 for actor and partner effects and 0.30 for the correlation of the actor and partner variables and the correlation of the errors. I obtained these estimates by inputting my sample size and by adjusting the minimal detectable effect sizes for actor and partner effects until I obtained the desired power level (.80). Therefore, the sample size was adequate to conduct the analyses in the standard APIM.

Whereas there are resources regarding power analysis for the standard APIM (e.g. Ackerman et al., 2015; Kenny et al., 2006), few existing resources provide guidance for power analysis for the APIMeM (e.g. Ledermann et al., 2011; Schoemann, Boulton, \& Short, 2017 for review). To my knowledge, no validated test of power has been developed for the APIMeM. A search for guidance from recent studies demonstrated that other studies utilizing the APIMeM methodology had sample sizes that ranged from 50 to 205 dyads with an average of 139 dyads (e.g. Bouchard, 2018; Chow \& Tan, 2013;

Fincham \& Beach, 2014; Landis et al., 2014; Lim et al., 2014; Park \& Haun, 2017;

Secinti et al., 2018; Tims et al., 2015; Wang et al. 2018; Yan et al., 2018). Therefore, the 
sample size of 147 dyads in the present study was well within the range of published sample sizes for hypothesis-testing with APIMeM.

Nonindependence. In the context of dyadic analysis, nonindependence is the assumption that dependent variables are linked between members of a dyad. Bivariate correlations were calculated to assess for nonindependence in the outcomes between veterans and spouses (Kenny et al., 2006). Kenny, Kashy and Bolger (1998) recommend raising the alpha level to .20 when testing correlations for nonindependence. The results of the correlations between veterans and spouses were as follows: positive affect $(r=.416$; $\mathrm{p}<.001)$, negative affect $(\mathrm{r}=.415 ; \mathrm{p}<.001)$, sleep quality $(\mathrm{r}=.164 ; \mathrm{p}<.05)$, and pain $(\mathrm{r}=.125$; $\mathrm{p}=.127)$. Therefore, the mediators and outcomes demonstrated adequate nonindependence. Although this sample size might be too small to detect low levels of nonindependence, even a small level of nonindependence can be consequential (Kenny et al., 1998; Kenny et al., 2006).

Additionally, I assessed nonindependence based on employer to determine if employees of a particular organization were linked in some way in regard to the health outcomes. For example, it is possible that employees of an organization in which rotating shifts and night shifts are common may have lower sleep quality than employees of other organizations that have more regular work schedules. To determine if organizational membership should be accounted for, I conducted two separate tests of nonindependence. Organizational membership accounted for no significant amount of variance for both sleep (Wald $Z=0.323 ; p=.745$ ) and pain (Wald $Z=0.245 ; p=.806$ ). Therefore, $I$ determined that I did not need to include organization membership in the analyses. 
Distinguishability of Dyads. As recommended by Kenny and colleagues (2006), the distinguishability of dyads was assessed. Distinguishability of the dyads refers to whether the groups (i.e. veterans and spouses) are different empirically. Conceptually, veterans and spouses are distinguishable in that one member is a current or former service member while the other overwhelmingly is a person with no military history. But, it is important to determine if veterans and spouses are empirically different (e.g. have significantly different variances) because certain analytic techniques that are appropriate for distinguishable dyads are not for indistinguishable dyads (Kenny et al., 2006). Therefore, for each of the pathways (e.g. perceived partner responsiveness - pain, perceived partner responsiveness - positive affect, positive affect - pain) I conducted empirical tests for distinguishability of the dyads utilizing the strategy described by Kenny and colleagues (2006) which involved running a linear model in which the dyads are distinguishable and another model in which they are indistinguishable in SPSS data analytic software (IBM Corp, 2016). Essentially, this consisted of retesting the models after constraining actor and partner effects to be equal (i.e. considering the partners to be indistinguishable) and then comparing these results with the models in which the dyads were considered distinguishable (i.e. had no equality restrains). The initial tests for distinguishability revealed that veterans and spouses were distinguishable by veteran/spouse status for the majority of pathways, with three exceptions. Specifically, the following pathways did not show evidence for distinguishability based on nonsignificant chi-square tests: perceived partner responsiveness - sleep $(\chi 2(4)=5.224$, $\mathrm{p}=.265)$, positive affect $-\operatorname{sleep}(\chi 2(4)=4.89, \mathrm{p}=.298)$, negative affect - sleep $(\chi 2(4)=$ 
$6.514, p=.164)$. The pathways that were revealed to be distinguishable on some metric in the initial distinguishability test were assessed with follow-up analyses to determine the source of distinguishability in the model (e.g. mean values, variances, actor effects, partner effects). The follow-up test consisted of conducting an interaction model using restricted maximum likelihood (REML) in which the dyads were considered distinguishable (i.e. had not equality restrains) per recommendations from Kenny and colleagues (2006). The three pathways concerning pain (perceived partner responsiveness - pain, positive affect - pain, and negative affect - pain) were found to be distinguishable in the follow-up tests. The two pathways from the predictor to the mediators (i.e. perceived partner responsiveness - positive affect, perceived partner responsiveness negative affect) were found to be distinguishable in the follow-up tests. Because the veterans and spouses were empirically distinguishable in the pathways in the models examining pain, I conducted all of the pain models by treating them as distinguishable to permit differences between these groups to be captured. In contrast, the sleep models included a mix of pathways that are distinguishable (perceived partner responsiveness positive affect, perceived partner responsiveness - negative affect) as well as pathways that are indistinguishable and thus were constrained to be equal (perceived partner responsiveness - sleep, positive affect - sleep, negative affect - sleep).

Covariates. Correlations between potential demographic control variables (age of youngest child, emotional distress, gender, relationship length, parental status, PTSS, and number of children) and the primary study variables (perceived partner responsiveness, positive affect, negative affect, sleep, and pain) were examined in preliminary analyses. 
Variables with p-values less than .05 that were not significantly correlated with the predictor were considered to be of theoretical relevance to the current study and were included as covariates in the APIMs and APIMeMs. The reason why the predictor was included alongside mediators and outcomes that are routinely included in relation to the consideration of potential covariates was that the inclusion of control variables that are highly correlated with the predictor may introduce serious statistical issues (see Bernerth \& Aguinis, 2016 for review). Rather than achieving my intended purpose of including a control variable, which was to remove variance associated with variables that are not the focus of the study (Carlson \& Wu, 2012), the inclusion of covariates that are highly correlated with the predictor may result in the reduction of explainable variance and can potentially produce results that seem to show that the predictor is unrelated to the outcome when in fact, there are bivariate correlations between the predictor and the outcome present (Bernerth \& Aguinis, 2016). Therefore, in the assessment of potential covariates, correlations were conducted with the predictor as well as with the mediators and outcomes.

\section{Hypothesis Testing using APIMs and APIMeMs}

Following the preliminary analyses, all hypothesis-testing analyses were conducted using Mplus version 8 structural equation modeling statistical software (Muthén \& Muthén, 2018). First, the direct effects of PPR predicting sleep and the direct effects of PPR predicting pain using two APIMs were explored. Then, the first mediated APIM (APIMeM) was conducted wherein the associations between indirect effects of PPR on sleep, via positive affect, aggregated over the 32-day study were assessed. The 
second APIMeM examined the indirect effects of PPR on sleep via negative affect, aggregated over the 32-day study. The third APIMeM explored the indirect effects of PPR on pain, via positive affect, aggregated over the 32-day study. The fourth and final APIMeM assessed the indirect effects of PPR on pain, via negative affect, aggregated over the 32-day study.

Bootstrapping. Boostrapping was utilized to estimate the models' direct effects and indirect effects (for discussion, see Preacher \& Hayes, 2004; Shrout \& Bolger, 2002). Bootstrapping is a computer-based method that creates an approximation of the sampling distribution of a statistic by sampling with replacement from the original dataset that combines the cases in a dataset in different ways. The benefits of conducting bootstrapping include circumventing problems associated with non-normal distributions (Efron \& Tibshirani, 1993; Shrout \& Bolger, 2002). The bootstrap methods featured in Mplus version 8 (Muthén \& Muthén, 2018) were utilized and per recommendations from Preacher and Hayes (2004), 5,000 resamples were conducted. 


\section{Chapter Three - Results}

\section{Descriptive Information and Correlational Statistics}

Before conducting analyses associated with hypothesis-testing, I assessed descriptive statistics (see Table 1-2) and histograms of my variables (see Figures 8-11). The histograms show that the mediators and outcomes were largely normally distributed except for negative affect and pain, which were positively skewed. The issue of violated assumption of normality and how it was managed is detailed below. Additionally, the data was explored to determine if there were differences in the study variables based on veteran or spouse status. Results of paired t-tests revealed that veterans and spouses did not significantly differ in negative affect and sleep quality. However, there were significant differences between veterans and spouses in perceived partner responsiveness, positive affect and pain. See Table 2 for descriptive statistics and the results of the paired sample t-tests for the study variables.

I calculated Pearson correlation coefficients to establish the presence, magnitude, and direction of bivariate associations between within-group study variables before investigating relationships in multivariate models. Additionally, I calculated correlation coefficients for the proposed control variables (age of youngest child, emotional distress, gender, relationship length, parental status, PTSS, and number of children). A simplified table of those correlations is presented in Table 3. Age, gender, shift worker status, and number of children were not significantly correlated to any of the study variables for either veterans or spouses. For veterans and spouses, emotional distress and PTSD were correlated with many of the primary study variables. Additionally, variables associated 
with parenthood and children's age only emerged as significantly correlated with the sleep quality variables. However, the age of one's youngest child had significant structural missing data (i.e. 53 participants did not provide data because they were not

parents) so it could not be included as a covariate. Emotional distress, PTSD and parental status were not included as covariates given correlations with the predictor. As noted above, correlations with the predictor would reduce much of the explainable variable (Bernerth \& Aguinis, 2016). Relationship length was significantly negatively correlated with veterans' negative affect and positively correlated with veterans' sleep quality. Therefore, the final variable that was included as a covariate was relationship length.

\section{Hypothesis Testing}

The purpose of this study was to examine within-person and between-person associations between perceived partner responsiveness and the health outcomes of sleep quality and pain as well as the mediators of positive and negative affect. To examine these associations, Mplus Version 8 statistical software (Muthén \& Muthén, 2018) was utilized to conduct APIMs and APIMeMs. The results reported below and in the corresponding tables and figures were unstandardized estimates.

\section{Results of Perceived Partner Responsiveness-Sleep Quality APIM}

For the standard APIM assessing associations between perceived partner responsiveness and sleep quality, evidence was found to support for Hypothesis 1 such that perceived partner responsiveness positively predicted sleep quality $(b=0.08 ; \mathrm{SE}=$ $0.02 ; \mathrm{p}<.001 ; 95 \% \mathrm{CI}[0.04,0.12])$. Evidence was not found to support Research 
Question 1 as no significant partner effects emerged. See Figure 12 for an illustration of the findings.

\section{Results of Perceived Partner Responsiveness-Positive Affect-Sleep Quality APIMeM}

For the APIMeM assessing connections between perceived partner responsiveness, positive affect, and sleep quality, evidence was found to support for Hypothesis 2 a such that perceived partner responsiveness positively predicted sleep quality through positive affect for veterans (specific indirect effect $b=0.06 ; \mathrm{SE}=0.01 ; \mathrm{p}$ $<.001 ; 95 \%$ CI $[0.03,0.09]$ ) and spouses (specific indirect effect $b=0.05 ; \mathrm{SE}=0.02 ; \mathrm{p}<$ $.01 ; 95 \%$ CI $[0.02,0.08])$. The findings revealed indirect effects for both veterans and spouses. Research Question 2a which regarded the presence of partner effects for this model was partially supported. Other than veteran perceived partner responsiveness positively predicting spouse positive affect $(b=0.149 ; \mathrm{SE}=0.05 ; \mathrm{p}<.01 ; 95 \% \mathrm{CI}[0.04$, 0.24]), no other significant partner effects emerged. See Figure 13 for an illustration of the findings and Table 4 for a table summarizing the indirect effects.

\section{Results of Perceived Partner Responsiveness-Negative Affect-Sleep Quality}

\section{APIMeM}

For the APIMeM assessing connections between perceived partner responsiveness, negative affect, and sleep quality, evidence was found to support for Hypothesis $2 \mathrm{~b}$ such that perceived partner responsiveness negatively predicted sleep quality through negative affect for veterans ( specific indirect effect $b=0.02 ; \mathrm{SE}=0.01 ; \mathrm{p}$ $<.01 ; 95 \% \mathrm{CI}[0.01,0.03])$ and spouses (specific indirect effect $\mathrm{b}=0.06 ; \mathrm{SE}=0.02 ; \mathrm{p}<$ $.001 ; 95 \%$ CI $[0.03,0.10])$. The findings revealed indirect effects for both veterans and 
spouses. Research Question 2b, which regarded the presence of partner effects for this model, was not supported. See Figure 14 for an illustration of the findings and Table 5 for a table summarizing the indirect effects.

\section{Results of Perceived Partner Responsiveness-Pain APIM}

For the standard APIM assessing connections between perceived partner responsiveness and pain, partial evidence was found to support for Hypothesis 3 such that perceived partner responsiveness negatively predicts pain. This effect was significant for veterans $(b=-2.51 ; \mathrm{SE}=1.27 ; \mathrm{p}<.05 ; 95 \% \mathrm{CI}[-5.36,-0.36])$ only. For spouses, the actor effect was nonsignificant $(b=-2.61 ; \mathrm{SE}=1.37 ; \mathrm{p}=\mathrm{n} . \mathrm{s}$.; $95 \% \mathrm{CI}[-5.21,0.23])$. Evidence was not found to support Research Question 3 such that no significant partner effects emerged. See Figure 15 for an illustration of the findings.

\section{Results of Perceived Partner Responsiveness-Positive Affect-Pain APIMeM}

For the APIMeM assessing connections between perceived partner responsiveness, positive affect, and pain, evidence was found to support Hypothesis $4 \mathrm{a}$ such that perceived partner responsiveness positively predicted positive affect which, in turn, negatively predicted pain. The findings revealed an indirect effect for veterans only (specific indirect effect $\mathrm{b}=-1.34 ; \mathrm{SE}=0.67 ; \mathrm{p}<.05 ; 95 \% \mathrm{CI}[-2.97,-0.27]$ ). For spouses, there was no evidence of a direct path or a complete indirect path once the mediator was added (specific indirect effect $b=-0.38 ; \mathrm{SE}=0.36 ; \mathrm{p}=\mathrm{n} . \mathrm{s} . ; 95 \% \mathrm{CI}[-1.21$, 0.24]). The association between the spouse perceived partner responsiveness and positive affect was significant $(\mathrm{b}=0.22 ; \mathrm{SE}=0.06 ; \mathrm{p}<.001 ; 95 \% \mathrm{CI}[0.09,0.35])$ but the path from positive affect to pain as well as the path from perceived partner responsiveness to 
pain were not significant. Research Question 4a, which regarded the presence of partner effects for this model, was partially supported. Other than veteran perceived partner responsiveness positively predicting spouse positive affect $(b=0.15 ; \mathrm{SE}=0.06 ; \mathrm{p}<.01$; $95 \%$ CI $[0.04,0.24])$, no other significant partner effects emerged for either dyad member. See Figure 16 for an illustration of the findings and Table 6 for a summary of the indirect effects.

\section{Results of Perceived Partner Responsiveness-Negative Affect-Pain APIMeM}

For the APIMeM assessing connections between perceived partner responsiveness, negative affect, and pain, evidence was found to support for Hypothesis $4 \mathrm{~b}$ such that perceived partner responsiveness negatively predicted negative affect which in turn positively predicted pain. The findings revealed an indirect effect for veterans only (specific indirect effect $b=-1.79 ; \mathrm{SE}=0.76 ; \mathrm{p}<.05 ; 95 \% \mathrm{CI}[-3.63,-0.63]$ ). For spouses, there was no evidence of complete direct or indirect paths once the mediator was added (specific indirect effect $\mathrm{b}=-0.58 ; \mathrm{SE}=0.59 ; \mathrm{p}=\mathrm{n} . \mathrm{s} . ; 95 \% \mathrm{CI}[-1.83,0.52]$ ). The association between the spouse perceived partner responsiveness and spouse negative affect was significant $(b=-0.14 ; \mathrm{SE}=0.04 ; \mathrm{p}<.001 ; 95 \% \mathrm{CI}[-0.25,-0.07])$ but the paths of negative affect to pain as well as perceived partner responsiveness to pain were not significant for spouses. Research Question 4b, which regarded the presence of partner effects for this model, was not supported. See Figure 17 for an illustration of the findings and Table 7 for a summary of the indirect effects. 


\section{Chapter Four - Discussion}

As hypothesized, within military-connected couples that endorsed higher ratings of perceived partner responsiveness at baseline, romantic partners demonstrated more positive emotional states (i.e. higher positive affect and lower negative affect) and healthier physical health outcomes (i.e. higher sleep quality and lower pain) in the following daily diary study. Each of the hypothesized actor effects in regard sleep were supported such that perceived partner responsiveness was found to positively predict sleep quality directly as well as via the indirect effect of downregulation of vigilance. The actor effects for sleep were observed for both members of the military-connected couple. In contrast, the hypothesized actor effects in regard to pain were found only for veterans rather than for both members of the military-connected couple. Specifically, greater veteran perceived partner responsiveness predicted reduced veteran pain directly as well as through the indirect effect of veteran emotion-regulation. These effects were not observed for spouses and potential reasons for the absence of pain-related effects for spouses are considered below. Most of the partner effects that were predicted to be present were not found except for the veteran perceived partner responsiveness on spouse positive affect in the APIMeMs concerning both sleep and pain. Next, I will situate these findings in the greater body of literature.

\section{Contributions to Literature}

The current work expands upon existing research on the sleep-promoting and analgesic effects of the intimacy process by demonstrating how these salubrious effects unfold for each romantic partner in military-connected couples using daily diary data. 
This research provides preliminary evidence that future studies can utilize when investigating the health-promoting effects of the intimacy process in civilian couples. This study fills two gaps in the military health literature. First, it assessed both partners of military-connected couples simultaneously on interpersonal processes, psychological processes, and health measures of sleep and pain. Second it analyzed the data dyadically via standard actor-partner interdependence models and mediated actor-partner interdependence models. The standard and mediated actor-partner interdependence models are an innovative statistical tool, which allows researchers to uncover differential impacts that members of a dyad have on each other's health and their own health to capture the nuances of relationship processes on health (Reed et al., 2013). This study utilized aggregated dyadic models to demonstrate that perceived partner responsiveness predicted sleep for both members of the military-connected couple via the downregulation of vigilance. Additionally, such models revealed that veterans showed a similar pattern of perceived partner responsiveness and pain as a function of emotionregulation. The sole partner effects that were found were veterans' perceptions of responsiveness predicting the spouses' positive affect (which was used in conjunction with negative affect to operationalize the psychological processes of downregulation of vigilance and emotion-regulation).

The present study benefits from methodological strengths including the study of the intimacy process in the context of sleep and pain using a dyadic design in a sample of current or former service members and their military-connected spouses at multiple timepoints. To the author's knowledge, this is the first study to date to examine perceived 
partner responsiveness as a predictor of sleep quality or of pain by analyzing responses from both members of romantic couples (civilian or military-connected) with standard and mediated actor-partner interdependence models. The author's collaborative research paper utilizing the same sample from SERVe demonstrated that a related but distinct process, responsiveness to capitalization attempts, influences sleep through the pathways of loneliness and intimacy (Arpin et al., 2018). Specifically, that study found actor effects for both veterans and spouses and partner effects for spouses only in the data's aggregated dyadic models (Arpin et al., 2018). The present work extends the work from Arpin and colleagues (2018) by investigating global perceptions of responsiveness as a predictor as well as by considering intrapersonal mechanisms of downregulation of vigilance and emotion-regulation. Another pertinent example in the literature revealed that perceived responsiveness influences sleep via the downregulation of depression and anxiety in a civilian sample (Selcuk et al., 2017). The present thesis corroborates their findings that responsiveness downregulates vigilance, measured with negative affect items like "sadness", to facilitate restorative, high-quality sleep. This study extends their work by adding the positive affective pathway with items like "relaxation" as manifest variables of the latent downregulation mechanism. Further this study verifies that this process extends to military-connected couples, who have higher prevalence of sleep problems than the civilian population (e.g. Holliday et al., 2016; Troxel et al., 2015). The finding that perceived partner responsiveness boosts positive affect and lowers negative affect demonstrates that this relationship process would be a potential avenue of intervention among military-connected couples, who may experience increased stressors 
which can impair relationship functioning (e.g. Baptist et al., 2011; Willerton, Wadsworth, \& Riggs, 2011). Fredrickson's broaden-and-build framework (1998) states that a function of positive emotions is to broaden an individual's thought-action repertoire (i.e. to facilitate a broader scope of cognition, attention, and action) and to build resources (i.e. to enhance the individual's physical, intellectual, and social resources). Working from this framework, the intimacy process services to build resources and encourage a positivity spiral. For example, an intervention targeting the intimacy process could include couples practicing making self-disclosures and learning how to provide more validating and caring responses to their partner's disclosures. This could in turn, promote positive affect which would promote the building and broadening of intrapersonal and relationship resources.

Support was not found for the spouse actor effects concerning pain as well as the majority of hypothesized partner effects. Spouse actor effects were not found for hypothesized direct effect of perceived partner responsiveness predicting pain as well as the indirect effect of perceived partner responsiveness predicting pain through emotionregulation. Compared to veterans, spouses had lower pain on average and therefore, a floor effect may explain the absence of associations between the predictor as well as the mediators and pain. In regard to the lack of partner effects, partner effects are more difficult to find than actor effects (Kenny et al., 2006). Although my sample was large enough to find actor effects, the sample may not have been large enough to detect partner effects and especially partner effects of a smaller magnitude. 


\section{Limitations}

Despite the strengths and contributions of this present research, this thesis has several limitations. One important limitation is the confounding of gender with the distinguishing variable of veteran military status. The implication of this is that I was not able to analyze potential gender effects independent of military status. Due to the large overlap between these variables, this research was not able to control for gender because the variance associated with veteran military status would have been absorbed by controlling for gender. In the literature, there is some evidence for potential gender differences in sleep such that women report more sleep-related complaints than men (Krishnan \& Collop, 2006). Additionally, the pain research points to sex-related influences on pain such that females have higher pain sensitivity and also are at greater risk for many clinical pain conditions (Fillingim, King, Ribeiro-Dasilva, RahimWilliams, \& Riley, 2009). Additionally, other limitations of the present study regard methodology. Whereas one of the benefits of daily process methodology is reduction in retrospective bias, the survey data is still self-report, which is subject to other biases such as social desirability concerns. Also, the present study does not have the added methodological benefit of objectively assessing sleep (e.g. with the use of actigraphy watches) but rather, relies on a survey to assess sleep quality. Although this research found significant results using a subjective measurement of sleep, future studies would benefit from including objective measures for the sleep outcomes. 


\section{Future Directions}

Given that higher perceived partner responsiveness was found to be predictive of beneficial health effects (i.e. increased sleep quality and decreased pain) in these aggregated models, I intend to explore the daily influences to investigate how the intimacy process unfolds over time in future studies. The indirect effect of psychological mechanisms and the health outcomes were measured in the daily diary study and were aggregated for analyses in the present thesis. Therefore, there is less temporal precedence to consider the psychological mechanisms preceding the health outcomes because the aggregated models do not allow for analytical designs featuring psychological mechanisms occurring before the outcomes. Further, the predictor was measured some time before the psychological mechanisms and the outcomes occurred. While perceived partner responsiveness can be a relatively stable global perception, it can still fluctuate day to day with positive and negative interactions that occur between the members of the couple (e.g. Laurenceau et al., 1998; Reis et al., 2004). To address the fluctuating nature of perceived partner responsiveness, overtime models would assess how daytime perceived partner responsiveness promotes downregulated vigilance which, in turn, facilitates sleep that night. Daily models could explore novel research questions about the influence of interpersonal processes on health. For example, daily process methodology could test if the analgesic effects of perceived partner responsiveness are only experienced the same day as the supportive conversation or if they endure for multiple days. Drawing from the same sample as the present study, Arpin and colleagues (2018) utilized such overtime models to demonstrate that responsiveness to capitalization 
attempts (i.e. the sharing of good news) predicted reductions in sleep difficulty through loneliness and intimacy overtime. This lends support for potential associations that could be revealed with lagged analyses to be conducted in future studies. To the author's knowledge, no such model has been tested for pain in regard to supportive relationship processes in either aggregated or overtime models. Finally, I intend to examine the associations between intimacy process, sleep and pain in an integrated, bidirectional, overtime model.

Future studies should explore the differential findings depending on veteran or spouse role from the present study in regard to pain. Specifically, it would be important to understand why veterans demonstrated reduced pain when experiencing greater perceived partner responsiveness but spouses did not demonstrate this beneficial effect. As noted earlier, the spouses in this sample had significantly less pain than the veterans so it is possible that a floor effect would explain the absence of an association between perceived partner responsiveness and pain for spouses. However, examinations of spouses with greater pain at baseline, and thus greater chance of pain variability over the 32-day diary study, might help to illuminate if the lack of spouse actor effect was due to a floor effect or role effects. These role effects could be related to military experience (i.e. something fundamentally different that does not allow civilian spouses to enjoy certain health-promoting effects of PPR compared to veterans) or could be due to gender differences in pain processes (e.g. potentially, women's pain is less influenced by social processes compared to men's pain). Due to the gender and military status overlap in this sample, future work might improve upon it by oversampling female veterans and their 
male civilian partners to disentangle role effects stemming from gender versus military experience.

Future studies should also examine the moderating influence of relationship length in regard to the salubrious effects of perceived partner responsiveness on health outcomes. I would like to explore the association of relationship length more deeply such as examining if this association is linear (e.g. longer relationships are associated with strengthened connections between perceived partner responsiveness and health outcomes), curvilinear (e.g. as relationship length increases, beneficial health effects of perceived partner responsiveness increases but only up to a certain point, after which, salubrious effects of perceived partner responsiveness decrease), or some other pattern altogether. Such a study would lend insights into the effect of relationship length and associated factors on the salubrious effect of perceived partner responsiveness. For example, increased relationship length could be associated with higher functioning relationships meaning that members of the couple might be more skilled at garnering social support and understanding their partners and so these couples might perceive their partners to be more responsive and thus have improved health outcomes. On the other hand, increased relationship length may also be associated with increased age which would likely increase the likelihood of worsened health. Therefore, examining relationship length would lend insights into both interpersonal and health dynamics of couples at various developmental stages interpersonally and chronologically.

Finally, multiple lines of research have shown that the relationships between and health outcomes and relationship functions are complex and bidirectional. For example, 
sleep and pain have been found to share mutual influence in studies across a variety of age groups in different countries as well as with clinical and healthy samples (for review see Andersen, Araujo, Frange, \& Tufik, 2018; e.g. Bonvanie, Oldehinkel, Rosmalen, \& Janssens, 2016; Chen et al., 2018; de la Vega et al., 2018; Mathias et al., 2018). Also sleep has been shown to have bidirectional relationships with interpersonal processes (Troxel, 2010). Therefore, future studies seeking to study the complex interplay of the variables should test bidirectional models in which these variables are specified to influence each other. In chronic pain populations, pain disrupts sleep and, in turn, poor sleep intensifies pain and increases irritability while decreasing psychological resources to cope with pain as well as to function in daily life (see Marshansky et al., 2017 for review). Further, health problems such as sleep disturbances can take a toll on relationship functioning in addition to being exacerbated by poor relationship functioning (e.g. Troxel, 2010). Often the broader health literature does not include the influence of relationship functioning in considering these phenomena (e.g. Dunkel Schetter, 2017, for review). Leading researchers have called the fields of health and relationships together to learn from one another in order to create more comprehensive theories and models (e.g. Holt-Lunstad, 2018; Reed et al., 2013; Sbarra, \& Coan, 2018). In this specific area of research, theoretical models should include the dynamic cycles of relationship processes, psychological processes, sleep, and pain for a more complete picture of these interconnected phenomena. 


\section{Implications}

Theoretically, this work lends support for the organizing framework presented by Pietromonaco and Collins (2017) asserting that relationship processes influence health indirectly through intrapersonal processes. Specifically, indirect effects of perceived partner responsiveness through intrapersonal processes were demonstrated for both members of the military-connected couple in regard to sleep, and for veterans only in regard to pain. The results of this research offer insights into the nature of positive relationship processes influencing health outcomes in veterans and their spouses that can inspire future research, as well as both preventive and secondary interventions. Particularly, the results replicate findings that the downregulation of vigilance is one mechanism by which perceived partner responsiveness affects sleep. Similarly, but for veterans only, emotion-regulation is one mechanism by which perceived partner responsiveness affects pain. Findings of the present work may help open avenues for holistic intervention designs when addressing health issues in military populations and military-connected spouse populations. For example, a dyadic intervention for PTSD in military-connected couples targeted the proximal outcome of improving communication within the couple to ultimately achieve the more distal outcome of reducing PTSD symptoms and promoting other positive mental health outcomes (Bowen et al., 2010). This study could inform similar interventions for military-connected couples struggling with sleep disturbances and pain. Optimizing the intimacy process would represent a mostly untapped resource in ameliorating sleep disturbances and pain. This could potentially be coupled with more conventional medical and other therapeutic 
interventions for a more holistic treatment approach that includes one of the most influential relationship for adults, their romantic partners. Health problems of one member of military-connected couples are managed by and affect both romantic partners (Lewis et al., 2012; Trump et al., 2015). Therefore, holistic treatment programs that include both romantic partners are likely to be the most impactful.

\section{Conclusion}

The present work utilized dyadic data analysis to examine the associations among perceived partner responsiveness, downregulation of vigilance, emotion-regulation, sleep, and pain. In regard to adding to the understanding of the sleep, the present study expanded upon recent work documenting the links between responsiveness and sleep by examining data from both members of the romantic couple. Likewise, the present work also builds on the preliminary work of experimental studies demonstrating the analgesic effect of supportive interpersonal processes by utilizing daily diary methodology to capture these processes as they occur 'in the real world' and by examining the interdependence between romantic partners. The results of this research lend insights regarding particular interpersonal and psychological mechanisms by which social relationships influence health. This study provides support for novel treatment venues such as holistic treatment approaches that supplement the more conventional medical treatment for sleep difficulty and pain with the promotion of supportive interpersonal processes with romantic partners. Importantly, this study investigated these supportive processes in the context of military-connected couples, who are at high-risk for both sleep problems and pain. 
Tables and Figures

Table 1. Descriptive statistics for the demographics.

\begin{tabular}{|c|c|c|c|c|}
\hline \multirow[b]{2}{*}{ Variable } & \multicolumn{2}{|c|}{ Veterans } & \multicolumn{2}{|c|}{ Spouses } \\
\hline & $\mathbf{N}$ & $\begin{array}{c}\text { Mean (SD)/ } \\
\text { Freq (\%) } \\
\end{array}$ & $\mathbf{N}$ & $\begin{array}{c}\text { Mean }(\text { SD)/ } \\
\text { Freq }(\%)\end{array}$ \\
\hline Age & 147 & $38.2(9.2)$ & 147 & $36.3(9.1)$ \\
\hline Race & 147 & & & \\
\hline White/Caucasian & & $123(83.7 \%)$ & & $119(81.0 \%)$ \\
\hline Multiple & & $18(12.2 \%)$ & & $15(10.2 \%)$ \\
\hline Black/African American & & $2(1.4 \%)$ & & $2(1.4 \%)$ \\
\hline Asian & & $0(0.0 \%)$ & & $8(5.4 \%)$ \\
\hline Native American & & $2(1.4 \%)$ & & $1(0.7 \%)$ \\
\hline Hispanic & & $1(0.7 \%)$ & & $2(1.4 \%)$ \\
\hline Other & & $1(0.7 \%)$ & & $0(0.0 \%)$ \\
\hline Gender & 147 & & 147 & \\
\hline Male & & $132(89.9 \%)$ & & $14(9.5 \%)$ \\
\hline Female & & $15(10.2 \%)$ & & $133(90.5 \%)$ \\
\hline Education & 147 & & 147 & \\
\hline Less than high school & & $0(0.0 \%)$ & & $1(0.7 \%)$ \\
\hline High school diploma/GED & & $8(504 \%)$ & & $9(6.1 \%)$ \\
\hline $\begin{array}{r}\text { Some college/ tech school, no } \\
\text { degree/certificate }\end{array}$ & & $39(26.5 \%)$ & & $34(23.1 \%)$ \\
\hline $\begin{array}{r}\text { Completed college/tech school } \\
\text { with degree/certificate }\end{array}$ & & $68(46.3 \%)$ & & $79(53.7 \%)$ \\
\hline $\begin{array}{r}\text { Graduate study in progress or } \\
\text { completed }\end{array}$ & & $32(21.8 \%)$ & & $24(16.3 \%)$ \\
\hline Relationship Length & 144 & $12.1(8.6)$ & 143 & $12.2(8.6)$ \\
\hline $\begin{array}{l}\text { Age of youngest child living at } \\
\text { home }\end{array}$ & 97 & $6.1(6.3)$ & 94 & $5.9(5.8)$ \\
\hline Parental Status & 147 & & 147 & \\
\hline Parent & & $83(53.5 \%)$ & & $88(59.9 \%)$ \\
\hline Nonparent & & $64(43.5 \%)$ & & $59(40.1 \%)$ \\
\hline Emotional Distress & 147 & $10.6(4.0)$ & 147 & $10.0(3.7)$ \\
\hline PTSD - summed score & 147 & $7.4(3.9)$ & 18 & $8.22(4.7)$ \\
\hline $\begin{array}{c}\text { PTSD - screen } \\
\text { (scores greater than } 12 \text { are } \\
\text { positive screen) }\end{array}$ & 147 & & 18 & \\
\hline Negative & & $131(89.1 \%)$ & & $16(88.9 \%)$ \\
\hline Positive & & $16(10.9 \%)$ & & $2(11.1 \%)$ \\
\hline
\end{tabular}


RESPONSIVENESS, SLEEP AND PAIN IN VETERANS AND SPOUSES

Table 2. Descriptive statistics and paired sample t-test statistics for the primary study variables.

\begin{tabular}{l|ll|ll:l}
\hline Variable & Mean (SD) & Min, Max & Mean (SD) & Min, Max & $\begin{array}{l}\text { Paired } \\
\text { Sample T-test }\end{array}$ \\
\hline PPR & $5.89(1.21)$ & $1.33,7.00$ & $6.11(0.97)$ & $2.00,7.00$ & $\mathrm{t}(147)=-2.20$, \\
$\mathrm{p}=.030$
\end{tabular}

Note: PPR = perceived partner responsiveness. 
Table 3. Within-veteran, within-spouse, inter-partner correlations and among study variables and considered control variables.

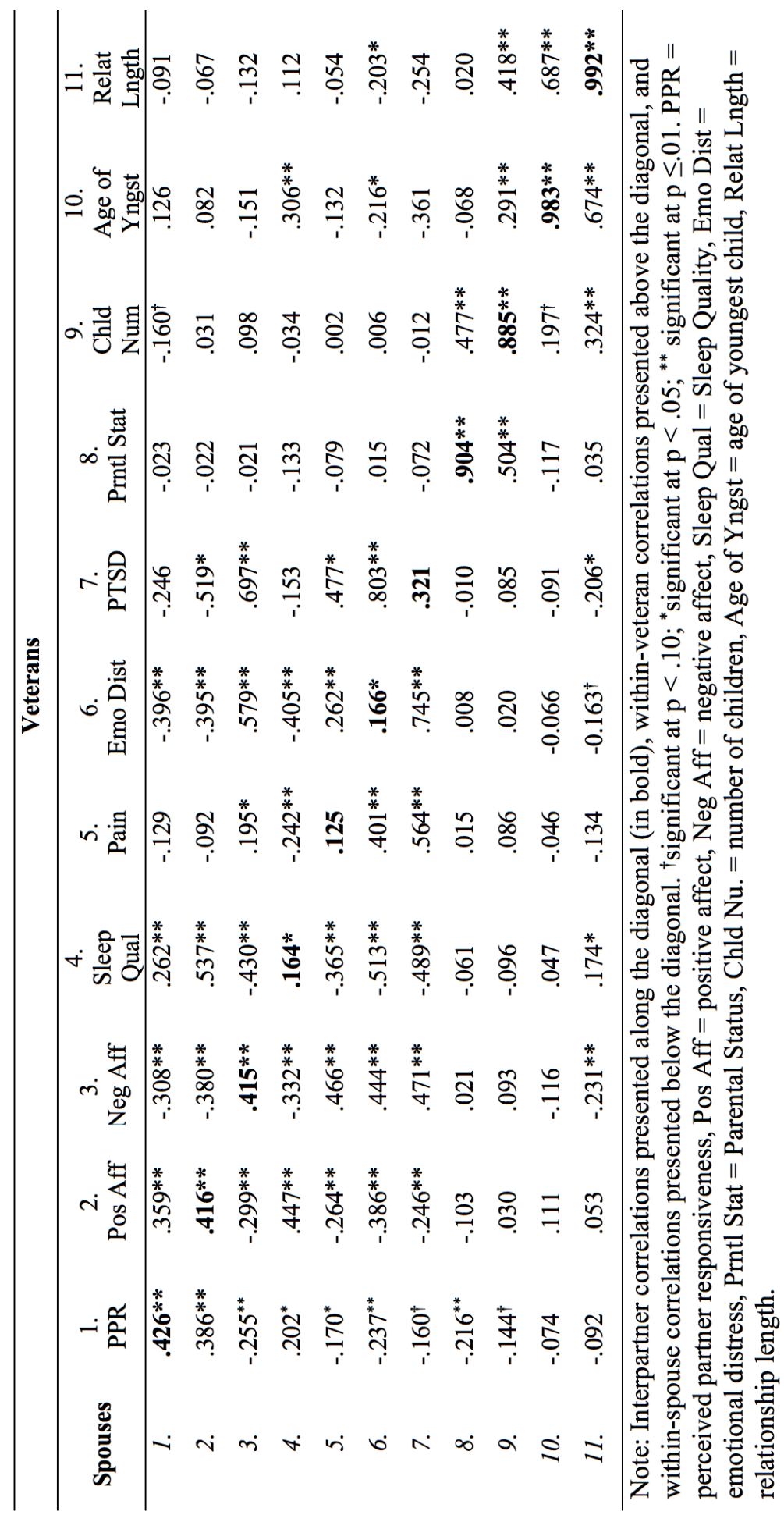


Table 4. Indirect effects for the APIMeM of perceived partner responsiveness predicting sleep quality via positive affect.

\begin{tabular}{|c|c|c|c|}
\hline \multirow[t]{2}{*}{ Effect } & \multicolumn{3}{|c|}{ Estimates } \\
\hline & $b$ & se & $95 \% C I$ \\
\hline \multicolumn{4}{|l|}{ Veteran PPR to Veteran Sleep Quality } \\
\hline Total Indirect Effect & $0.06 * * *$ & 0.02 & $0.03,0.09$ \\
\hline Indirect through Actor (V) Positive Affect & $0.06 * * *$ & 0.01 & $0.03,0.09$ \\
\hline Indirect through Partner (Sp) Positive Affect & 0.00 & 0.01 & $-0.01,0.01$ \\
\hline \multicolumn{4}{|l|}{ Spouse PPR to Spouse Sleep Quality } \\
\hline Total Indirect Effect & $0.05 * *$ & 0.02 & $0.02,0.09$ \\
\hline Indirect through Actor ( $\mathrm{Sp}$ ) Positive Affect & $0.05 * *$ & 0.02 & $0.02,0.09$ \\
\hline Indirect through Partner (V) Positive Affect & 0.00 & 0.00 & $-0.01,0.01$ \\
\hline \multicolumn{4}{|l|}{ Spouse PPR to Veteran Sleep Quality } \\
\hline Total Indirect Effect & 0.01 & 0.02 & $-0.02,0.06$ \\
\hline Indirect through Actor (V) Positive Affect & 0.01 & 0.02 & $-0.02,0.05$ \\
\hline Indirect through Partner ( $\mathrm{Sp}$ ) Positive Affect & 0.00 & 0.01 & $-0.01,0.02$ \\
\hline \multicolumn{4}{|l|}{ Veteran PPR to Spouse Sleep Quality } \\
\hline Total Indirect Effect & 0.04 & 0.02 & $0.01,0.07$ \\
\hline Indirect through Actor ( $\mathrm{Sp}$ ) Positive Affect & $0.03 * *$ & 0.01 & $0.01,0.06$ \\
\hline Indirect through Partner (V) Positive Affect & 0.00 & 0.01 & $-0.02,0.02$ \\
\hline
\end{tabular}

Note: $\mathrm{V}=$ veterans, $\mathrm{Sp}=$ spouses, $\mathrm{PPR}=$ Perceived partner responsiveness, ${ }^{*}$ significant at $\mathrm{p}<.05, * *$ significant at $\mathrm{p} \leq .01, * * *$ significant at $\mathrm{p} \leq .001$. Table corresponds to Figure 14. 
Table 5. Indirect effects for the APIMeM of perceived partner responsiveness predicting sleep quality via negative affect.

\begin{tabular}{|c|c|c|c|}
\hline \multirow[t]{2}{*}{ Effect } & \multicolumn{3}{|c|}{ Estimates } \\
\hline & $b$ & se & $95 \% C I$ \\
\hline \multicolumn{4}{|l|}{ Veteran PPR to Veteran Sleep Quality } \\
\hline Total Indirect Effect & $0.02 *$ & 0.01 & $0.01,0.03$ \\
\hline Indirect through Actor (V) Negative Affect & $0.02 * *$ & 0.01 & $0.01,0.03$ \\
\hline Indirect through Partner ( $\mathrm{Sp}$ ) Negative Affect & 0.00 & 0.00 & $-0.00,0.00$ \\
\hline \multicolumn{4}{|l|}{ Spouse PPR to Spouse Sleep Quality } \\
\hline Total Indirect Effect & $0.06 * * *$ & 0.02 & $0.03,0.10$ \\
\hline Indirect through Actor (Sp) Negative Affect & $0.06 * * *$ & 0.02 & $0.03,0.10$ \\
\hline Indirect through Partner (V) Negative Affect & 0.00 & 0.00 & $-0.01,0.01$ \\
\hline \multicolumn{4}{|l|}{ Spouse PPR to Veteran Sleep Quality } \\
\hline Total Indirect Effect & 0.01 & 0.01 & $-0.02,0.04$ \\
\hline Indirect through Actor (V) Negative Affect & 0.01 & 0.01 & $-0.01,0.03$ \\
\hline Indirect through Partner ( $\mathrm{Sp}$ ) Negative Affect & 0.00 & 0.00 & $-0.02,0.02$ \\
\hline \multicolumn{4}{|l|}{ Veteran PPR to Spouse Sleep Quality } \\
\hline Total Indirect Effect & -0.01 & 0.01 & $-0.03,0.02$ \\
\hline Indirect through Actor ( $\mathrm{Sp}$ ) Negative Affect & -0.01 & 0.01 & $-0.03,0.02$ \\
\hline Indirect through Partner (V) Negative Affect & 0.00 & 0.00 & $-0.01,0.01$ \\
\hline
\end{tabular}

Note: $\mathrm{V}=$ veterans, $\mathrm{Sp}=$ spouses, $\mathrm{PPR}=$ Perceived partner responsiveness, $*$ significant at $\mathrm{p}<.05, * *$ significant at $\mathrm{p} \leq .01, * * *$ significant at $\mathrm{p} \leq .001$. Table corresponds to Figure 15. 
Table 6. Indirect effects for the APIMeM of perceived partner responsiveness predicting pain via positive affect.

\begin{tabular}{lccc}
\multicolumn{1}{c}{ Effect } & \multicolumn{3}{c}{ Estimates } \\
& $b$ & $s e$ & $95 \%$ CI \\
\hline Veteran PPR to Veteran Pain & & & \\
\hline Total Indirect Effect & $-1.17^{*}$ & 0.60 & $-2.58,-0.22$ \\
Indirect through Actor (V) Positive Affect & $-1.34^{*}$ & 0.66 & $-2.97,-0.27$ \\
Indirect through Partner (Sp) Positive Affect & 0.17 & 0.37 & $-0.56,0.95$ \\
\hline Spouse PPR to Spouse Pain & & & \\
\hline Total Indirect Effect & -0.33 & 0.35 & $-1.14,0.27$ \\
Indirect through Actor (Sp) Positive Affect & -0.38 & 0.36 & $-1.21,0.24$ \\
Indirect through Partner (V) Positive Affect & 0.05 & 0.16 & $-0.11,0.64$ \\
\hline Spouse PPR to Veteran Pain & & & \\
\hline Total Indirect Effect & -0.05 & 0.68 & $-1.26,1.46$ \\
Indirect through Actor (V) Positive Affect & -0.30 & 0.45 & $-1.65,0.36$ \\
Indirect through Partner (Sp) Positive Affect & 0.25 & 0.57 & $-0.72,1.58$ \\
\hline Veteran PPR to Spouse Pain & & & \\
\hline Total Indirect Effect & -0.03 & 0.37 & $-0.77,0.69$ \\
Indirect through Actor (Sp) Positive Affect & -0.25 & 0.25 & $-0.88,0.16$ \\
Indirect through Partner (V) Positive Affect & 0.22 & 0.40 & $-0.55,1.05$ \\
\hline Note: V veterans, Sp = & & & \\
\hline
\end{tabular}

Note: $\mathrm{V}=$ veterans, $\mathrm{Sp}=$ spouses, $\mathrm{PPR}=$ Perceived partner responsiveness, ${ }^{*}$ significant at $\mathrm{p}<.05, * *$ significant at $\mathrm{p} \leq .01, * * *$ significant at $\mathrm{p} \leq .001$. Table corresponds to Figure 17. 
Table 7. Indirect effects for the APIMeM of perceived partner responsiveness predicting pain via negative affect.

\begin{tabular}{|c|c|c|c|}
\hline \multirow[t]{2}{*}{ Effect } & \multicolumn{3}{|c|}{ Estimates } \\
\hline & $b$ & se & $95 \% C I$ \\
\hline \multicolumn{4}{|l|}{ Veteran PPR to Veteran Pain } \\
\hline Total Indirect Effect & $-1.88 * *$ & 0.70 & $-3.41,-0.74$ \\
\hline Indirect through Actor (V) Negative Affect & $-1.79 *$ & 0.76 & $-3.63,-0.63$ \\
\hline Indirect through Partner $(\mathrm{Sp})$ Negative Affect & -0.09 & 0.24 & $-0.83,0.15$ \\
\hline \multicolumn{4}{|l|}{ Spouse PPR to Spouse Pain } \\
\hline Total Indirect Effect & -0.73 & 0.57 & $-1.95,0.38$ \\
\hline Indirect through Actor ( $\mathrm{Sp}$ ) Negative Affect & -0.58 & 0.59 & $-1.83,0.52$ \\
\hline Indirect through Partner (V) Negative Affect & -0.16 & 0.26 & $-1.02,0.14$ \\
\hline \multicolumn{4}{|l|}{ Spouse PPR to Veteran Pain } \\
\hline Total Indirect Effect & -0.23 & 1.23 & $-2.91,1.98$ \\
\hline Indirect through Actor (V) Negative Affect & -1.01 & 1.02 & $-3.31,0.74$ \\
\hline Indirect through Partner ( $\mathrm{Sp}$ ) Negative Affect & 0.78 & 0.65 & $-0.49,2.09$ \\
\hline \multicolumn{4}{|l|}{ Veteran PPR to Spouse Pain } \\
\hline Total Indirect Effect & -0.21 & 0.40 & $-1.02,0.59$ \\
\hline Indirect through Actor ( $\mathrm{Sp}$ ) Negative Affect & 0.07 & 0.17 & $-0.12,0.67$ \\
\hline Indirect through Partner (V) Negative Affect & -0.28 & 0.33 & $-1.04,0.28$ \\
\hline
\end{tabular}

Note: $\mathrm{V}=$ veterans, $\mathrm{Sp}=$ spouses, $\mathrm{PPR}=$ Perceived partner responsiveness, ${ }^{*}$ significant at $\mathrm{p}<.05, * *$ significant at $\mathrm{p} \leq .01, * * *$ significant at $\mathrm{p} \leq .001$. Table corresponds to Figure 18. 
Figure 1. Theoretical framework from Pietromonaco \& Collins (2017)
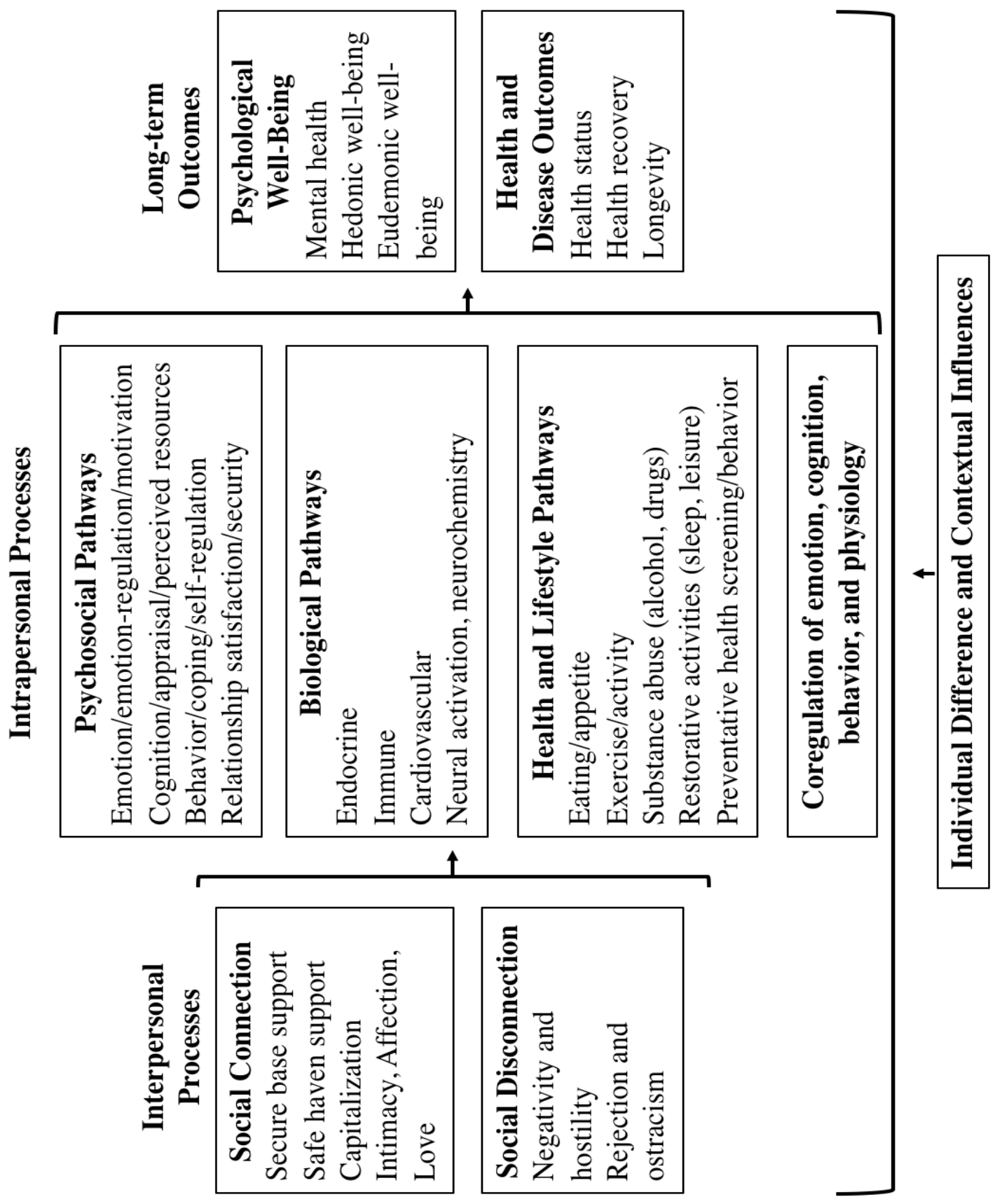
Figure 2. Conceptual model depicting how perceived partner responsiveness (PPR) promotes sleep.

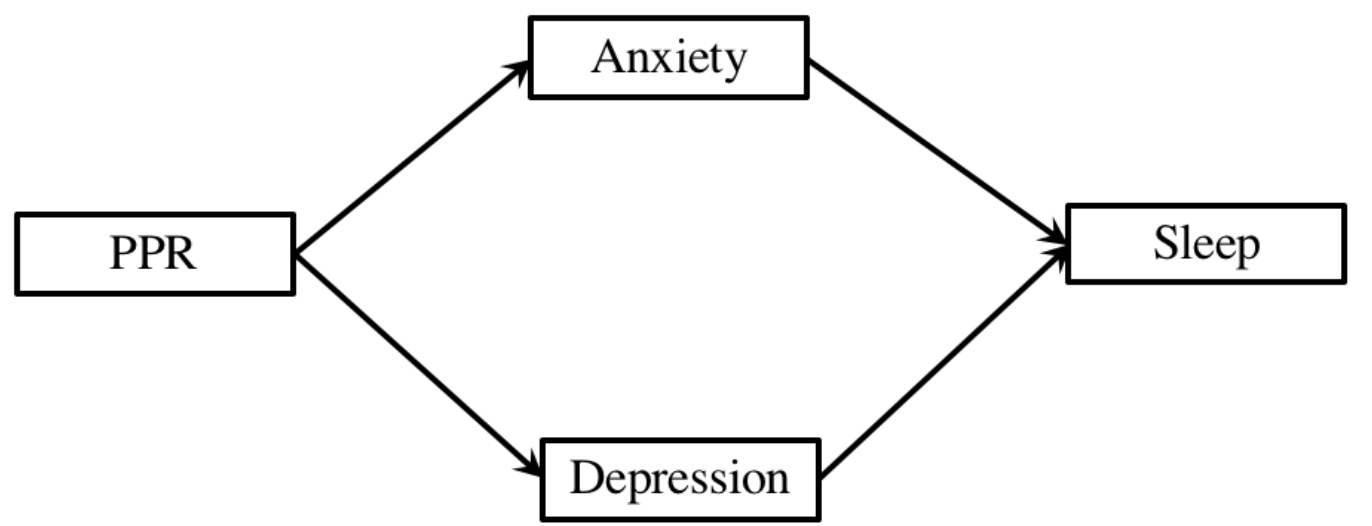

Note: Model adapted from Selcuk and colleagues (2017). 
Figure 3. Hypothesized APIM: PPR-Sleep quality

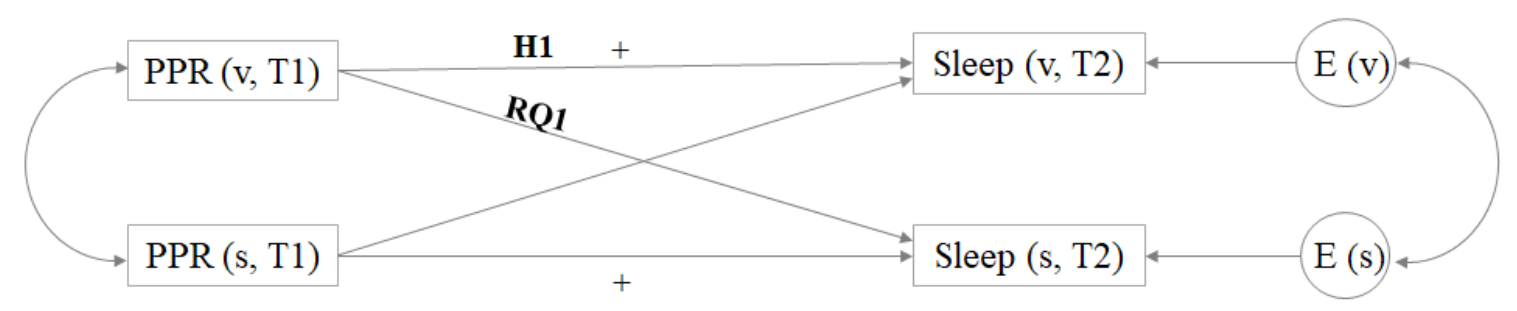

SERVe Baseline

DFS Baseline

Note: The figure depicts the APIM in which perceived partner responsiveness is positively associated with sleep. Note that PPR was assessed in the baseline survey for SERVe which occurred, on average about a month before the DFS baseline survey began. PPR- perceived partner responsiveness, v- veteran, $\mathrm{s}$ - spouse. The direction of the association is represented by pluses and minuses. The numbered pathways correspond to hypotheses and research questions. Note that only the veteran's pathways were numbered to simplify the depiction. 
Figure 4. Hypothesized APIMeM: PPR-Downregulation of vigilance-Sleep quality

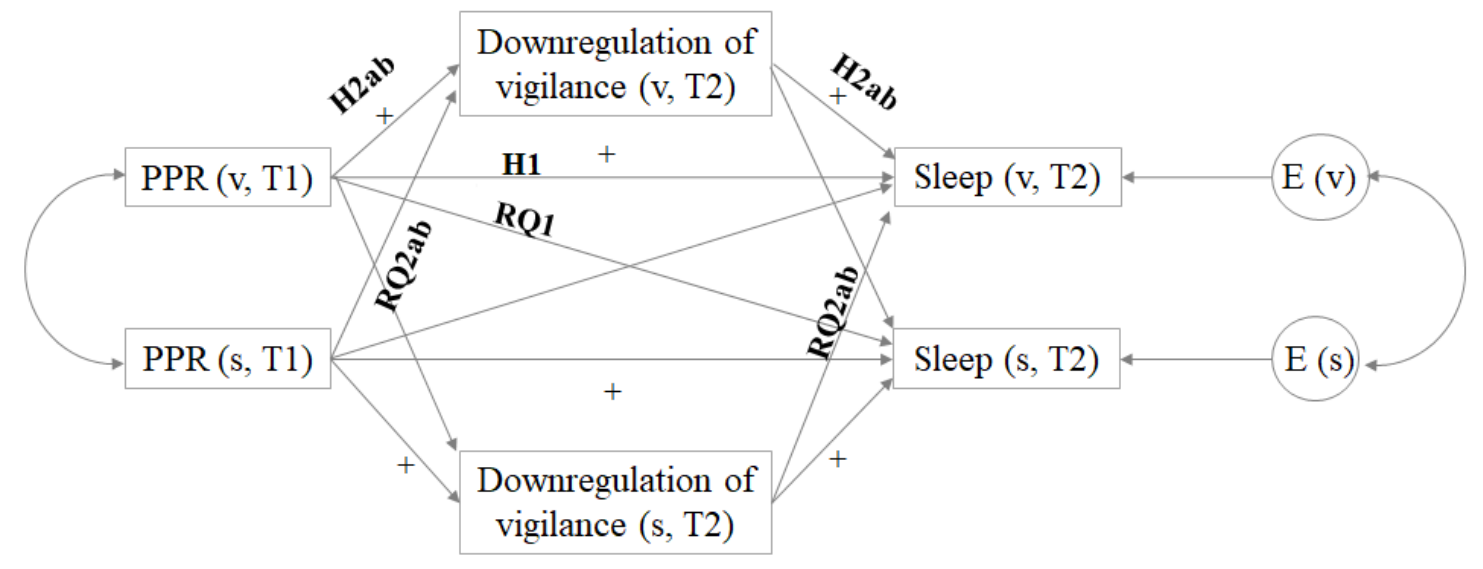

SERVe Baseline DFS Baseline DFS Baseline

Note: The figure depicts the APIMeM in which perceived partner responsiveness is positively associated with sleep as mediated by downregulation of vigilance, which is comprised of increased positive affect and decreased negative affect. This model presents downregulation of vigilance in one model although I tested positive affect and negative affect separately. PPR- perceived partner responsiveness, $v$ - veteran, $\mathrm{s}-$ spouse. The direction of the association is represented by pluses and minuses. The numbered pathways correspond to hypotheses and research questions. Note that only the veteran's pathways were numbered to simplify the depiction 
Figure 5. Hypothesized APIM: PPR-Pain

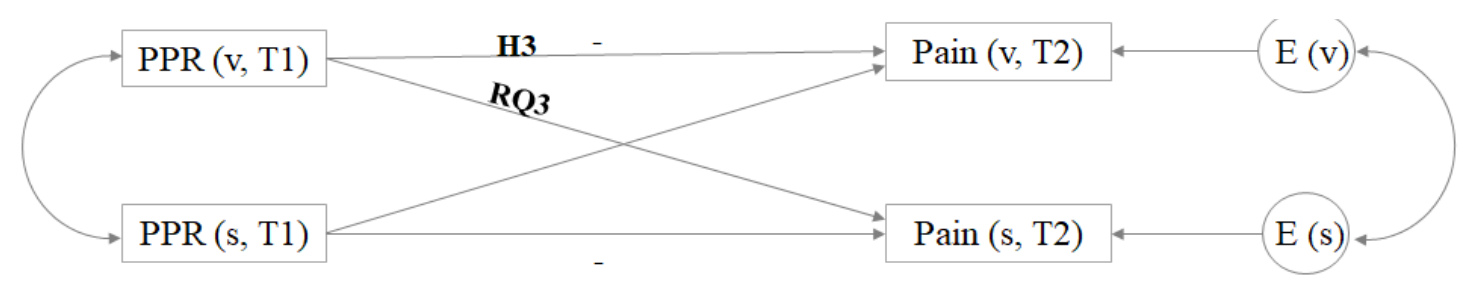

SERVe Baseline DFS Baseline

Note: The figure depicts the APIM in which perceived partner responsiveness is negatively associated with pain. PPR- perceived partner responsiveness, v- veteran, $\mathrm{s}-$ spouse. The direction of the association is represented by pluses and minuses. The numbered pathways correspond to hypotheses and research questions. Note that only the veteran's pathways were numbered to simplify the depiction 
Figure 6. Hypothesized APIMeM: PPR-Emotion regulation-Pain

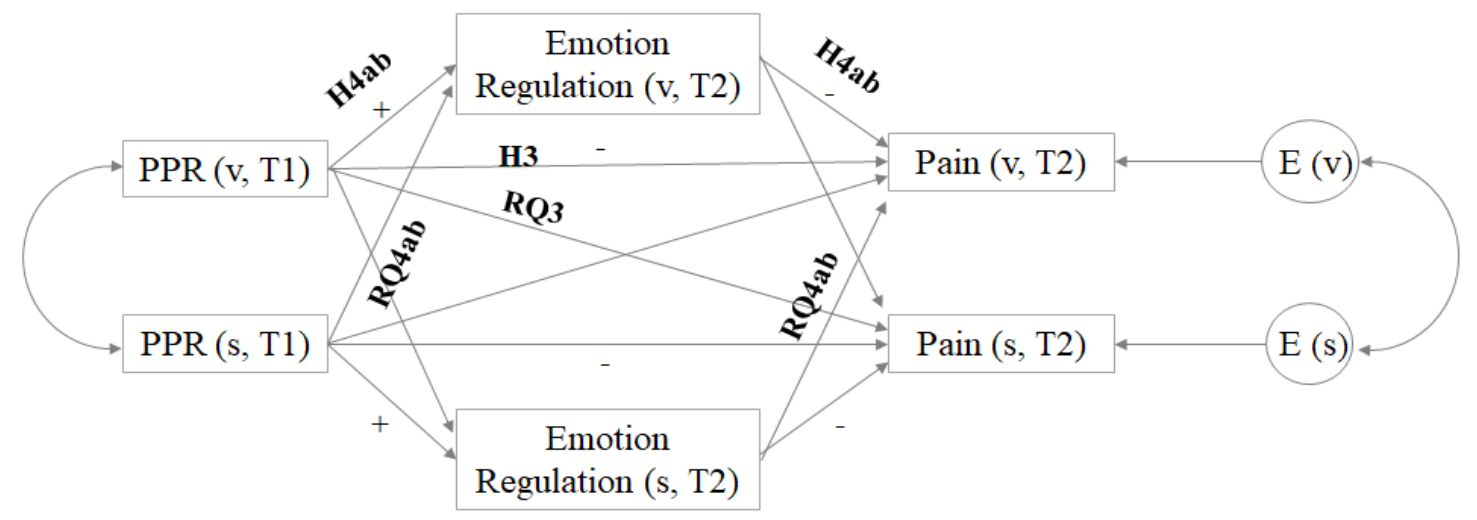

SERVe Baseline DFS Baseline DFS Baseline

Note: The figure depicts the APIMeM in which perceived partner responsiveness is negatively associated with pain as mediated by increased positive affect and decreased negative affect, collectively presented here as emotion regulation for simplicity. PPRperceived partner responsiveness, $\mathrm{v}$ - veteran, $\mathrm{s}-$ spouse. The direction of the association is represented by pluses and minuses. The numbered pathways correspond to hypotheses and research questions. Note that only the veteran's pathways were numbered to simplify the depiction 
RESPONSIVENESS, SLEEP AND PAIN IN VETERANS AND SPOUSES

Figure 7. Visual analog scale used to rate pain severity.

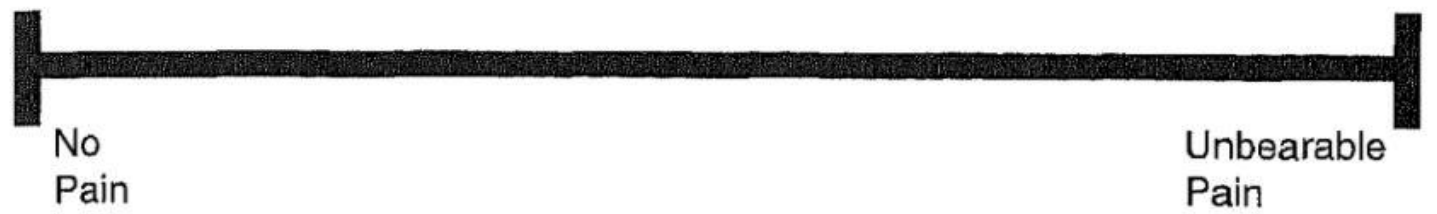

Note: Figure from Mattacola, Perrin, Gansneder, Allen \& Mickey, 1997. 
Figure 8 . Histograms of the outcome of sleep quality

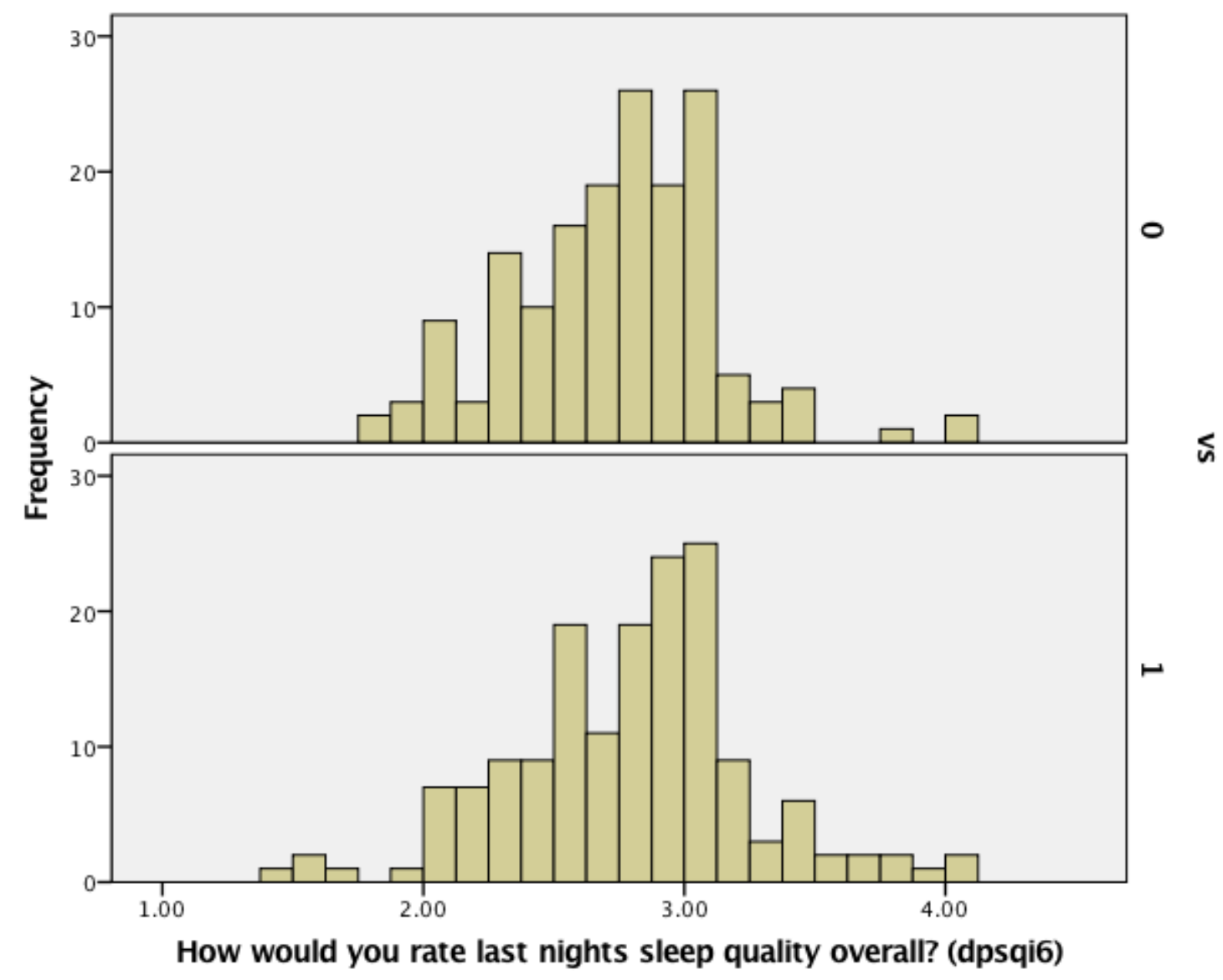

Note: $0=$ veterans; $1=$ spouses. 
Figure 9. Histograms of the outcome of pain

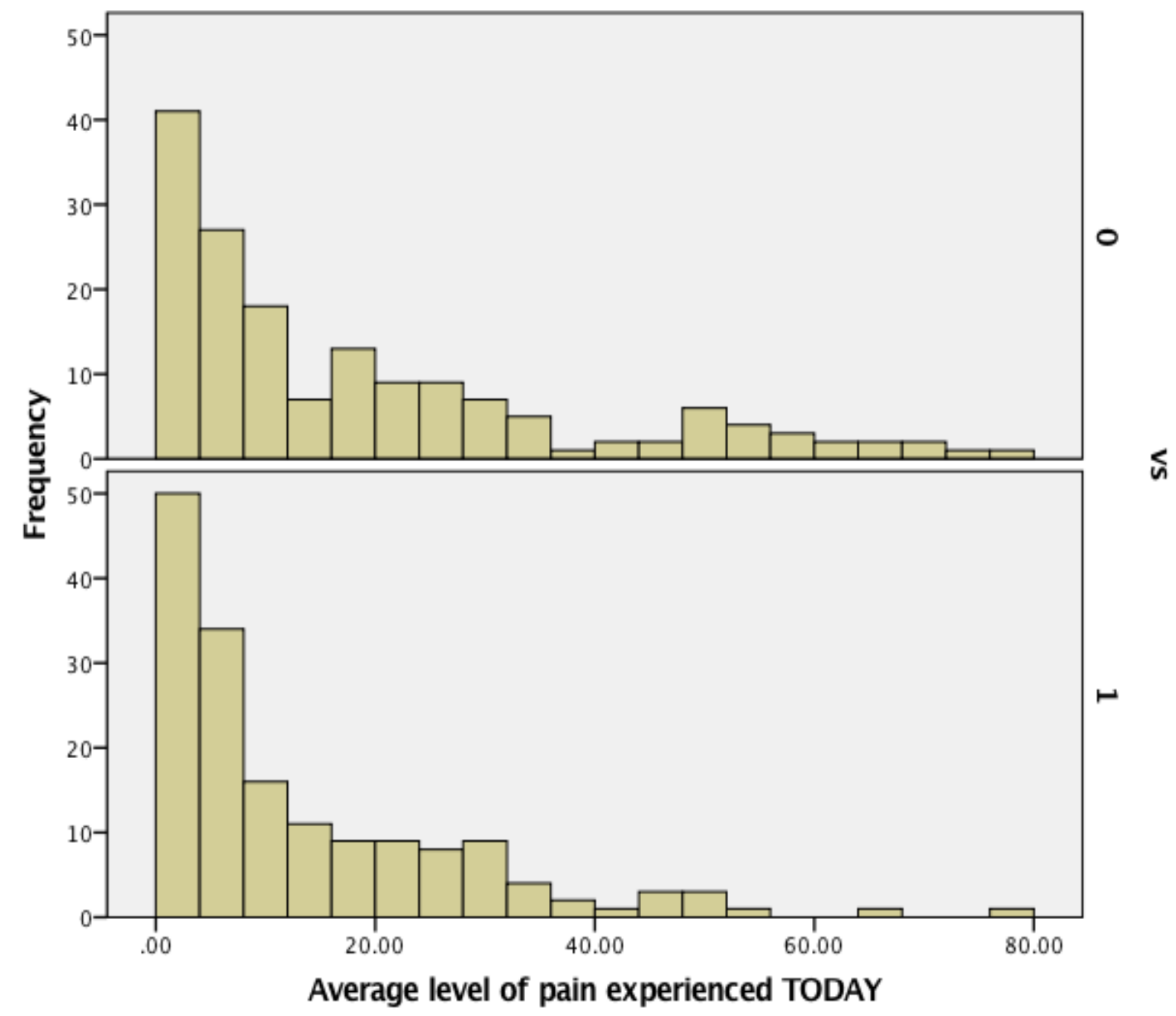

Note: $0=$ veterans; 1 =spouses. 
Figure 10. Histograms of the mediator of positive affect

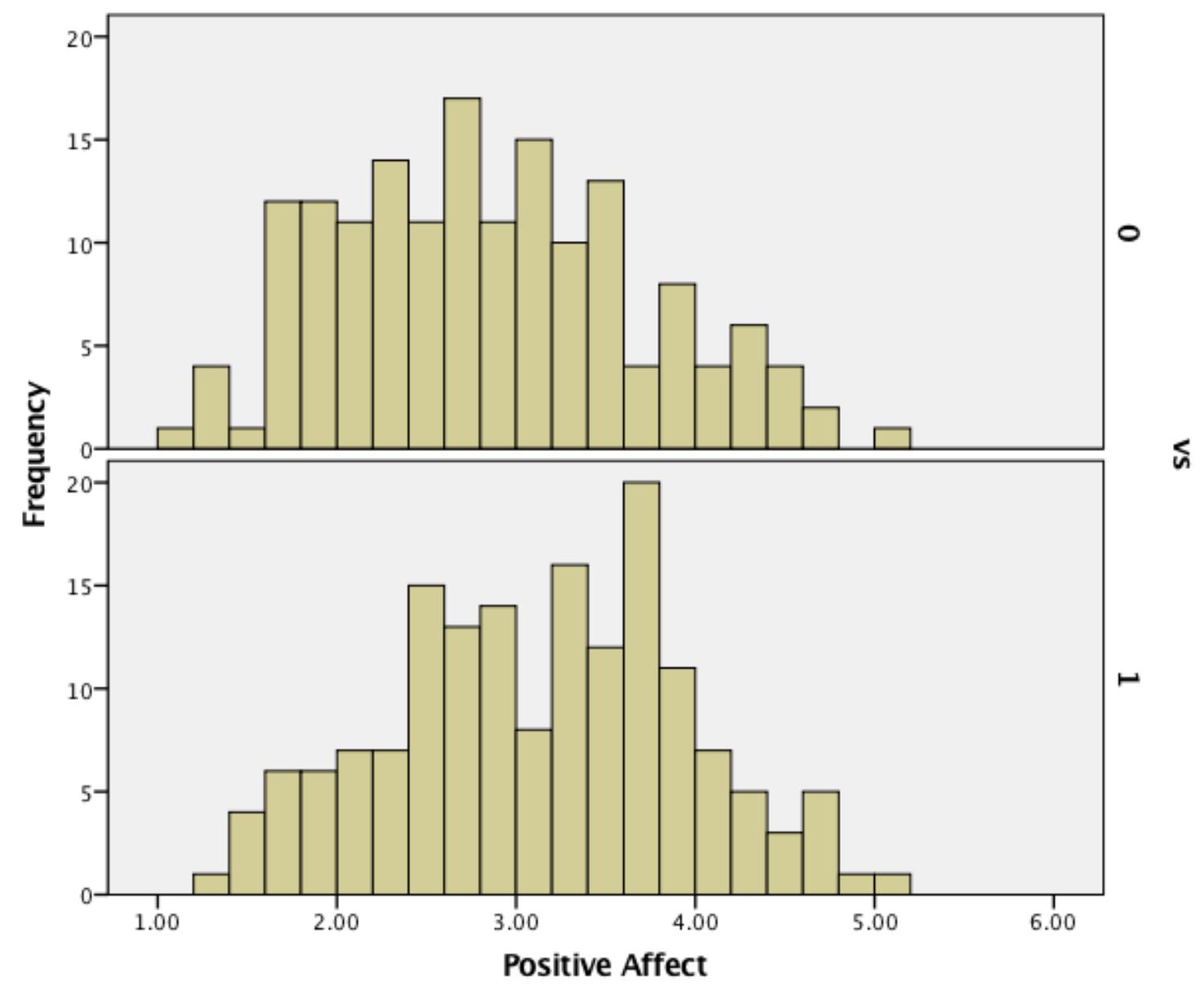

Note: $0=$ veterans; $1=$ spouses 
Figure 11. Histograms of the mediator of negative affect

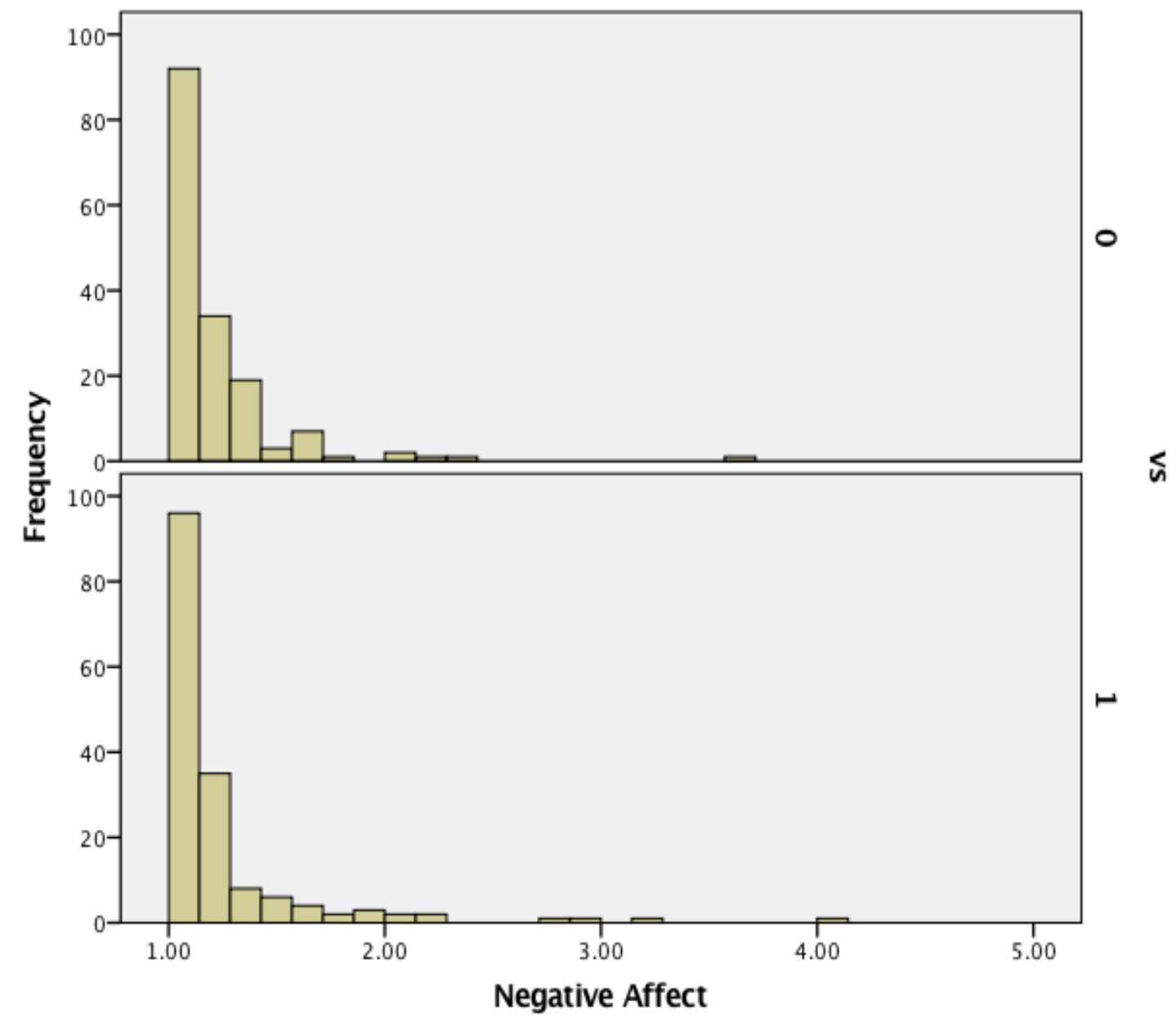

Note: $0=$ veterans; $1=$ spouses. 
Figure 12. Results of APIM: PPR-Sleep Quality

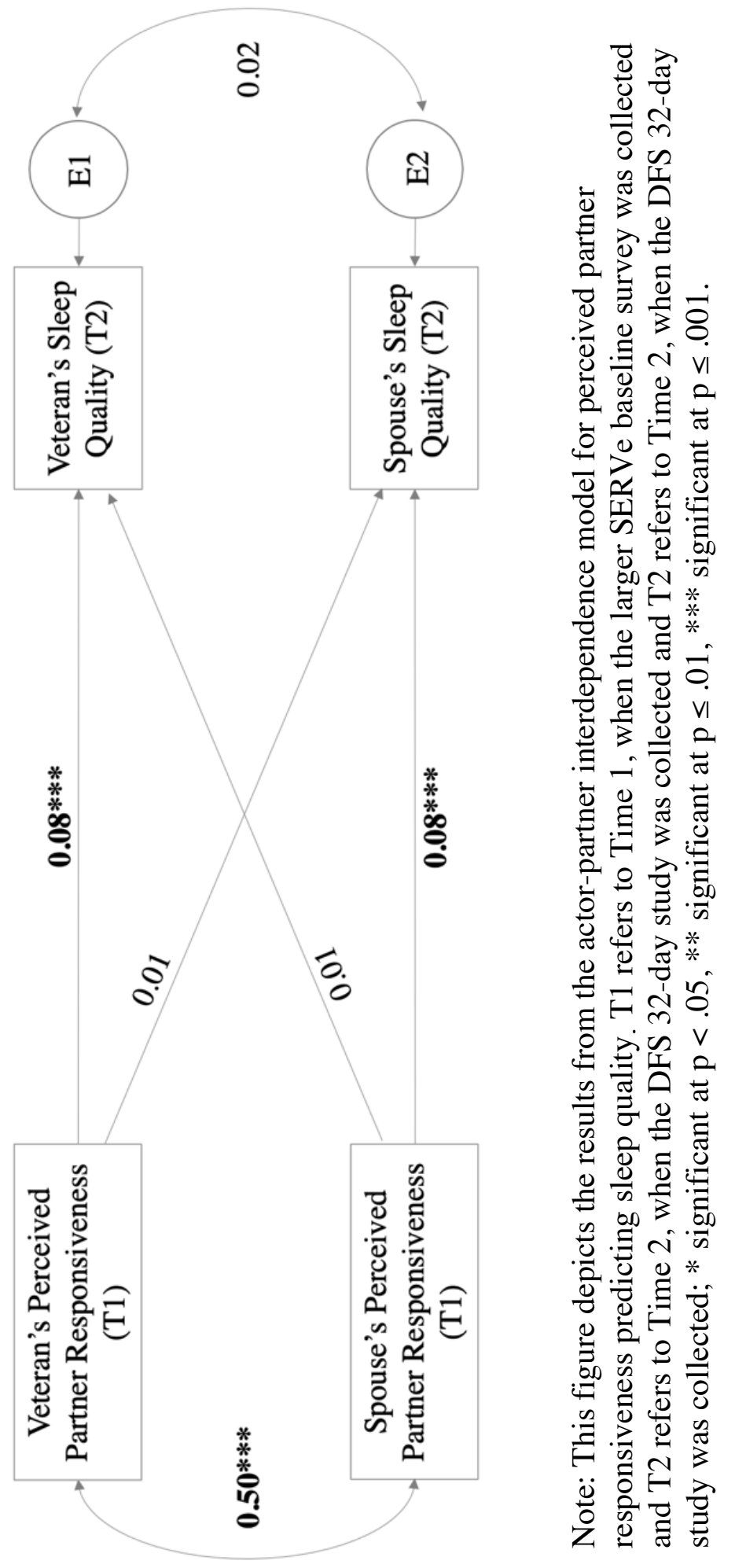


Figure 13. Results of APIMeM: PPR-Positive Affect-Sleep Quality

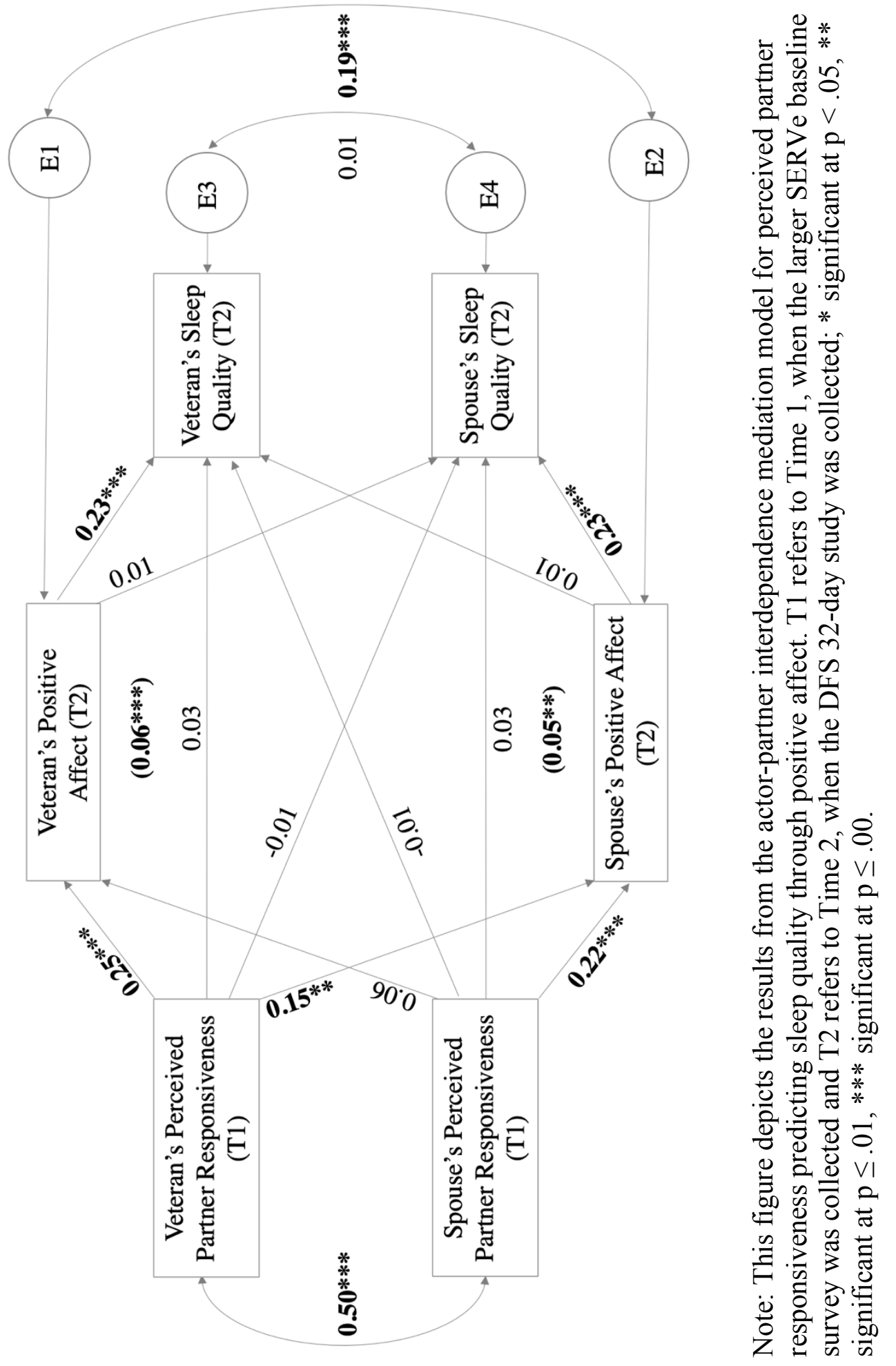


Figure 14. Results of APIMeM: PPR-Negative Affect-Sleep Quality

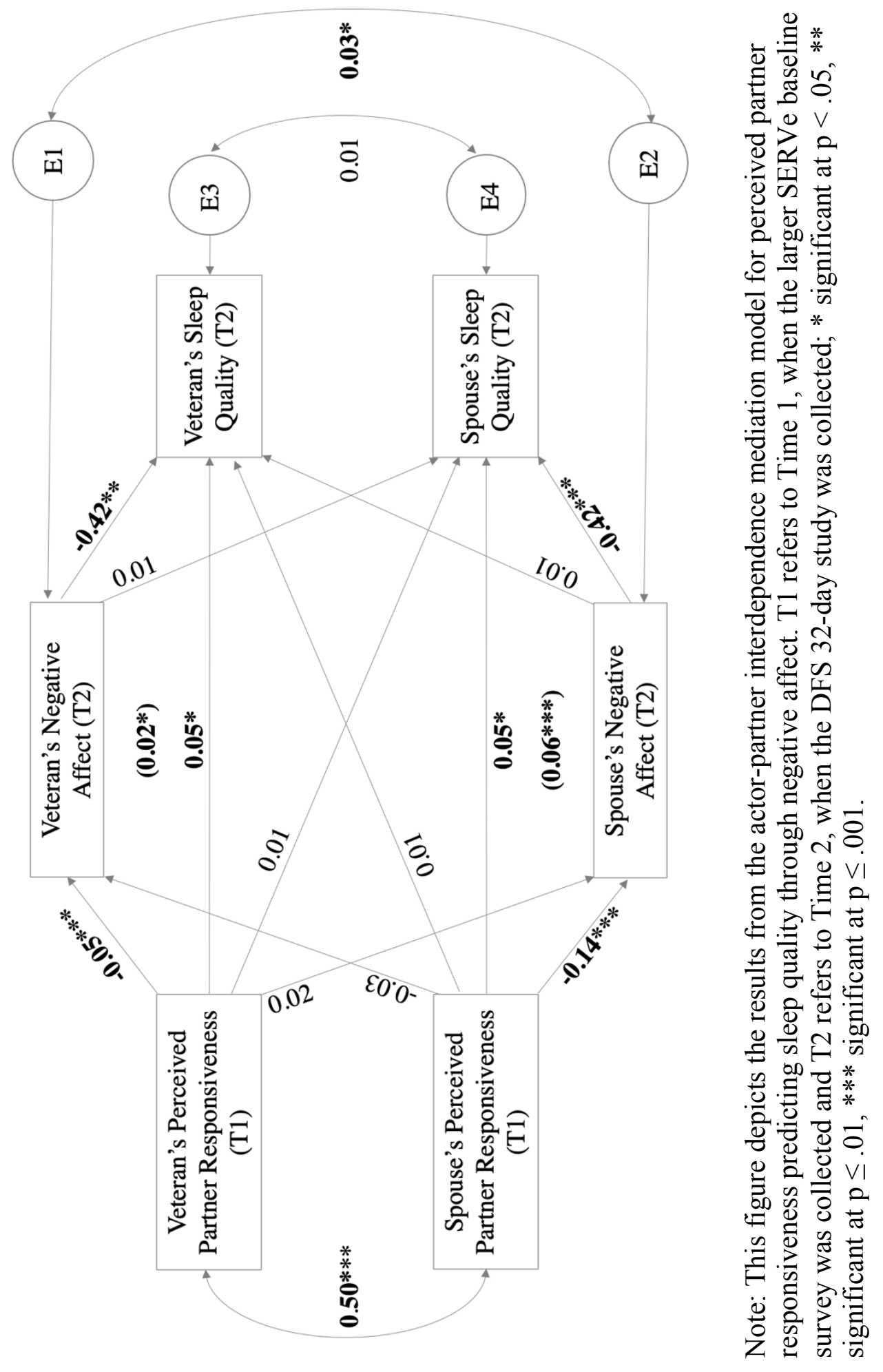


Figure 15. Results of APIM: PPR-Pain

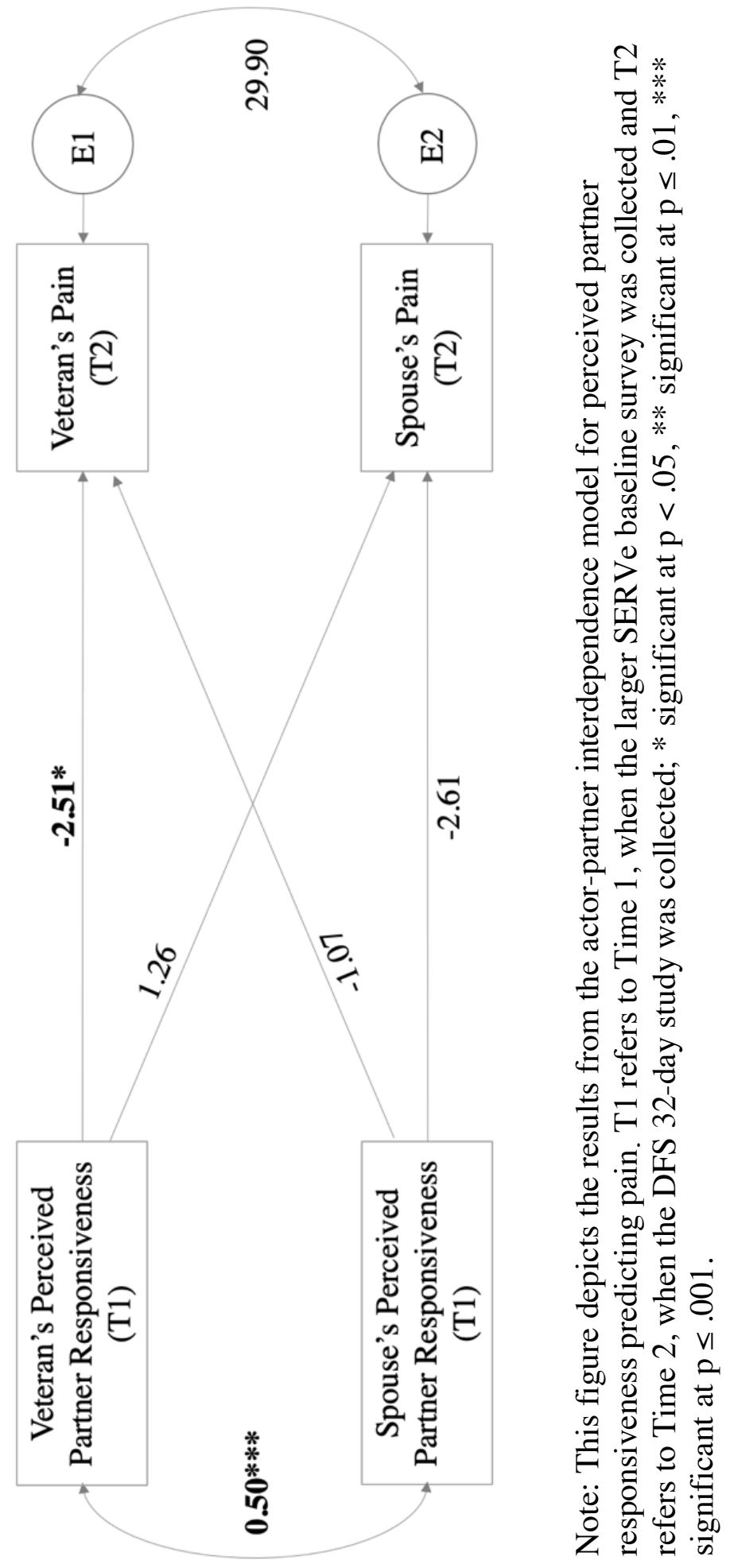


Figure 16. Results of APIMeM: PPR-Positive Affect-Pain

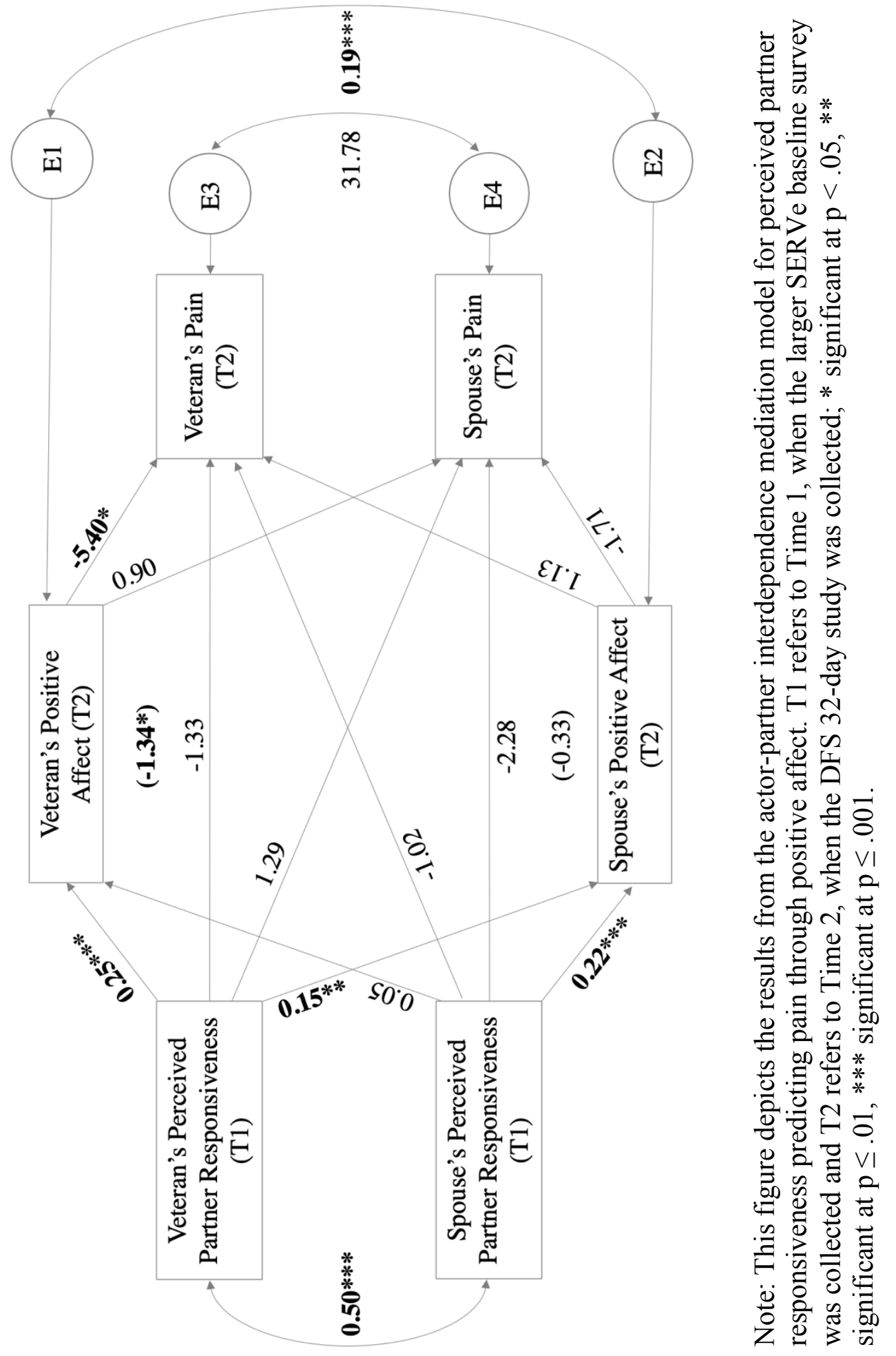


Figure 17. Results of APIMeM: PPR-Negative Affect-Pain

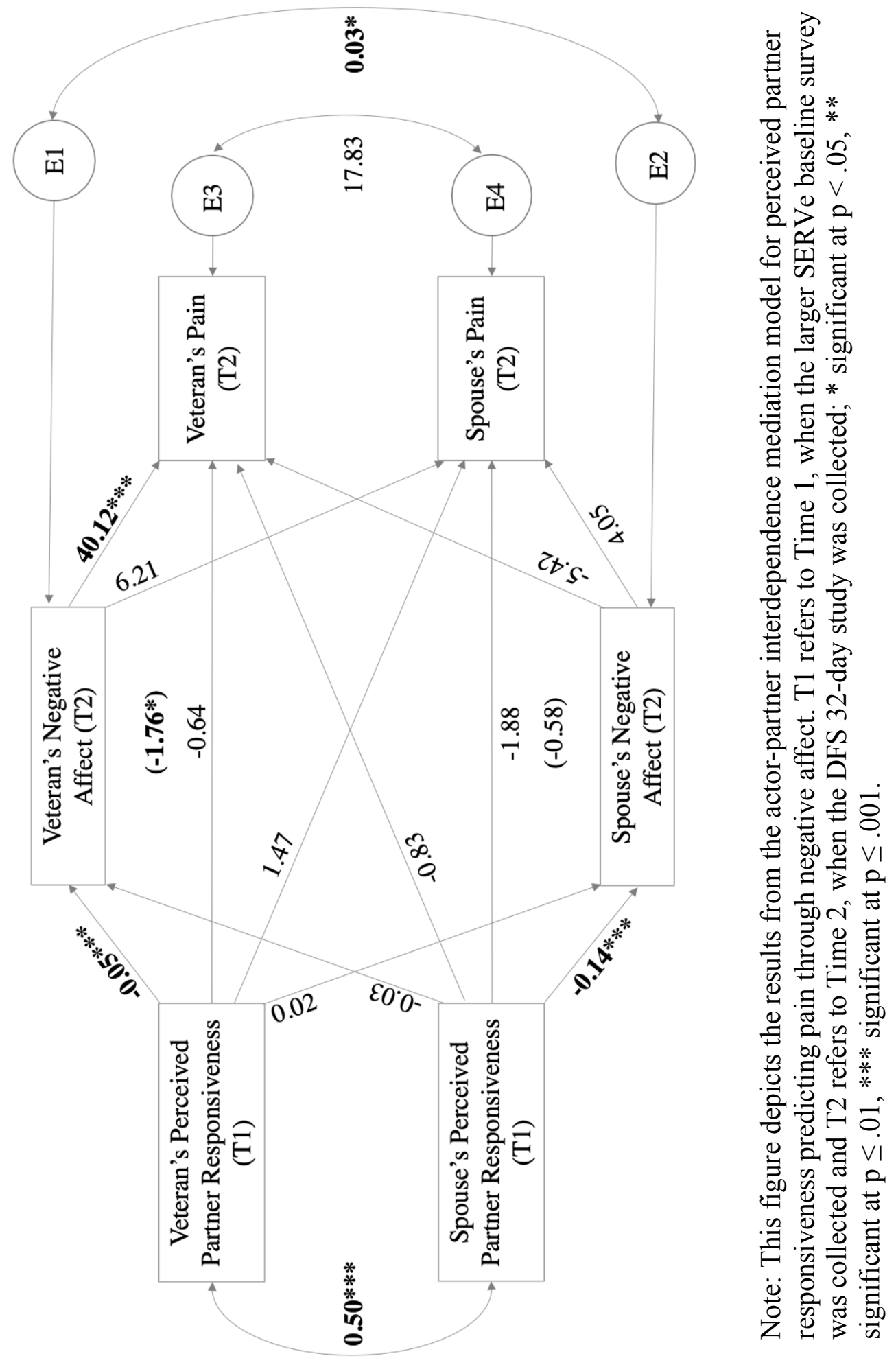


RESPONSIVENESS, SLEEP AND PAIN IN VETERANS AND SPOUSES

\section{References}

Abelson, R. P. (1985). A variance explanation paradox: When a little is a lot. Psychological Bulletin, 97(1), 129-134. doi:10.1037/0033-2909.97.1.129

Ackerman, R. A., Ledermann, T., \& Kenny, D. A. (2015). Power analysis for the actorpartner interdependence model. Manuscript in preparation.

Adams, C. (2013, March 15). Millions went to war in Iraq, Afghanistan, leaving many with lifelong scars. Wounds That Don't Heal. Retrieved from http://www.woundsthatdontbleed.com/millions- went-to-war-in-iraq-afghanistanleaving-many-with-lifelong-scars/

Adams, R. S., Larson, M. J., Corrigan, J. D., Horgan, C. M., \& Williams, T. V. (2012). Frequent binge drinking after combat-acquired traumatic brain injury among active duty military personnel with a past year combat deployment. The Journal of Head Trauma Rehabilitation, 27(5), 349-360.

doi:10.1097/HTR.0b013e318268db94

Ainsworth, M. S. (1979). Infant-mother attachment. American Psychologist, 34(10), 932937. doi:10.1037/0003-066X.34.10.932

Akerstedt, T., Kecklund, G., \& Axelsson, J. (2007). Impaired sleep after bedtime stress and worries. Biological Psychology, 76, 170-173.

doi:0.1016/j.biopsycho.2007.07.010

Allison, P. D. (2001). Missing data (Vol. 136). Sage publications.

Altman, I., \& Taylor, D. (1973). Social penetration theory. New York: Holt, Rinehart \&Winston. 
RESPONSIVENESS, SLEEP AND PAIN IN VETERANS AND SPOUSES

American Psychological Association Presidential Task Force on Military Deployment Services for Youth, Families and Service Members. (2007, February). The psychological needs of U.S. Military service members and their families: A preliminary report. Retrieved April 1, 2018, from http://www.apa.org/releases/MilitaryDeploymentTaskForceReport.pdf

Amin, M. M., Parisi, J. A., Gold, M. S., \& Gold, A. R. (2010). War-related illness symptoms among Operation Iraqi Freedom/Operation Enduring Freedom returnees. Military Medicine, 175(3), 156-165. doi:http://dx.doi.org/10.7205/MILMED-D-09-00153

Andersen, M., Araujo, P., Frange, C., \& Tufik, S. (2018). Sleep Disturbance and Pain. Chest., 154(5), 1249-1259. doi:10.1016/j.chest.2018.07.019

Arpin, S. N., Starkey, A. R., Mohr, C. D., Greenhalgh, A. M. D., \& Hammer, L. B. (2018). “A well spent day brings happy sleep": A dyadic study of capitalization support in military-connected couples. Journal of Family Psychology, 32(7), 975985. doi:10.1037/fam0000469

Autor, D.H., Duggan, M., Greenberg, K., \& Lyle, D. S. (2016). The impact of disability benefits on labor supply: Evidence from the VA's disability compensation program. American Economic Journal: Applied Economics, 8(3), 31-68. doi:10.1257/app.20150158

Bair, M. J., Robinson, R. L., Katon, W., \& Kroenke, K. (2003). Depression and pain comorbidity: a literature review. Archives of Internal Medicine, 163(20), 24332445. doi:10.1001/archinte.163.20.2433 
Balderrama-Durbin, C., Snyder, D. K., Cigrang, J., Talcott, G. W., Tatum, J., Baker, M., ... \& Smith Slep, A. M. (2013). Combat disclosure in intimate relationships: Mediating the impact of partner support on posttraumatic stress. Journal of Family Psychology, 27(4), 560-568. doi:10.1037/a0033412

Baptist, J. A., Amanor-Boadu, Y., Garrett, K., Goff, B. S. N., Collum, J., Gamble, P., ... \& Wick, S. (2011). Military marriages: The aftermath of operation Iraqi freedom (OIF) and operation enduring freedom (OEF) deployments. Contemporary Family Therapy, 33(3), 199-214. doi:199-214. 10.1007/s10591-011-9162-6

Barger, S.D., \& Cribbet, M.R. (2016). Social support sources matter: Increased cellular aging among adults with unsupportive spouses. Biological Psychiatry, 115, 43-49. doi:10.1016/j.biopsycho.2016.01.003 0301-0511

Barlas, F. M., Higgins, W. B., Pflieger, J. C., \& Diecker, K. (2013). 2011 Health related behaviors survey of active duty military personnel. Available at: www.murray.senate.gov/public/_cache/files/889efd07-2475-40ee-b3b0508947957a0f/final-2011-hrb-active-duty-survey-re port.pdf. Accessed February $22,2016$.

Barnes, C. M., \& Drake, C. L. (2015). Prioritizing sleep health: public health policy recommendations. Perspectives on Psychological Science, 10(6), 733-737. doi:10.1177/1745691615598509

Baumeister, R., \& Leary, M. (1995). The need to belong: Desire for interpersonal attachments as a fundamental human motivation. Psychological Bulletin, 117(3), 497-529. doi:10.1037/0033-2909.117.3.497 
Beckes, L., \& Coan, J. A. (2011). Social baseline theory: The role of social proximity in emotion and economy of action. Social and Personality Psychology Compass, 5(12), 976-988. doi:10.1111/j.1751-9004.2011.00400.x

Bell, D. B., \& Schumm, W. R. (2000). Providing family support during military deployments. In J. A. Martin, L. n . Rosen, \& L. R. Sparacino (Eds.), The military family: A practice guide for human service providers, (pp. 139-152) Westport, CT: Prageger.

Berkman, L. F. (1995). The role of social relations in health promotion. Psychosomatic Medicine, 57(3), 245-254. doi:10.1097/00006842-199505000-00006

Berkman, L. F., Glass, T., Brissette, I., \& Seeman, T. E. (2000). From social integration to health: Durkheim in the new millennium. Social Science \& Medicine, 51, 843857. doi:10.1016/S0277-9536(00)00065-4

Bernerth, J. B., \& Aguinis, H. (2016). A critical review and best-practice recommendations for control variable usage. Personnel Psychology, 69(1), 229283. doi:10.1111/peps.12103

Berscheid, E., \& Reis, H. T. (1998). Attraction and close relationships. In Gilbert, D. T., Fiske, S., T. \& Lindzey, G.(Eds.), The Handbook of Social Psychology, (4 ${ }^{\text {th }}$ ed.), (pp. 193-281). New York: Oxford University Press.

Birditt, K. S., \& Antonucci, T. C. (2007). Relationship quality profiles and well-being among married adults. Journal of Family Psychology, 21, 595-604.

doi:10.1037/0893- 3200.21.4.595 
Bliese, P. D., Wright, K. M., Adler, A. B., Cabrera, O., Castro, C. A., \& Hoge, C. W. (2008). Validating the primary care posttraumatic stress disorder screen and the posttraumatic stress disorder checklist with soldiers returning from combat. Journal of Consulting and Clinical Psychology, 76(2), 272-281. doi:10.1037/0022-006X.76.2.272

Boehm, J. K., \& Kubzansky, L. D. (2012). The heart's content: the association between positive psychological well-being and cardiovascular health. Psychological bulletin, 138(4), 655-691. doi:10.1037/a0027448

Bonvanie, I. J., Oldehinkel, A. J., Rosmalen, J. G., \& Janssens, K. A. (2016). Sleep problems and pain: a longitudinal cohort study in emerging adults. Pain, 157(4), 957-963. doi:10.1097/j.pain.0000000000000466.

Bordeleau, S., Bernier, A., \& Carrier, J. (2012). Longitudinal associations between the quality of parent-child interactions and children's sleep at preschool age. Journal of Family Psychology, 26, 254-262. doi:10.1037/a0027366

Bouchard, G. (2018). A Dyadic Examination of Marital Quality at the Empty-Nest Phase. The International Journal of Aging and Human Development, 86(1), 3450. doi:10.1177/0091415017691285

Bowen, A., Shelley, M., Helmes, E., \& Landman, M. (2010). Disclosure of traumatic experiences, dissociation, and anxiety in group therapy for posttraumatic stress. Anxiety, Stress, \& Coping, 23(4), 449-461. doi:10.1080/10615800903414315

Bowen, G. L. (1989). Satisfaction with family life in the military. Armed Forces \& Society, 15(4), 571-592. doi:10.1177/0095327X8901500406 
Bowlby, J. (1969), Attachment and loss, Vol. 1: Attachment. New York: Basic Books.

Bowlby, J. (1973). Attachment and loss, Vol. 2: Separation. New York: Basic Books.

Bradbury, T. N., Fincham, F. D., \& Beach, S. R. (2000). Research on the nature and determinants of marital satisfaction: A decade in review. Journal of Marriage and Family, 62(4), 964-980. doi:10.1111/j.1741-3737.2000.00964.x

Bray, R. M., Pemberton, M. R., Hourani, L. L., Witt, M., Olmsted, K. L., Brown, J. M., ... \& Scheffler, S. (2009). Department of Defense survey of health related behaviors among active duty military personnel (No. RTI/10940-FR). Research triangle institute $(\mathrm{RTI})$ research triangle park NC. Available at: www.documentcloud.org/documents/ 694941-2008-department-of-defensesurvey-of-health.html. Accessed February 22, 2018.

Buchanan, C., Kemppainen, J., Smith, S., MacKain, S., \& Cox, C. W. (2011). Awareness of posttraumatic stress disorder in veterans: a female spouse/intimate partner perspective. Military Medicine, 176(7), 743-751. doi:10.7205/MILMED-D-1000378

Burrell, L. M., Adams, G. A., Durand, D. B., \& Castro, C. A. (2006). The impact of military lifestyle demands on well-being, army, and family outcomes. Armed Forces \& Society, 33(1), 43-58. doi:10.1177/0002764206288804.

Buysse, D. J. (2014). Sleep health: can we define it? Does it matter? Sleep, 37(1), 9-17. doi:10.5665/sleep.3298 
Buysse, D. J., Monk, T. H., Reynolds III, C. F., Mesiano, D., Houck, P. R., \& Kupfer, D. J. (1993). Patterns of sleep episodes in young and elderly adults during a 36-hour constant routine. Sleep, 16(7), 632-637.

Buysse, D. J., Reynolds, C. F., Monk, T. H., Berman, S. R., \& Kupfer, D. J. (1989). The Pittsburgh Sleep Quality Index: a new instrument for psychiatric practice and research. Psychiatry research, 28(2), 193-213.

Cacioppo, J. T., Hawkley, L. C., Berntson, G. G., Ernst, J.M., Gibbs, A. C., Stickgold, R., \& Hobson, J. A. (2002). Do lonely days invade the nights? Potential social modulation of sleep efficiency. Psychological Science, 13, 384-387.

doi:10.1111/1467-9280.00469

Caldwell, J.A., Knapik, J. J., \& Lieberman, H. R. (2017). Trends and factors associated with insomnia and sleep apnea in all United States military service members from 2005 to 2014. Journal of Sleep Research, 26(5), 665-670. doi:10.1111/jsr.12543

Campbell, J. S., Markwald, R., Chinoy, E. D., Germain, A., Grieser, E., Lim, I., \& Bowles, S. V. (2017). A Sleep Primer for Military Psychologists. In S. Bowles, P. Bartone (Eds), Handbook of Military Psychology (pp. 239-258). Springer, Cham. doi: https://doi.org/10.1007/978-3-319-66192-6_15

Cano, A., Gillis, M., Heinz, W., Geisser, M., \& Foran, H. (2004). Marital functioning, chronic pain, and psychological distress. Pain, 107(1-2), 99-106. doi:10.1016/j.pain.2003.10.003 
Cappuccio, F. P., D'Elia, L., Strazzullo, P., \& Miller, M. A. (2010). Sleep duration and all-cause mortality: a systematic review and meta-analysis of prospective studies. Sleep, 33(5), 585-592. doi:org/10.1093/sleep/33.5.585

Caprariello, P. A., \& Reis, H. T. (2011). Perceived partner responsiveness minimizes defensive reactions to failure. Social Psychological and Personality Science, 2(4), 365-372. doi:10.1177/1948550610391914

Carlino, E., \& Benedetti, F. (2016). Different contexts, different pains, different experiences. Neuroscience, 338, 19-26. doi:10.1016/j.neuroscience.2016.01.053

Carlino, E., Frisaldi, E., \& Benedetti, F. (2014). Pain and the context. Nature Reviews Rheumatology, 10(6), 348-355. doi:10.1038/nrrheum.2014.17

Carlson K.D., \& Wu J. (2012). The illusion of statistical control: Control variable practice in management research. Organizational Research Methods, 15, 413435. doi: $10.1177 / 1094428111428817$

Carpenter, J. S., \& Andrykowski, M. A. (1998). Psychometric evaluation of the Pittsburgh sleep quality index. Journal of psychosomatic research, 45(1), 5-13. doi:10.1016/S0022-3999(97)00298-5

Cervero, F. (2012). Understanding pain: exploring the perception of pain. MIT Press. Chandola, T., Ferrie, J. E., Perski, A., Akbaraly, T., \& Marmot, M. G. (2010). The effect of short sleep duration on coronary heart disease risk is greatest among those with sleep disturbance: a prospective study from the Whitehall II cohort. Sleep, 33(6), 739-744. doi:10.1093/sleep/33.6.739 
Chapman, J. R., Norvell, D. C., Hermsmeyer, J. T., Bransford, R. J., DeVine, J., McGirt, M. J., \& Lee, M. J. (2011). Evaluating common outcomes for measuring treatment success for chronic low back pain. Spine, 36, S54-S68. doi:10.1097/BRS.0b013e31822ef74d

Chen, T. Y., Lee, S., Schade, M. M., Saito, Y., Chan, A., \& Buxton, O. M. (2018). Longitudinal relationship between sleep deficiency and pain symptoms among community-dwelling older adults in Japan and Singapore. Sleep, zsy219. doi:10.1093/sleep/zsy219

Chida, Y., \& Steptoe, A. (2008). Positive psychological well-being and mortality: a quantitative review of prospective observational studies. Psychosomatic medicine, 70(7), 741-756. doi:10.1097/PSY.0b013e31818105ba

Chow, C. M., \& Tan, C. C. (2013). Attachment and Commitment in Dyadic Friendships: Mediating Roles of Satisfaction, Quality of Alternatives, and Investment Size. Journal of Relationships Research, 4, e4, p1-11. doi:10.1017/jrr.2013.4

Clark, M. E., Bair, M. J., Buckenmaier III, C. C., Gironda, R. J., \& Walker, R. L. (2007). Pain and combat injuries in soldiers returning from Operations Enduring Freedom and Iraqi Freedom: Implications for research and practice. Journal of Rehabilitation Research and Development, 44(2), 179-193. doi:10.1682/JRRD.2006.05.0057

Clark, M. S. \& Reis, H. T. (1988). Interpersonal Processes in Close Relationships. Annual Review of Psychology, 39, 609-672. doi:10.1146/annurev.ps.39.020188.003141 
Claude Blais, M., \& Boisvert, J. M. (2005). Psychological and marital adjustment in couples following a traumatic brain injury (TBI): A critical review. Brain Injury, 19(14), 1223-1235. doi:10.1080/02699050500309387

Coan, J. A. (2011). The social regulation of emotion. In J. Decety \& J. T. Cacioppo (Eds.),The Oxford handbook of social neuroscience. New York: Oxford University Press. doi:10.1093/oxfordhb/9780195342161.013.0041

Coan, J. A., \& Sbarra, D. A. (2015). Social baseline theory: The social regulation of risk and effort. Current opinion in psychology, 1, 87-91. doi:L10.1016/j.copsyc.2014.12.021

Coan, J. A., Schaefer, H. S., \& Davidson, R. J. (2006). Lending a hand: Social regulation of the neural response to threat. Psychological science, 17(12), 1032-1039. doi:10.1111/j.1467-9280.2006.01832.x

Cohen, J. (1988). Statistical power analysis for the behavioral sciences (2nd Ed.). Mahwah, NJ: Erlbaum.

Cohen, J. (1992). A power primer. Psychological Bulletin, 112(1), 155-159. doi: 10.1037/0033-2909.112.1.155

Cohen, J., Cohen, P., West, S. G., \& Aiken, L. S. (2003). Applied multiple regression/correlation analysis for the behavioral sciences,(3rd ed.). Mahwah, NJ: Erlbaum.

Cohen, S. (2004). Social relationships and health. American Psychologist, 59(8), 676730. doi:10.1037/0003-066X.59.8.676 
Cohen, S., \& Lemay, E. (2007). Why would social networks be linked to affect and health practices? Health Psychology: The Official Journal of the Division of Health Psychology, American Psychological Association., 26(4), 410-417. doi:10.1037/0278-6133.26.4.410

Cohen, S., \& Wills, T. A. (1985). Stress, social support, and the buffering hypothesis. Psychological Bulletin, 98(2), 310-357. doi:10.1037/0033-2909.98.2.310

Collins, N. L., \& Ford, M. B. (2010). Responding to the needs of others: The caregiving behavioral system in intimate relationships. Journal of Social and Personal Relationships, 27(2), 235-244. doi:10.1177/0265407509360907

Cook, W. L., \& Kenny, D. A. (2005). The actor-partner interdependence model: A model of bidirectional effects in developmental studies. International Journal of Behavioral Development, 29(2), 101-109. doi:10.1080/01650250444000405

Cox, R., Tuck, C., \& Olatunji, B. (2017). Sleep Disturbance in Posttraumatic Stress Disorder: Epiphenomenon or Causal Factor? Current Psychiatry Reports, 19(4), 1-10. doi:10.1007/s11920-017-0773-y

Craig, K. D., \& Hadjistavropoulos, T. (2004). Psychological perspectives on pain: Controversies. Pain: Psychological Perspectives, 303-326. doi:10.3138/physio.60.2.203

Dahl, R. E., \& El-Sheikh, M. (2007). Considering sleep in a family context: Introduction to the special issue. Journal of Family Psychology, 21(1), 1-3. doi:10.1037/08933200.21.1.1 
Dahl, R.E. (1996). The regulation of sleep and arousal: Development and psychopathology. Development and Psychopathology. 8(1), 3-27. doi:10.1017/S0954579400006945

De Boer, A. G. E. M., Van Lanschot, J. J. B., Stalmeier, P. F. M., Van Sandick, J. W., Hulscher, J. B., De Haes, J. C. J. M., \& Sprangers, M. A. G. (2004). Is a singleitem visual analogue scale as valid, reliable and responsive as multi-item scales in measuring quality of life? Quality of Life Research, 13(2), 311-320. doi:10.1023/B:QURE.0000018499.64574.1f

De Burgh, H. T., White, C. J., Fear, N. T., \& Iversen, A. C. (2011). The impact of deployment to Iraq or Afghanistan on partners and wives of military personnel. International Review of Psychiatry, 23(2), 192-200. doi:10.3109/09540261.2011.560144.

de la Vega, R., Racine, M., Castarlenas, E., Solé, E., Roy, R., Jensen, M. P., ... \& Cane, D. (2018). The role of sleep quality and fatigue on the benefits of an interdisciplinary treatment for adults with chronic pain. Pain Practice. doi:10.1111/papr.12746

DeBruyne, N.F. (2017). American War and Military Operations Casualties: Lists and Statistics. Retrieved from: https://fas.org/sgp/crs/natsec/RL32492.pdf Defense Manpower Data Center (2004). August 2004 Status of Forces Survey of ActiveDuty Members: Administration, Datasets, and Codebook (No. 2004-016). DMDC Report. 
Dement, W. C., \& Vaughan, C. (1999). The promise of sleep: A pioneer in sleep medicine explores the vital connection between health, happiness, and a good night's sleep. New York, NY: Dell Publishing Co.

Department of Defense. (2016). Demographics: Profile of the Military Community. http://download.militaryonesource.mil/12038/MOS/Reports/2015-DemographicsReport.pdf

Derlega, V. J., Metts, S., Petronio, S., \& Margulis, S. T. (1993). Self-disclosure. Newbury Park, CA: Sage.

Diamond, L. M., Hicks, A. M., \& Otter-Henderson, K. D. (2008). Every time you go away: Changes in affect, behavior, and physiology associated with travel-related separations from romantic partners. Journal of Personality and Social Psychology, 95(2), 385-403. doi:10.1037/0022-3514.95.2.385

Dogar I.A. (2007). Biopsychosocial model. Annals of Punjab Medical College, 1(1), 1113. http://applications.emro.who.int/imemrf/Ann_Punjab_Med_Coll/Ann_Punjab_Me d_Coll_2007_1_1_11_13.pdf

Dunkel Schetter, C. (2017). Moving research on health and close relationships forwarda challenge and an obligation: Introduction to the special issue. American Psychologist, 72(6), 511-516. doi:10.1037/amp0000158

Durkheim, E. (1951). Suicide: A study in sociology (JA Spaulding \& G. Simpson, trans.). Glencoe, IL: Free Press.(Original work published 1897). 
Efron, T., \& Tibshirani, R. J. (1993). An introduction to the bootstrap. New York: Chapman \& Hall.

Eisenberger, N. I. (2013). An empirical review of the neural underpinnings of receiving and giving social support: Implications for health. Psychosomatic Medicine, 75(6), 545-556. doi:10.1097/PSY.0b013e31829de2e7

Eisenberger, N. I., Lieberman, M. D., \& Williams, K. D. (2003). Does rejection hurt? An fMRI study of social exclusion. Science, 302, 290-292. doi:10.1126/science. 1089134

Eisenberger, N. I., Master, S. L., Inagaki, T. K., Taylor, S. E., Shirinyan, D., Lieberman, M. D., \& Naliboff, B. D. (2011). Attachment figures activate a safety signalrelated neural region and reduce pain experience. Proceedings of the National Academy of Sciences of the United States of America, 108(28), 11721-11726. doi:10.1073/pnas.1108239108

Emmons, R. A., \& McCullough, M. E. (2003). Counting blessings versus burdens: an experimental investigation of gratitude and subjective well-being in daily life. Journal of Personality and Social Psychology, 84(2), 377-389. doi:10.1037/0022-3514.84.2.377

Erbes, C. R. (2011). Couple functioning and PTSD in returning OIF soldiers: Preliminary findings from the Readiness and Resilience in National Guard Soldiers project. In S. M. Wadsworth \& D. Riggs (Eds.), Risk and resilience in U.S. military families (pp. 47-67). New York: Springer Science + Business Media. doi:http://dx.doi.org/10.1007/978-1-4419-7064-0_3 
Erbes, C. R., Meis, L. A., Polusny, M. A., \& Compton, J. S. (2011). Couple adjustment and posttraumatic stress disorder symptoms in National Guard veterans of the Iraq war. Journal of Family Psychology, 25(4), 479-487. doi:10.1037/a0024007

Erickson, E. H. (1950). Childhood and society. New York: Norton.

Erickson, E. H. (1968). Identity: Youth and crisis. New York: Norton.

Ertel, K. A., Glymour, M. M., \& Berkman, L. F. (2009). Social networks and health: A life course perspective integrating observational and experimental evidence. Journal of Social and Personal Relationships, 26(1), 73-92. doi: $10.1177 / 0265407509105523$

Faber, A. J., Willerton, E., Clymer, S. R., MacDermid, S. M., \& Weiss, H. M. (2008). Ambiguous absence, ambiguous presence: A qualitative study of military reserve families in wartime. Journal of Family Psychology, 22(2), 222-230. doi:10.1037/0893-3200.22.2.222.

Feeney, B. C., \& Collins, N. L. (2015). A new look at social support: A theoretical perspective on thriving through relationships. Personality and Social Psychology Review, 19(2), 113-147. doi: 10.1177/1088868314544222

Fillingim, R. B. (2017). Sex, gender, and pain. In M. J. Legato (ed), Principles of Gender-Specific Medicine (3rd ed.) (pp. 481-496). San Diego, CA, US: Academic Press.

Fillingim, R. B., King, C. D., Ribeiro-Dasilva, M. C., Rahim-Williams, B., \& Riley, J. L. (2009). Sex, gender, and pain: a review of recent clinical and experimental findings. The Journal of Pain, 10(5), 447-485. doi: 10.1016/j.jpain.2008.12.001. 
Fillo, J., Holliday, S. B., DeSantis, A., Germain, A., Buysse, D. J., Matthews, K. A., \& Troxel, W. M. (2017). Observed Relationship Behaviors and Sleep in Military Veterans and Their Partners. Annals of Behavioral Medicine, 51(6), 879-889. doi:10.1007/s12160-017-9911-3

Fincham, F. D., \& Beach, S. R. (2014). I say a little prayer for you: Praying for partner increases commitment in romantic relationships. Journal of Family Psychology, 28(5), 587-593. doi:10.1037/a0034999.

Fincham, F. D., \& Bradbury, T. N. (1987). The assessment of marital quality: A reevaluation. Journal of Marriage and the Family, 49(4), 797-809. doi: $10.2307 / 351973$

Fischer, H. (2015). A Guide to U.S. Military Casualty Statistics: Operation Freedom's Sentinel, Operation Inherent Resolve, Operation New Dawn, Operation Iraqi Freedom, and Operation Enduring Freedom. Congressional Research Service, 7, 5700. Retrieved from: www.crs.gov.

Fiske, S.T. (2004). Social beings: A core motives approach to social psychology. Chapter 8: Close Relationships: Passion, interdependence, commitment, and intimacy. (279- 314) Hoboken, NJ: John Wiley \& Sons, Inc.

Fredrickson, B. L. (1998). What good are positive emotions? Review of General Psychology, 2(3) 300-319. doi:10.1037/1089-2680.2.3.300

Gable, S. L., \& Reis, H. T. (2010). Good news! Capitalizing on positive events in an interpersonal context. In M. P. Zanna (Ed.), Advances in experimental social psychology, vol 42; advances in experimental social psychology, vol. 42 (pp. 195- 
RESPONSIVENESS, SLEEP AND PAIN IN VETERANS AND SPOUSES

257, Chapter x, 391 Pages) San Diego, CA Academic Press,. doi:10.1016/S00652601(10)42004-3

Galovski, T., \& Lyons, J. A. (2004). Psychological sequelae of combat violence: A review of the impact of PTSD on the veteran's family and possible interventions. Aggression and Violent Behavior, 9(5), 477-501. doi:10.1016/S13591789(03)00045-4

Gatchel, R. J. (2005). Clinical essentials of pain management. American Psychological Association.

Gatchel, Robert J., Peng, Yuan Bo, Peters, Madelon L., Fuchs, Perry N., \& Turk, Dennis C. (2007). The Biopsychosocial Approach to Chronic Pain: Scientific Advances and Future Directions. Psychological Bulletin, 133(4), 581-624.

doi:10.1037/0033-2909.133.4.581

Gerlock, A. A., Grimesey, J., \& Sayre, G. (2014). Military-related posttraumatic stress disorder and intimate relationship behaviors: A developing dyadic relationship model. Journal of Marital and Family Therapy, 40(3), 344-356.

doi:10.1111/jmft.12017

Gibson C. D. (2012). Review of posttraumatic stress disorder and chronic pain: The path to integrated care. Journal of Rehabilitation Research \& Development,49(5), 753776. doi: $10.1155 / 2013 / 174728$

Gifford, L. (1998). Pain, the tissues and the nervous system: a conceptual model. Physiotherapy, 84(1), 27-36. doi:10.1016/S0031-9406(05)65900-7 
Goff, B. S. N., Crow, J. R., Reisbig, A. M., \& Hamilton, S. (2007). The impact of individual trauma symptoms of deployed soldiers on relationship satisfaction. Journal of Family Psychology, 21(3), 344-353. doi:10.1037/0893-3200.21.3.344

Goldstein, P., Shamay-Tsoory, S. G., Yellinek, S., \& Weissman-Fogel, I. (2016). Empathy predicts an experimental pain reduction during touch. The Journal of Pain, 17(10), 1049-1057. doi:10.1016/j.jpain.2016.06.007

Gordon, A. M., \& Chen, S. (2014). The role of sleep in interpersonal conflict: Do sleepless nights mean worse fights? Social Psychological \& Personality Science, 5, 168-175. doi:10.1177/1948550613488952

Gordon, A. M., Mendes, W. B., \& Prather, A. A. (2017). The social side of sleep: Elucidating the links between sleep and social processes. Current Directions in Psychological Science, 26(5), 470-475. doi:10.1177/0963721417712269

Greene, K., Derlega, V. J., \& Mathews, A. (2006). Self-disclosure in personal relationships. The Cambridge handbook of personal relationships, (pp. 409-427). New York, NY, US: Cambridge University Press.

Gross, J. J. (1998). The emerging field of emotion regulation: an integrative review. Review of general psychology, 2(3), 271-299. doi:10.1037/1089-2680.2.3.271

Gunn, H. E., Troxel, W. M., Hall, M. H., \& Buysse, D. J. (2014). Interpersonal distress is associated with sleep and arousal in insomnia and good sleepers. Journal of Psychosomatic Research, 76(3), 242-248. doi:10.1016/j.jpsychores.2013.11.010 
Gunthert, K. C., \& Wenze, S. J. (2012). Daily diary methods. In M. R. Mehl \& T. S. Conner (Eds.), Handbook of research methods for studying daily life (pp. 144159). New York, NY, US: Guilford Press.

Gureje, O., Von Korff, M., Simon, G. E., \& Gater, R. (1998). Persistent pain and wellbeing: a World Health Organization study in primary care. Jama, 280(2), 147151. doi:10.1001/jama.280.2.147

Hammer, L. B., Wan, W. H., Brockwood, K. J., Mohr, C. D., \& Carlson, K. F. (2017). Military, work, and health characteristics of separated and active service members from the study for employment retention of veterans (SERVe). Military Psychology, 29(6), 491-512. doi:10.1037/mil0000196

Harris, C., Daniels, K., \& Briner, R. B. (2003). A daily diary study of goals and affective well-being at work. Journal of Occupational and Organizational Psychology, 76, 401-410.

Harvey, A. G. (2000). Pre-sleep cognitive activity: A comparison of sleep-onset insomniacs and good sleepers. British Journal of Clinical Psychology, 39, 275286.

Haskell, S. G., Heapy, A., Reid, M. C., Papas, R. K., \& Kerns, R. D. (2006). The prevalence and age-related characteristics of pain in a sample of women veterans receiving primary care. Journal of Women's Health, 15(7), 862-869. doi: 10.1089/jwh.2006.15.862

Hasler, B. P., \& Troxel, W. M. (2010). Couples' nighttime sleep efficiency and concordance: evidence for bidirectional associations with daytime relationship 
RESPONSIVENESS, SLEEP AND PAIN IN VETERANS AND SPOUSES

functioning. Psychosomatic medicine, 72(8), 794-801.

doi:10.1097/PSY.0b013e3181ecd08a

Hazan, C., \& Shaver, P. R. (1994). Attachment as an organizational framework for research on close relationships. Psychological Inquiry, 5(1), 1-22. doi: $10.1207 / \mathrm{s} 15327965$ pli0501_1

Hendrick, C., \& Hendrick, S. (1983). Liking, loving, and relating. Monterey, CA: Brooks/Cole.

Hicks, A. M., \& Diamond, L. M. (2011). Don't go to bed angry: Attachment, conflict, and affective and physiological reactivity. Personal Relationships, 18(2), 266-284. doi:10.1111/j.1475-6811.2011.01355.x

Hoge, C. W., Auchterlonie, J. L., \& Milliken, C. S. (2006). Mental health problems, use of mental health services, and attrition from military service after returning from deployment to iraq or afghanistan. JAMA: Journal of the American Medical Association, 295(9), 1023-1032. doi: 10.1001/jama.295.9.1023

Hoge, C. W., Castro, C. A., Messer, S. C., McGurk, D., Cotting, D. I., \& Koffman, R. L. (2004). Combat duty in Iraq and Afghanistan, mental health problems, and barriers to care. New England Journal of Medicine, 351(1), 13-22. doi:10.1056/NEJMoa040603

Holliday, S. B., \& Troxel, W. (2017). Relationship quality: Implications for sleep quality and sleep disorders. In S. M. McHale, V. King, \& O. M. Buxton (Eds.), National symposium on family issues: Vol. 8. Family contexts of sleep and health across 
the life course (pp. 53-84). Cham, Switzerland: Springer International Publishing. doi:http://dx.doi.org/10.1007/978-3-319-64780-7_3

Holliday, S. B., Haas, A., Shih, R. A., \& Troxel, W. M. (2016). Prevalence and consequences of sleep problems in military wives. Sleep Health: Journal of the National Sleep Foundation, 2(2), 116-122. doi:10.1016/j.sleh.2016.03.004

Holt-Lunstad, J. (2018). Why Social Relationships Are Important for Physical Health: A Systems Approach to Understanding and Modifying Risk and Protection. Annual Review of Psychology, 69(1), 437-458. doi:10.1146/annurev-psych-122216011902

Holt-Lunstad, J., Smith, T. B., \& Layton, J. B. (2010). Social relationships and mortality risk: a meta-analytic review. PLoS medicine, 7(7), e1000316. doi:10.1371/journal.pmed.1000316

Hosek, J., Kavanagh, J. E., \& Miller, L. L. (2006). How deployments affect service members. Rand Corporation.

Hourani, L. L., Williams, T. V., \& Kress, A. M. (2006). Stress, mental health, and job performance among active duty military personnel: findings from the 2002 Department of Defense Health-Related Behaviors Survey. Military Medicine, $171(9), 849-856$.

House, J. S., Landis, K. R., \& Umberson, D. (1988). Social relationships and health. Science, 241(4865), 540-545. doi:10.1126/science.3399889 
Hoyt, T., \& Renshaw, K. D. (2014). Emotional disclosure and posttraumatic stress symptoms: Veteran and spouse reports. International Journal of Stress Management, 21(2), 186-206. doi:10.1037/a0035162

Hughes, J. M., Ulmer, C. S., Gierisch, J. M., Nicole Hastings, S., \& Howard, M. O. (2018). Insomnia in United States military veterans: An integrated theoretical model. Clinical Psychology Review, 59, 118-125. doi:10.1016/j.cpr.2017.11.005

Hyman, J., Ireland, R., Frost, L., \& Cottrell, L. (2012). Suicide incidence and risk factors in an active duty US military population. American Journal of Public Health, 102, S138-S146. doi:10.2105/AJPH.2011.300484

IBM Corp. Released 2016. IBM SPSS Statistics for Windows, Version 24.0. Armonk, NY: IBM Corp.

Ilgen, M. A., Zivin, K., Austin, K. L., Bohnert, A. S., Czyz, E. K., Valenstein, M., \& Kilbourne, A. M. (2010). Severe pain predicts greater likelihood of subsequent suicide. Suicide and Life-Threatening Behavior, 40(6), 597-608. doi:10.1521/suli.2010.40.6.597

International Association for the Study of Pain (IASP). (1994). Descriptions of chronic pain syndromes and definitions of pain terms. In: H. Merskey \& N. Bogduk, (Eds.), Classification of chronic pain (2nd ed, pp. 94-95). Seattle, WA: IASP Press.

Jackson, J. B., Miller, R. B., Oka, M., \& Henry, R. G. (2014). Gender differences in marital satisfaction: A meta-analysis. Journal of Marriage and Family, 76(1), 105-129. doi:10.1111/jomf.12077. 
Kane, H. S., Slatcher, R. B., Reynolds, B. M., Repetti, R. L., \& Robles, T. F. (2014). Daily self-disclosure and sleep in couples. Health Psychology, 33(8), 813-822. doi: $10.1037 /$ hea0000077.

Karademas, E. C., \& Roussi, P. (2017). Financial strain, dyadic coping, relationship satisfaction, and psychological distress: A dyadic mediation study in Greek couples. Stress and Health, 33(5), 508-517.

Karney, B. R., \& Crown, J. S. (2007). Families under stress: An assessment of data, theory, and research on marriage and divorce in the military (Vol. 599). Rand Corporation.

Karney, B. R., \& Crown, J. S. (2011). Does deployment keep military marriages together or break them apart? Evidence from Afghanistan and Iraq. In S. M. Wadsworth \& D. Riggs (Eds.), Risk and Resilience in US Military Families (pp. 23-45). New York, NY: Springer.

Karney, B. R., \& Trail, T. E. (2017). Associations between prior deployments and marital satisfaction among army couples. Journal of Marriage and Family, 79(1), 147160. doi:10.1111/jomf.12329

Kashy, D. A., \& Kenny, D. A. (2000). The analysis of data from dyads and groups. In H. T. Reis \& C. M. Judd (Eds.), Handbook of research methods in social psychology (pp. 451-477). New York: Cambridge University Press.

Kawachi, I., \& Berkman, L. F. (2001). Social ties and mental health. Journal of Urban Health, 78(3), 458-467. doi:10.1093/jurban/78.3.458 
Kelley, H. H., \& Thibaut, J. W. (1978). Interpersonal relations: A theory of interdependence. New York: Wiley.

Kelly, A. C., \& Stephen, E. (2016). A daily diary study of self-compassion, body image, and eating behavior in female college students. Body Image, 17, 152-160. doi:10.1016/j.bodyim.2016.03.006

Kenny, D. A. (1996). Models of Non-Independence in Dyadic Research. Journal of Social and Personal Relationships, 13(2), 279-294. doi:10.1177/0265407596132007

Kenny, D. A. \& Cook, W. L.(1999). Partner effects in relationship research: Conceptual issues, analytic difficulties, and illustrations. Personal Relationships, 6(4), 433448. doi:10.1111/j.1475-6811.1999.tb00202.x

Kenny, D. A., \& Ackerman, R. A. (2015). APIM Power [Web-based software]. Retrieved from https://robert-ackerman.shinyapps.io/APIMPowerR/

Kenny, D. A., Kashy, D. A., \& Cook, W. L. (2006). Dyadic data analysis. New York, NY: Guilford Press.

Kenny, D. A., Kashy, D., \& Bolger, N. (1998). Data analysis in social psychology. In D. Gilbert, S. Fiske, and G. Lindzey (Eds.), Handbook of social psychology (4th ed., pp. 233-265). New York: McGraw-Hill.

Kerns, R. D., Philip, E. J., Lee, A. W., \& Rosenberger, P. H. (2011). Implementation of the Veterans Health Administration National Pain Management Strategy. Translational Behavioral Medicine, 1(4), 635-643. doi:10.1007/s13142011-0094-3 
Kerns, R., Otis, J., Rosenberg, R., \& Reid, M. (2003). Veterans' reports of pain and associations with ratings of health, health-risk behaviors, affective distress, and use of the healthcare system. Journal of Rehabilitation Research and Development, 40(5), 371-379.

Kessler, R. C., Andrews, G., Colpe, L. J., Hiripi, E., Mroczek, D. K., Normand, S. L., ... \& Zaslavsky, A. M. (2002). Short screening scales to monitor population prevalences and trends in non-specific psychological distress. Psychological Medicine, 32(6), 959-976. doi:10.1017/S0033291702006074

Kiecolt-Glaser, J., \& Newton, T. L. (2001). Marriage and health: His and hers. Psychological Bulletin, 127, 472-503. doi:10.1037/0033-2909.127.4.472.

King, P. R., Donnelly, K. T., Warner, G., Wade, M., \& Pigeon, W. R. (2017). The natural history of sleep disturbance among OEF/OIF veterans with TBI and PTSD and the role of proxy variables in its measurement. Journal of Psychosomatic Research, 96, 60-66. doi:10.1016/j.jpsychores.2017.03.012

Kline, R. B. (2010). Principles and practice of structural equation modeling (3rd ed.). New York: Guilford Press.

Kline, R.B. (2016). Principles and Practice of Structural Equation Modeling,(4 $4^{\text {th }}$ ed). New York: Guilford.

Knutson, K. L., Phelan, J., Paskow, M. J., Roach, A., Whiton, K., Langer, G., ... \& Lichstein, K. L. (2017). The National Sleep Foundation's sleep health index. Sleep Health: Journal of the National Sleep Foundation, 3(4), 234-240. doi:10.1016/j.sleh.2017.05.011 
Krahé, C., Springer, A., Weinman, J., \& Fotopoulou, A. (2013). The social modulation of pain: Others as predictive signals of salience - a systematic review. Frontiers in Human Neuroscience, 7, 386. 1-21. doi:10.3389/fnhum.2013.00386

Krishnan, V., \& Collop, N. A. (2006). Gender differences in sleep disorders. Current opinion in pulmonary medicine, 12(6), 383-389.

doi:10.1097/01.mcp.0000245705.69440.6a

Kumashiro, M., \& Sedikides, C. (2005). Taking on board liability-focused information: Close positive relationships as a self-bolstering resource. Psychological Science, 16(9), 732-739. doi:10.1111/j.1467-9280.2005.01603.x

Kuntsche, Knibbe, \& Gmel. (2009). Social roles and alcohol consumption: A study of 10 industrialized countries. Social Science \& Medicine, 68(7), 1263-1270. doi:10.1016/j.socscimed.2009.01.018

Lakey, B., \& Orehek, E. (2011). Relational regulation theory: A new approach to explain the link between perceived social support and mental health. Psychological Review, 118, 482-495. doi:10.1037/a0023477.

Lambert, J. E., Engh, R., Hasbun, A., \& Holzer, J. (2012). Impact of posttraumatic stress disorder on the relationship quality and psychological distress of intimate partners: A meta-analytic review. Journal of Family Psychology, 26(5), 729-737. $10.1037 / \mathrm{a} 0029341$

Landis, M., Bodenmann, G., Bradbury, T. N., Brandstätter, V., Peter-Wight, M., Backes, S., ... \& Nussbeck, F. W. (2014). Commitment and dyadic coping in long-term 
RESPONSIVENESS, SLEEP AND PAIN IN VETERANS AND SPOUSES

relationships. GeroPsych: The Journal of Gerontopsychology and Geriatric

Psychiatry, 27(4), 139-149. doi:10.1024/1662-9647/a000112

Langston, C. (1994). Capitalizing on and coping with daily-life events: Expressive responses to positive events. Journal of Personality and Social Psychology, 67(6), 1112-1125. doi:10.1037/0022-3514.67.6.1112

Larsen, R. J., \& Diener, E. (1992). Promises and problems with the circumplex model of emotion. In M. S. Clark (Ed.), Review of personality and social psychology, No. 13. Emotion (pp. 25-59). Thousand Oaks, CA, US: Sage Publications, Inc.

Larson, M. J., Adams, R. S., Mohr, B. A., Harris, A. H., Merrick, E. L., Funk, W., ... \& Williams, T. V. (2013). Rationale and methods of the Substance Use and Psychological Injury Combat Study (SUPIC): a longitudinal study of Army service members returning from deployment in FY2008-2011. Substance use \& misuse, 48(10), 863-879. doi:10.3109/10826084.2013.794840

Laurenceau, J. P., Barrett, L. F., \& Rovine, M. J. (2005). The interpersonal process model of intimacy in marriage: A daily-diary and multilevel modeling approach. Journal of Family Psychology, 19(2), 314-323. doi:10.1037/0893-3200.19.2.314

Laurenceau, J. P., Rivera, L. M., Schaffer, A. R., \& Pietromonaco, P. R. (2004). Intimacy as an interpersonal process: Current status and future directions. Handbook of Closeness and Intimacy, 61-78.

Laurenceau, J., Barrett, L. F., \& Pietromonaco, P. R. (1998). Intimacy as an interpersonal process: The importance of self-disclosure, partner disclosure, and perceived partner responsiveness in interpersonal exchanges. Journal of Personality and 
RESPONSIVENESS, SLEEP AND PAIN IN VETERANS AND SPOUSES

Social Psychology: Interpersonal Relations and Group Processes, 74(5), 1238-

1251. doi:10.1037/0022-3514.74.5.1238

Lazar, S. G. (2014). The mental health needs of military service members and veterans. Psychodynamic Psychiatry, 42(3), 459-478.

Ledermann, T., \& Bodenmann, G. (2006). Moderator- und mediatoreffekte bei dyadischen daten: zwei erweiterunge des kteur-Partner-Interdependenz-Modells [Moderator and mediator effects in dyadic research: Two extensions of the actorpartner interdependence model]. Zeitschrift für Sozialpsychologie, 37, 27-40.

Ledermann, T., Macho, S., \& Kenny, D. A. (2011). Assessing mediation in dyadic data using the actor-partner interdependence model. Structural Equation Modeling: A Multidisciplinary Journal, 18(4), 595-612. doi:10.1080/10705511.2011.607099

Lee, J. H., Chopik, W. J., \& Schiamberg, L. B. (2017). Longitudinal associations between marital quality and sleep quality in older adulthood. Journal of Behavioral Medicine, 40(5), 821-831. doi:10.1007/s10865-017-9850-2

Lee, S., Crain, T. L., McHale, S. M., Almeida, D. M., \& Buxton, O. M. (2017). Daily antecedents and consequences of nightly sleep. Journal of sleep research, 26(4), 498-509. doi:10.1111/jsr.12488.

Lemay, E., Clark, M., \& Feeney, B. (2007). Projection of responsiveness to needs and the construction of satisfying communal relationships. Journal of Personality and Social Psychology, 92(5), 834-853. doi:10.1037/0022-3514.92.5.834 
Lewis, M. E., Lamson, A. L., \& Lesueur, B. (2012). Health dynamics of military and veteran couples: A biopsychorelational overview. Journal of Contemporary Family Therapy, 34, 259-276. doi:10.1007/s10591-012-9193-7.

Lewis, M. E., Lamson, A. L., White, M. B., \& Russoniello, C. (2013). Contextualizing military health and trauma: Recommendations for integrated care and couplecentered interventions. Military Behavioral Health Journal, 1(2), 167-172. doi:10.1080/21635781.2013.839923.

Lim, J. W., Shon, E. J., Paek, M., \& Daly, B. (2014). The dyadic effects of coping and resilience on psychological distress for cancer survivor couples. Supportive Care in Cancer, 22(12), 3209-3217. doi: 10.1007/s00520-014-2334-9

Lincoln, A., Swift, E., \& Shorteno-Fraser, M. (2008). Psychological adjustment and treatment of children and families with parents deployed in military combat. Journal of Clinical Psychology, 64(8), 984-992. doi:10.1002/jclp.20520.

Little, R. J., \& Rubin, D. B. (2014). Statistical analysis with missing data (Vol. 333). John Wiley \& Sons. Retrieved at https://leseprobe.buch.de/imagesadb/61/97/61976bf3-cfac-463d-bb88-ca1ddb674cdf.pdf

Luyster, F. S., Strollo, P. J., Zee, P. C., \& Walsh, J. K. (2012). Sleep: a health imperative. Sleep, 35(6), 727-734. doi:10.5665/sleep.1846

MacDermid Wadsworth, S. M. (2010). Family risk and resilience in the context of war and terrorism. Journal of Marriage and Family, 72(3), 537-556.

MacDermid Wadsworth, S., Lester, P., Marini, C., Cozza, S., Sornborger, J., Strouse, T., \& Beardslee, W. (2013). Approaching family-focused systems of care for military 
RESPONSIVENESS, SLEEP AND PAIN IN VETERANS AND SPOUSES

and veteran families. Military Behavioral Health, 1, 1-10.

doi:10.1080/21635781.2012.721062

MacDonald, G., \& Leary, M. R. (2005). Why does social exclusion hurt? The relationship between social and physical pain. Psychological bulletin, 131(2), 202-223. doi:10.1037/0033-2909.131.2.202

Machin, A. J., \& Dunbar, R. I. (2011). The brain opioid theory of social attachment: a review of the evidence. Behaviour, 148(9-10), 985-1025. doi:10.1163/000579511X596624.

Magnusson, D., \& Cairns, R. B. (1996). Developmental science: Toward a unified framework. In R. B. Cairns, G. H. Elder, Jr., \& E. J. Costello (Eds.), Developmental Science (pp. 7-30). New York, NY, US: Cambridge University Press.

Maisel, N. C., \& Gable, S. L. (2009). The paradox of received social support: The importance of responsiveness. Psychological Science, 20(8), 928-932. doi:10.1037/t06070-000

Maisel, N. C., Gable, S. L., \& Strachman, A. M. Y. (2008). Responsive behaviors in good times and in bad. Personal Relationships, 15(3), 317-338. doi:10.1111/j.14756811.2008.00201.x

Mansfield, A. J., Kaufman, J. S., Marshall, S. W., Gaynes, B. N., Morrissey, J. P., \& Engel, C. C. (2010). Deployment and the use of mental health services among US Army wives. New England Journal of Medicine, 362(2), 101-109. doi:10.1056/NEJMoa0900177 
Marshansky, S., Mayer, P., Rizzo, D., Baltzan, M., Denis, R., \& Lavigne, G. J. (2017).

Sleep, chronic pain, and opioid risk for apnea. Progress in Neuro-

Psychopharmacology and Biological Psychiatry, 234-244.

doi:10.1016/j.pnpbp.2017.07.014

Martindale, S. L., Morissette, S. B., Rowland, J. A., \& Dolan, S. L. (2017). Sleep quality affects cognitive functioning in returning combat veterans beyond combat exposure, PTSD, and mild TBI history. Neuropsychology, 31(1), 93-104. doi:10.1037/neu0000312

Master, S. L., Eisenberger, N. I., Taylor, S. E., Naliboff, B. D., Shirinyan, D., \& Lieberman, M. D. (2009). A picture's worth: Partner photographs reduce experimentally induced pain. Psychological Science, 20(11), 1316-1318. doi:10.1111/j.1467-9280.2009.02444.x

Mathias, J. L., Cant, M. L., \& Burke, A. L. J. (2018). Sleep disturbances and sleep disorders in adults living with chronic pain: A meta-analysis. Sleep Medicine, 52, 198-210. doi:10.1016/j.sleep.2018.05.023

Mattacola, C.G., Perrin, D.H., Gansneder, B.M., Allen, J.D., Mickey, C.A. (1997). A comparison of visual analog and graphic rating scales for assessing pain following delayed onset muscle soreness. Journal of Sport Rehabilitation, 6, 38-46. Retrieved from: https://pdfs.semanticscholar.org/8a8b/cd6d5e393df8640195cf717e699af5daa54b. pdf 
Maume, D. J., \& Ruppanner, L. (2017). Couple Dynamics and Sleep Quality in International Perspective. In McHale, S. M., King, V., \& Buxton, O. M. (Eds.), Family Contexts of Sleep and Health Across the Life Course (pp. 85-103). New York: Springer.

McHale, S. M., King, V., \& Buxton, O. M. (Eds.). (2017). Family Contexts of Sleep and Health Across the Life Course. Springer International Publishing.

Meadows, S. O., Tanielian, T., \& Karney, B. R. (2016). How Military Families Respond Before, During and After Deployment: Findings from the RAND Deployment Life Study. RAND Arroyo Center. Santa Monica United States.

Melzack, R. (2001). Pain and the neuromatrix in the brain. Journal of Dental Education, 65(12), 1378-1382.

Melzack, R., \& Casey, K. L. (1968). Sensory, motivational and central control determinants of pain: a new conceptual model. In D. R. Kenshalo (Ed.), The Skin Senses, (pp. 423-439). Springfield, IL: Charles C Thomas.

Menchaca, D., \& Dehle, C. (2005). Marital quality and physiological arousal: How do I love thee? Let my heartbeat count the ways. The American Journal of Family Therapy, 33(2), 117-130. doi:10.1080/01926180590915897

Mendes, W. B. (2016). Emotion and the autonomic nervous system. In L. E. Barrett, M. Lewis, \& J. Haviland-Jones (Eds.), Handbook of emotions (4th ed., pp. 166-181). New York, NY: Guilford.

Mohr, C. D., Armeli, S., Tennen, H., Temple, M., Todd, M., Clark, J., \& Carney, M. A. (2005). Moving beyond the keg party: a daily process study of college student 
RESPONSIVENESS, SLEEP AND PAIN IN VETERANS AND SPOUSES

drinking motivations. Psychology of Addictive Behaviors, 19(4), 392-403. doi:10.1037/0893-164X.19.4.392

Mollayeva, T., Thurairajah, P., Burton, K., Mollayeva, S., Shapiro, C. M., \& Colantonio, A. (2016). The Pittsburgh sleep quality index as a screening tool for sleep dysfunction in clinical and non-clinical samples: a systematic review and metaanalysis. Sleep Medicine Reviews, 25, 52-73.

Moriarty, H., Winter, L., Robinson, K., Piersol, C. V., Vause-Earland, T., Iacovone, D. B., ... \& Gitlin, L. N. (2016). A randomized controlled trial to evaluate the veterans' in-home program for military veterans with traumatic brain injury and their families: Report on impact for family members. Physical Medicine \&Rehabilitation, 8(6), 495-509. doi:10.1016/j.pmrj.2015.10.008

Moseley, L., \& Butler, D. (2003). Explain pain. Australia: NOIgroup publication. Muthén, L. K., \& Muthén, B. O. (2018). Mplus (Version 8). Los Angeles, CA: Muthén \& Muthén.

National Heart, Lung and Blood Institute. (2018). Sleep Deprivation and Deficiency. In National Institute of Health. Retrieved from Sleep Deprivation and Deficiency. (n.d.). Retrieved from https://www.nhlbi.nih.gov/health-topics/sleep-deprivationand-deficiency

National Research Council. (2012). Treatment for posttraumatic stress disorder in military and veteran populations: Initial assessment. Washington, DC: National Academies Press. 
National Research Council. (2013). Returning home from Iraq and Afghanistan: Assessment of readjustment needs of veterans, service members, and their families. Washington, DC: National Academies Press.

National Sleep Foundation (2012). Bedroom poll: Summary of findings. Washington, DC. https://sleepfoundation.org/sleep-polls-data/other-polls/2012-bedroom-poll

Negrusa, S., Negrusa, B., \& Hosek, J. (2014). Gone to war: have deployments increased divorces? Journal of Population Economics, 27(2), 473-496.

Niv, D., \& Kreitler, S. (2001). Pain and Quality of Life. Pain Practice, 1(2), 150-161. doi:10.1046/j.1533-2500.2001.01016.x

Nock, M. K., Deming, C. A., Fullerton, C. S., Gilman, S. E., Goldenberg, M., Kessler, R. C., . . Ursano, R. J. (2013). Suicide among soldiers: A review of psychosocial risk and protective factors. Psychiatry: Interpersonal and Biological Processes, 76(2), 97-125. doi:10.1521/psyc.2013.76.2.97

Oishi, S., Schiller, J., \& Gross, E. B. (2013). Felt understanding and misunderstanding affect the perception of pain, slant, and distance. Social Psychological and Personality Science, 4(3), 259-266. doi:10.1177/1948550612453469

Ong, A. D. (2010). Pathways linking positive emotion and health in later life. Current Directions in Psychological Science, 19(6), 358-362.

Orthner, D. K., \& Rose, R. (2009). Work Separation Demands and Spouse Psychological Well-Being. Family Relations, 58(4), 392-403. doi:10.1111/j.17413729.2009.00561.x 
Park, Y., \& Haun, V. C. (2018). The long arm of email incivility: Transmitted stress to the partner and partner work withdrawal. Journal of Organizational Behavior, 39(10). doi:10.1002/job.2289

Partridge, E. (1966). Origins: A short etymological dictionary of modern English. New York: Macmillan.

Pennebaker, J. W., \& Chung, C. K. (2011). Expressive writing: Connections to physical and mental health. In H. S. Friedman (Ed.), Oxford library of psychology. The Oxford handbook of health psychology (pp. 417-437). New York, NY, US: Oxford University Press. doi: 10.1093/oxfordhb/9780195342819.013.0018

Peterson, A. L., Goodie, J. L., Satterfield, W. A., \& Brim, W. L. (2008). Sleep disturbance during military deployment. Military Medicine, 173, 230-235. doi:10.7205/MILMED.173.3.230

Pickett, T., Rothman, D., Crawford, E. F., Brancu, M., Fairbank, J. A., \& Kudler, H. S. (2015). Mental health among military personnel and veterans. North Carolina Medical Journal, 76(5), 299-306. doi:10.18043/ncm.76.5.299

Pietromonaco, P. R., \& Collins, N. L. (2017). Interpersonal mechanisms linking close relationships to health. American Psychologist, 72(6), 531-542. doi:10.1037/amp0000129

Pigeon, W., Pinquart, M., \& Conner, K. (2012). Meta-analysis of sleep disturbance and suicidal thoughts and behaviors. The Journal of Clinical Psychiatry, 73(9), E1160-1167. doi:10.4088/JCP.11r07586 
Plumb, T. R., Peachey, J. T., \& Zelman, D. C. (2014). Sleep disturbance is common among service members and veterans of Operations Enduring Freedom and Iraqi Freedom. Psychological Services, 11(2), 209-219. doi:10.1037/a0034958

Powell, M., Corbo, V., Fonda, J., Otis, J., Milberg, W., \& McGlinchey, R. (2015). Sleep Quality and Reexperiencing Symptoms of PTSD Are Associated With Current Pain in U.S. OEF/OIF/OND Veterans With and Without mTBIs. Journal of Traumatic Stress, 28(4), 322-329. doi:10.1002/jts.22027

Preacher, K. J., \& Hayes, A. F. (2004). SPSS and SAS procedures for estimating indirect effects in simple mediation models. Behavior Research Methods, Instruments, \& Computers, 36(4), 717-731. doi:10.3758/BF03206553

Pressman, S. D., \& Cohen, S. (2005). Does positive affect influence health?. Psychological bulletin, 131(6), 925. doi:10.1037/0033-2909.131.6.925.

Pressman, S. D., Cohen, S., Miller, G. E., Barkin, A., Rabin, B. S., \& Treanor, J. J. (2005). Loneliness, social network size, and immune response to influenza vaccination in college freshmen. Health Psychology, 24(3), 297-306. doi:10.1037/0278-6133.24.3.297

Raykov, T., \& Marcoulides, G. A. (2012). An introduction to applied multivariate analysis. New York: Routledge.

Reeck, C., Ames, D. R., \& Ochsner, K. N. (2016). The social regulation of emotion: An integrative, cross-disciplinary model. Trends in Cognitive Sciences, 20(1), 47-63. doi:10.1016/j.tics.2015.09.003 
Reed, R. G., Butler, E. A., \& Kenny, D. A. (2013). Dyadic models for the study of health. Social and Personality Psychology Compass, 7(4), 228-245. doi:10.1111/spc3.12022

Reger, M. A., Smolenski, D. J., Skopp, N. A., Metzger-Abamukang, M. J., Kang, H. K., Bullman, T. A., ... \& Gahm, G. A. (2015). Risk of suicide among US military service members following Operation Enduring Freedom or Operation Iraqi Freedom deployment and separation from the US military. JAMA psychiatry, 72(6), 561-569. doi:10.1001/jamapsychiatry.2014.3195

Reis, H. T. (2014). Responsiveness: Affective interdependence in close relationships. In M. Mikulincer \& P. R. Shaver (Eds.), The Herzliya series on personality and social psychology. Mechanisms of social connection: From brain to group (pp. 255-271). Washington, DC, US: American Psychological Association. doi:http://dx.doi.org/10.1037/14250-015

Reis, H. T., \& Gosling, S. D. (2010). Social psychological methods outside the laboratory. In S. T. Fiske, D. T. Gilbert, \& G. Lindzey (Eds.), Handbook of Social Psychology (Vol. 1, 5th ed, pp. 82-114). Hoboken, NJ: Wiley \& Sons.

Reis, H. T., \& Patrick, B. C. (1996). Attachment and intimacy: Component processes. In E. T. Higgins \& A. W. Kruglanski (Eds.), Social psychology: Handbook of basic principles (pp. 523-563). New York: Guilford.

Reis, H. T., \& Shaver, P. (1988). Intimacy as an interpersonal process. In S. D. Duck (Ed.), Handbook of personal relationships: Theory, research and interventions (pp. 367-389). Oxford, England: Wiley. 
Reis, H. T., Clark, M. S., \& Holmes, J. G. (2004). Perceived partner responsiveness as an organizing construct in the study of intimacy and closeness. In D. J. Mashek \& $A$. P. Aron (Eds.), Handbook of closeness and intimacy (pp. 201-225). Mahwah, NJ, US: Lawrence Erlbaum Associates Publishers.

Revenson, T. A., Marín-Chollom, A. M., Rundle, A. G., Wisnivesky, J., \& Neugut, A. I. (2016). Hey Mr. Sandman: Dyadic effects of anxiety, depressive symptoms and sleep among married couples. Journal of behavioral medicine, 39(2), 225-232. doi:10.1007/s10865-015-9693-7

Reynolds, P., \& Kaplan, G. A. (1990). Social connections and risk for cancer: prospective evidence from the Alameda County Study. Behavioral Medicine, 16(3), 101-110. doi:10.1080/08964289.1990.993459

Robles, T. F., Slatcher, R. B., Trombello, J. M., \& McGinn, M. M. (2014). Marital quality and health: A meta-analytic review. Psychological Bulletin, 140(1), 140187. doi:10.1037/a0031859

Rusbult, C. E., \& Van Lange, P. A. M. (2008). Why we need interdependence theory. Social and Personality Psychology Compass, 2, 2049- 2070. doi:10.1111/j.17519004.2008.00147.x.

Samitz, G., Egger, M., \& Zwahlen, M. (2011). Domains of physical activity and all-cause mortality: systematic review and dose-response meta-analysis of cohort studies. International Journal of Epidemiology, 40(5), 1382-1400.

Satcher, D., Tepper, M. S., Thrasher, C., \& Rachel, S. A. (2012). Breaking the silence: Supporting intimate relationships for our wounded troops and their partners: A 
call to action. International Journal of Sexual Health, 24(1), 6-13.

doi:10.1080/19317611.2011.645949

Sbarra, D. A., \& Coan, J. A. (2018). Relationships and health: The critical role of affective science. Emotion Review, 10(1), 40-54. doi:10.1177/1754073917696584

Schoemann, A. M., Boulton, A. J., \& Short, S. D. (2017). Determining Power and Sample Size for Simple and Complex Mediation Models. Social Psychological and Personality Science, 8(4), 379-386. doi:10.1177/1948550617715068

Schoenbaum, M., Kessler, R. C., Gilman, S. E., Colpe, L. J., Heeringa, S. G., Stein, M. B., ... \& Cox, K. L. (2014). Predictors of suicide and accident death in the Army Study to Assess Risk and Resilience in Servicemembers (Army STARRS): results from the Army Study to Assess Risk and Resilience in Servicemembers (Army STARRS). JAMA psychiatry, 71(5), 493-503.

doi:10.1001/jamapsychiatry.2013.4417

Secinti, E., Rand, K. L., Johns, S. A., O’Neil, B. H., Helft, P. R., Shahda, S., ... \& Mosher, C. E. (2018). Social correlates of mental health in gastrointestinal cancer patients and their family caregivers: Exploring the role of loneliness. Supportive Care in Cancer, 1-10. doi:10.1007/s00520-018-4467-8

Seelig A.D., Jacobson I.G., Smith B., et al. (2010). Sleep patterns before, during, and after deployment to Iraq and Afghanistan. Sleep, 33(12):1615-1622.

Seeman, T. E. (1996). Social ties and health: The benefits of social integration. Annals of Epidemiology, 6(5), 442-451. doi:10.1016/S1047-2797(96)00095-6 
Segal, M. W. (1989). The nature of work and family linkages: A theoretical perspective. In G. L. Bowen \& D. K. Orthner (Eds.), The organization family: Work and family linkages in the U.S. military (pp. 3-36). New York: Praeger.

Segrin, C., \& Burke, T. J. (2015). Loneliness and sleep quality: dyadic effects and stress effects. Behavioral Sleep Medicine, 13(3), 241-254.

doi:10.1080/15402002.2013.860897

Selcuk, E., \& Ong, A. D. (2013). Perceived partner responsiveness moderates the association between received emotional support and all-cause mortality. Health Psychology, 32, 231-235. doi:10.1037/a0028276

Selcuk, E., Stanton, S. C. E., Slatcher, R. B., \& Ong, A. D. (2017). Perceived partner responsiveness predicts better sleep quality through lower anxiety. Social Psychological and Personality Science, 8(1), 83-92.

doi: $10.1177 / 1948550616662128$

Selcuk, E., Zayas, V., \& Hazan, C. (2010). Beyond satisfaction: The role of attachment in marital functioning. Journal of Family Theory \& Review, 2, 258 -279. doi:10.1111/j.17562589.2010.00061.x

Shrout, P. E., \& Bolger, N. (2002). Mediation in experimental and nonexperimental studies: new procedures and recommendations. Psychological Methods, 7(4), 422-445. doi:10.1037//1082-989X.7.4.422

Sin, N. L., Almeida, D. M., Crain, T. L., Kossek, E. E., Berkman, L. F., \& Buxton, O. M. (2017). Bidirectional, temporal associations of sleep with positive events, affect, 
and stressors in daily life across a week. Annals of Behavioral Medicine, 51(3), 402-415.

Slatcher, R. B., Selcuk, E., \& Ong, A. D. (2015). Perceived partner responsiveness predicts diurnal cortisol profiles 10 years later. Psychological Science, 26(7), 972982. doi:10.1177/0956797615575022

Solomon, Z., Dekel, R., \& Mikulincer, M. (2008). Complex trauma of war captivity: A prospective study of attachment and post-traumatic stress disorder. Psychological Medicine, 38(10), 1427-1434. doi:10.1017/S0033291708002808

Steptoe, A., O'Donnell, K., Marmot, M., \& Wardle, J. (2008). Positive affect, psychological well-being, and good sleep. Journal of Psychosomatic Research, 64(4), 409-415.

Sternberg, R. J. (1986). A triangular theory of love. Psychological Review, 93(2), 119135. doi:10.1037/0033-295X.93.2.119

Stroebe, M., Schut, H., \& Stroebe, W. (2006). Who benefits from disclosure? Exploration of attachment style differences in the effects of expressing emotions. Clinical Psychology Review, 26(1), 66-85.

Sullivan, H. H. (1953). The interpersonal theory of psychiatry. New York: Norton Taft, C. T., Watkins, L. E., Stafford, J., Street, A. E., \& Monson, C. M. (2011). Posttraumatic stress disorder and intimate relationship problems: a meta-analysis. Journal of Consulting and Clinical Psychology, 79(1), 22-33. doi:10.1037/a0022196. 
Tan, G., Fink, B., Dao, T. K., Hebert, R., Farmer, L. S., Sanders, A., ... \& Gevirtz, R. (2009). Associations among pain, PTSD, mTBI, and heart rate variability in veterans of Operation Enduring and Iraqi Freedom: a pilot study. Pain Medicine, $10(7), 1237-1245$.

Terrio, H., Brenner, L. A., Ivins, B. J., Cho, J. M., Helmick, K., Schwab, K., ... \& Warden, D. (2009). Traumatic brain injury screening: preliminary findings in a US Army Brigade Combat Team. The Journal of Head Trauma Rehabilitation, 24(1), 14-23. doi:10.1097/HTR.0b013e31819581d8.

Tims, M., Bakker, A. B., \& Derks, D. (2015). Examining job crafting from an interpersonal perspective: Is employee job crafting related to the well-being of colleagues?. Applied Psychology, 64(4), 727-753. doi:10.1111/apps.12043

Troxel, W. M. (2010). It's more than sex: Exploring the dyadic nature of sleep and implications for health. Psychosomatic Medicine, 72(6), 578-586.

doi:10.1097/PSY.0b013e3181de7ff8

Troxel, W. M., Robles, T. F., Hall, M., \& Buysse, D. J. (2007). Marital quality and the marital bed: Examining the covariation between relationship quality and sleep. Sleep Medicine Reviews, 11, 389-404. doi:10.1016/j.smrv.2007.05.002

Troxel, W. M., Shih, R. A., Pedersen, E. R., Geyer, L., Fisher, M. P., Griffin, B. A., ... \& Steinberg, P. S. (2015). Sleep in the military: Promoting healthy sleep among US servicemembers. Rand Health Quarterly, 5(2), 19. 
Trump, L. J., Lamson, A. L., Lewis, M. E., \& Muse, A. R. (2015). His and hers: The interface of military couples' biological, psychological, and relational health. Contemporary Family Therapy, 37(3), 316-328. doi:10.1007/s10591-015-9344-8

Turk, D. C., \& Melzack, R. (Eds.). (2011). Handbook of pain assessment. Guilford Press.

Turk, D. C., \& Monarch, E. S. (2002). Biopsychosocial perspective on chronic pain. In D. C. Turk \& R. J. Gatchel (Eds.), Psychological approaches to pain management: A practitioner's handbook (pp. 3-29). New York, NY, US: Guilford Press.

Uchino, B. (2004). Social support and physical health: Understanding the health consequences of relationships (Current perspectives in psychology). New Haven: Yale University Press.

Uchino, B. N., Bowen, K., Carlisle, M., \& Birmingham, W. (2012). Psychological pathways linking social support to health outcomes: A visit with "ghosts" of research past, present, and future. Social Science \& Medicine, 74, 949-957. doi:10.1016/j.socscimed.2011.11.023.

Uchino, B. N., Cacioppo, J. T., \& Kiecolt-Glaser, J. K. (1996). The relationship between social support and physiological processes: A review with emphasis on underlying mechanisms and implications for health. Psychological Bulletin, 119(3), 488-531. doi:10.1037/0033-2909.119.3.488

Umberson, D., \& Karas Montez, J. (2010). Social relationships and health: A flashpoint for health policy. Journal of Health and Social Behavior, 51(1), S54-S66. doi:10.1177/0022146510383501 
Vanderploeg, R. D., Curtiss, G., Duchnick, J. J., \& Luis, C. A. (2003). Demographic, medical, and psychiatric factors in work and marital status after mild head injury. The Journal of Head Trauma Rehabilitation, 18(2), 148-163.

doi:10.1097/00001199-200303000-00006

Venn, S., Arber, S., Meadows, R., \& Hislop, J. (2008). The fourth shift: exploring the gendered nature of sleep disruption among couples with children. The British Journal of Sociology, 59(1), 79-97.

Veteran Health Administration Pain Management Directive (2009-053) Department of Veterans Affairs: Washington, D.C; 2009.

Wang, H., Han, Z. R., Bai, L., \& Li, X. (2018). Attachment experience and cortisol recovery from romantic conflict among young Chinese couples: A dyadic analysis. International Journal of Psychology. doi:10.1002/ijop.12539

Watson, D., \& Clark, L. A. (1999). The PANAS-X: Manual for the positive and negative affect schedule-expanded form. University of Iowa: David Watson and Lee Anna Clark. Retrieved from:

https://ir.uiowa.edu/cgi/viewcontent.cgi?referer=https://www. google.com/\&httpsredir=1\&article=1011\&context=psychology_pubs/

Watson, D., Clark, L. A., \& Harkness, A. R. (1994). Structures of personality and their relevance to psychopathology. Journal of Abnormal Psychology, 103(1), doi:1831. $10.1037 / 0021-843 X .103 .1 .18$

Watson, D., Clark, L. A., \& Tellegen, A. (1988). Development and validation of brief measures of positive and negative affect: the PANAS scales. Journal of 
RESPONSIVENESS, SLEEP AND PAIN IN VETERANS AND SPOUSES

Personality and Social Psychology, 54(6), 1063-1070. doi:10.1037/00223514.54.6.1063

Willerton, E., Wadsworth, S. M., \& Riggs, D. (2011). Introduction: Military families under stress: What we know and what we need to know. In S. M. Wadsworth \& D. Riggs (Eds.), Risk and Resilience in US Military Families (pp. 1-20). Springer, New York, NY.

Williams, K. D., \& Jarvis, B. (2006). Cyberball: A program for use in research on interpersonal ostracism and acceptance. Behavior Research Methods, 38, 174180. doi:10.3758/BF03192765

Wilson, S. J., Martire, L. M., \& Sliwinski, M. J. (2017). Daily spousal responsiveness predicts longer-term trajectories of patients' physical function. Psychological Science, 28(6), 786-797. doi:10.1177/0956797617697444

Windsor, T. D., Gerstorf, D., Pearson, E., Ryan, L. H., \& Anstey, K. J. (2014). Positive and negative social exchanges and cognitive aging in young-old adults: Differential associations across family, friend, and spouse domains. Psychology and Aging, 29(1), 28 -43. doi:10.1037/a0035256.

Wood, R. L., \& Yurdakul, L. K. (1997). Change in relationship status following traumatic brain injury. Brain Injury, 11(7), 491-501. doi:10.1080/713802183

Xie, X., Bratec, S. M., Schmid, G., Meng, C., Doll, A., Wohlschläger, A., ... \& Schilbach, L. (2016). How do you make me feel better? Social cognitive emotion regulation and the default mode network. NeuroImage, 134, 270-280.

doi:10.1016/j.neuroimage.2016.04.015 
Yan, J., Olsavsky, A., Schoppe-Sullivan, S. J., \& Kamp Dush, C. M. (2018). Coparenting in the family of origin and new parents' couple relationship functioning. Journal of Family Psychology, 32(2), 206-216. doi:10.1037/fam0000353.

Younger, J., Aron, A., Parke, S., Chatterjee, N., \& Mackey, S. (2010). Viewing pictures of a romantic partner reduces experimental pain: Involvement of neural reward systems. PloS one, 5(10), e13309. doi:10.1371/journal.pone.0013309

Zadro, L., Williams, K. D., \& Richardson, R. (2004). How low can you go? Ostracism by a computer lowers belonging, control, self-esteem, and meaningful existence. Journal of Experimental Social Psychology, 40, 560-567. doi: 10.1016/j.jesp.2003.11.006

Zaki, J., \& Williams, W. C. (2013). Interpersonal emotion regulation. Emotion, 13(5), 803-810. doi:10.1037/a0033839

Zautra, A. J., Johnson, L. M., \& Davis, M. C. (2005). Positive affect as a source of resilience for women in chronic pain. Journal of Consulting and Clinical Psychology, 73(2), 212-220. doi:10.1037/0022-006X.73.2.212 